\title{
EARLY ON-SET PREDICTION OF VORTEX-RING STATE OF QUADROTORS
}

by

\author{
Joel McQuaid \\ Bachelor of Engineering, Ryerson University, Toronto (2018)
}

\author{
A thesis \\ presented to Ryerson University \\ in partial fulfillment of the \\ requirements for the degree of \\ Master of Applied Science \\ in the program of \\ Aerospace Engineering
}

Toronto, Ontario, Canada, 2020

(C) Joel McQuaid, 2020 


\section{AUTHOR'S DECLARATION FOR ELECTRONIC SUBMISSION OF A THESIS}

I hereby declare that I am the sole author of this thesis. This is a true copy of the thesis, including any required final revisions, as accepted by my examiners.

I authorize Ryerson University to lend this thesis to other institutions or individuals for the purpose of scholarly research.

I further authorize Ryerson University to reproduce this thesis by photocopying or by other means, in total or in part, at the request of other institutions or individuals for the purpose of scholarly research.

I understand that my thesis may be made electronically available to the public. 


\title{
EARLY ON-SET PREDICTION OF VORTEX-RING STATE OF QUADROTORS
}

\author{
Joel McQuaid
}

Master of Applied Science, Aerospace Engineering, Ryerson University (2020)

\begin{abstract}
The OpenFOAM CFD package was used to initially investigate the aerodynamic effects of vortex-ring state of a quadrotor, then to study various quadrotor flight maneuvers to minimize the thrust loses of vortex-ring state and followed by possible detection methods for a drone entering vortex-ring state. Vortex-ring state is characteristic of a decrease in the effective angle of attack of incoming airflow due to a rotor descending into its downwash. This causes significant loses in the thrust of the rotor, which typically leads to severe flight upsets for rotorcraft. A quadrotor was studied at varying descent velocities to investigate wake roll-up at the rotor tips and the subsequent effects on rotor thrust and power. The quadrotor was then subjected to non-vertical descent angles to investigate thrust loss mitigation approaches due to vortex-ring state. A method of detecting the on-set of vortex-ring state is proposed using various differential pressure measurements on the quadrotor. It has been shown that by monitoring the pressure difference between the top of the quadrotor body and the bottom of one of the quadrotor legs, a pressure drop can be seen just prior to the on-set of vortex-ring state. This pressure drop was shown to occur during descending flight regimes and may prove to be an effective pre-vortex-ring state warning system.
\end{abstract}




\section{Acknowledgements}

The authors would like to gratefully thank the Smart Computing for Innovation (SOSCIP) Centre for granting access to the IBM BlueGene/Q HPC cluster through the grant SDF-046 "HighFidelity Aerodynamic Analysis of Unmanned Multirotor Vehicles." This support was invaluably in assisting this research effort by providing additional computational resources. Furthermore, the investigation was made possible through funds from the Ontario Centre of Excellence (OCE) and through the support from Aeryon Labs Inc. (now part of FLIR Systems), which provided the geometric models for purposes of this study. 


\section{Table of Contents}

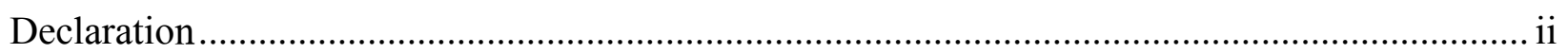

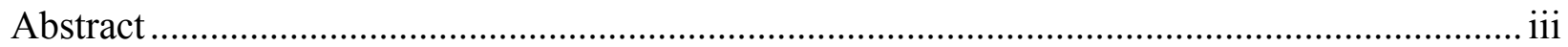

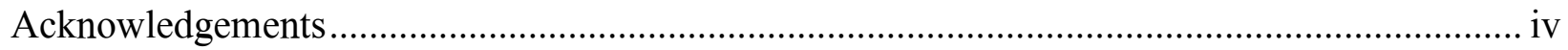

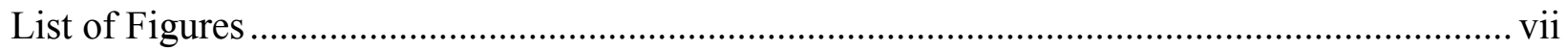

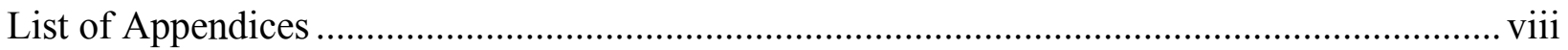

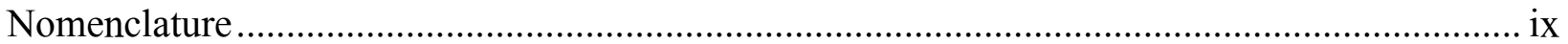

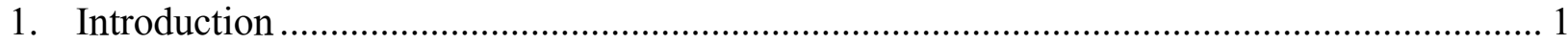

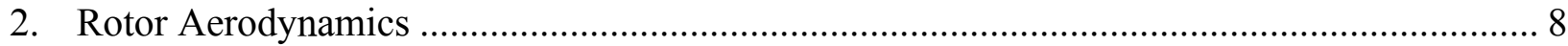

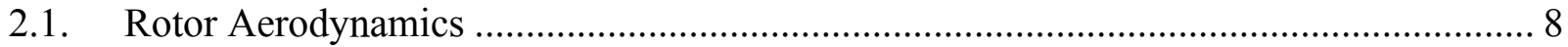

2.2. Momentum Theory ......................................................................................... 10

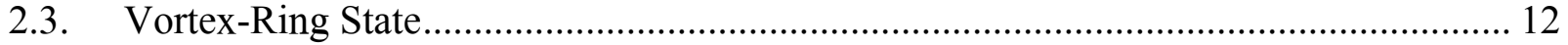

2.4. VAPTOR Formulation ...................................................................................... 13

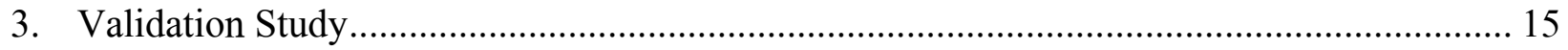

3.1. Geometric Model............................................................................................... 16

3.2. OpenFOAM Numerical Model ............................................................................. 17

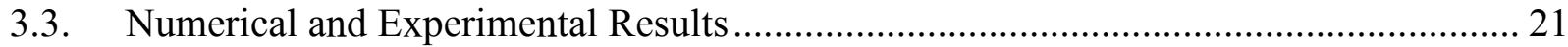

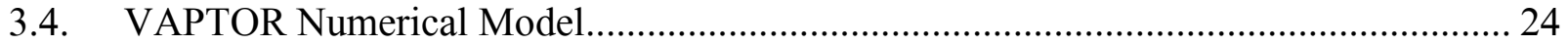

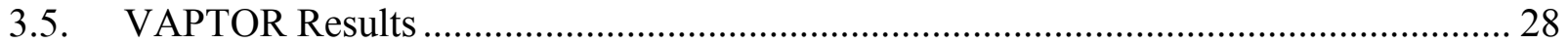

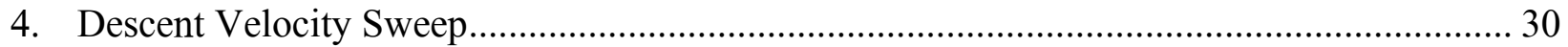

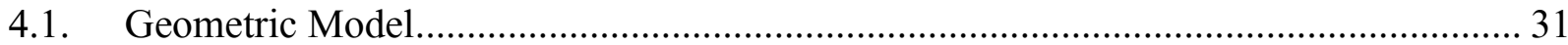

4.2. OpenFOAM Numerical Model ………………….............................................. 32

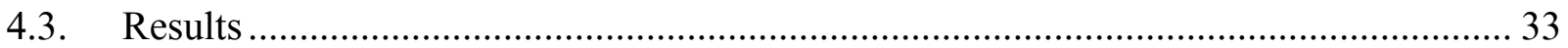

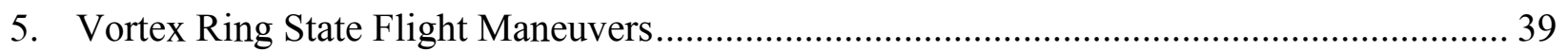

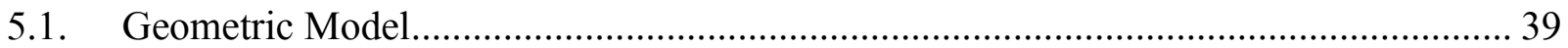

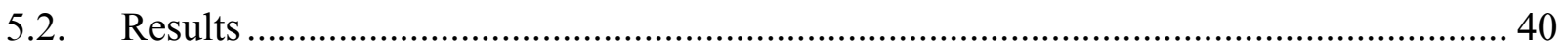

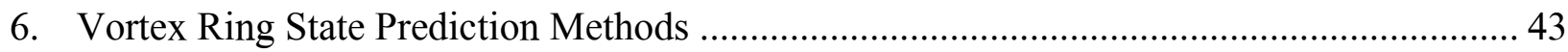

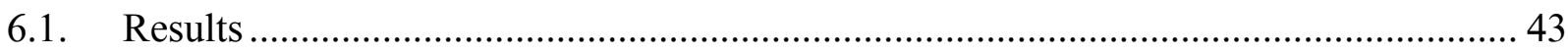

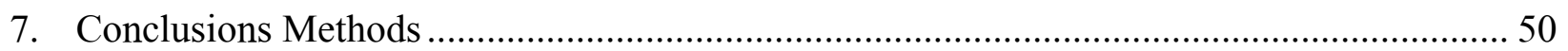

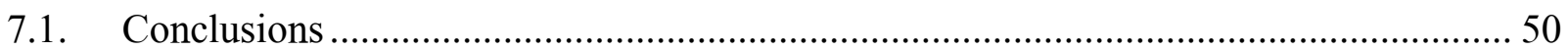

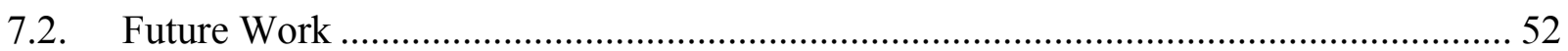

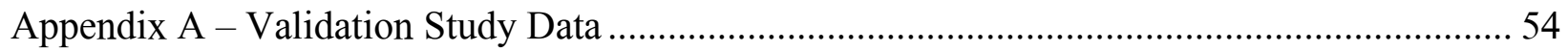

A.1. T-motor Rotor Experimental Results ....................................................................... 54 
A.2. T-motor Rotor Numerical Grid Specifications ............................................................ 55

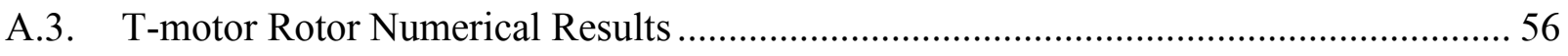

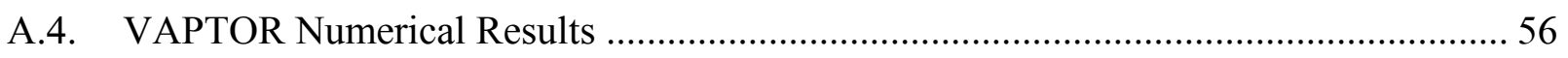

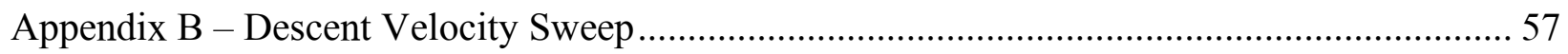

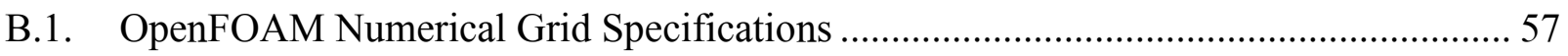

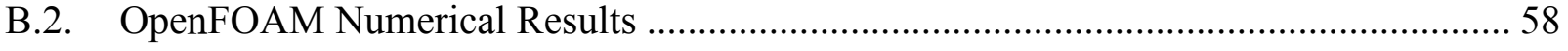

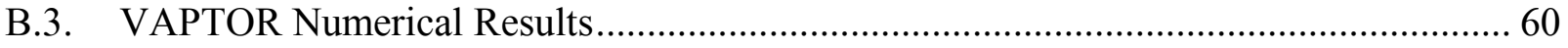

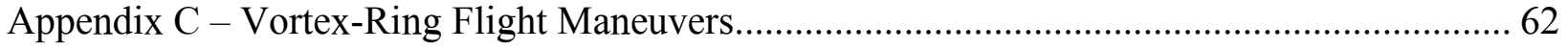

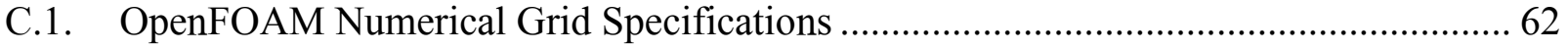

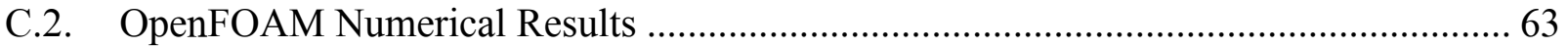

Appendix D - Vortex-Ring State Prediction Methods …….......................................................... 65

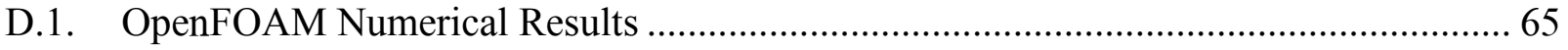

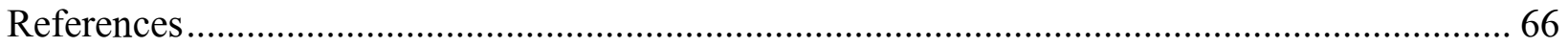




\section{List of Figures}

Figure 1. Rotor wake structure during vortex-ring state shown by Q-criterion.............................. 2

Figure 2. Rotor wake structure in the windmill brake state shown by Q-criterion.......................... 2

Figure 3. Rotor inflow velocity sign convention. ……….................................................... 9

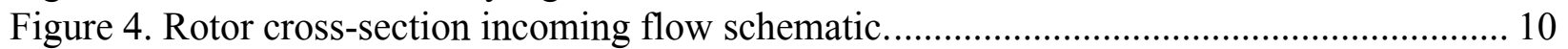

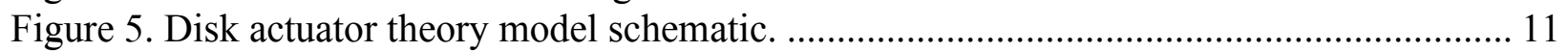

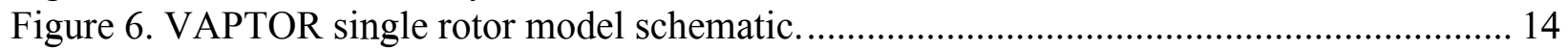

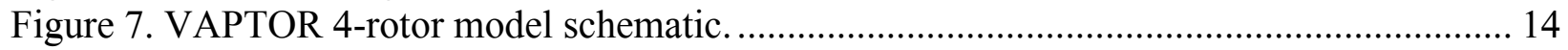

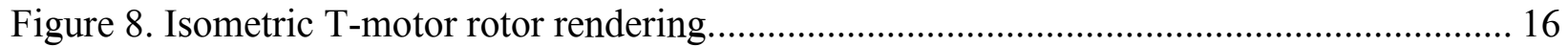

Figure 9. T-motor computational domain, model sizing and boundary conditions...................... 17

Figure 10. T-motor rotor computational domain overview. .................................................... 18

Figure 11. T-motor model, control volume grid transition spacing between subregions............. 19

Figure 12. T-motor rotor boundary layer mesh. .................................................................. 20

Figure 13. Rotor test stand within large subsonic wind tunnel of Ryerson University. ............... 21

Figure 14. T-motor rotor numerical and experimental results [27] ........................................... 22

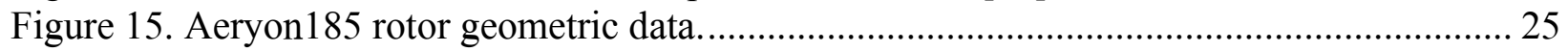

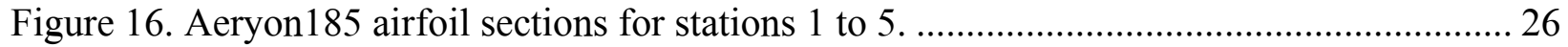

Figure 17. Aeryon 185 airfoil sections for stations 6 to 10 ......................................................... 27

Figure 18. Aeryon 185 airfoil sections for stations 11 to 15 ...................................................... 27

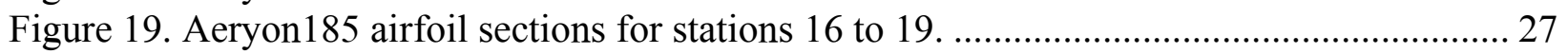

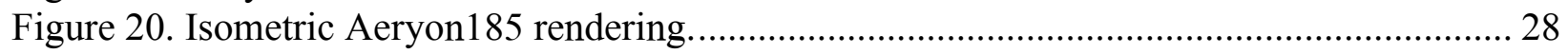

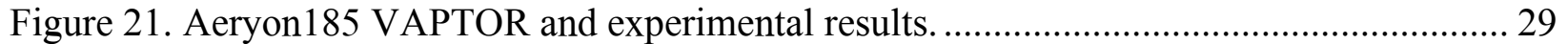

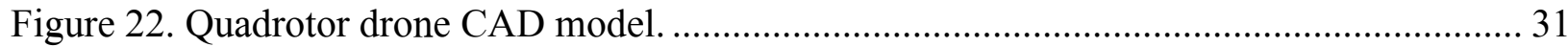

Figure 23. Computational domain, model sizing and boundary conditions of quadrotor. ............ 32

Figure 24. Quadrotor drone computational grid, 2D section plane. ............................................ 33

Figure 25. Quadrotor drone descent velocity sweep, rotor performance................................... 34

Figure 26. Descent velocity sweep, numerical model comparison of rotor performance. ............ 36

Figure 27. Unstable rotor wake vortex shown with vorticity at $-0.968 \mathrm{Vz} / \mathrm{Vh} \ldots \ldots \ldots \ldots \ldots \ldots \ldots \ldots . . . . . . . . . . . . . . . .37$

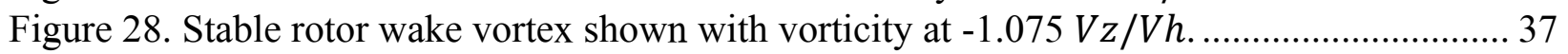

Figure 29. Rotor wake shown with Q-criterion (left) and Vorticity (right) at $-1.613 \mathrm{Vz} / \mathrm{Vh} \ldots . . . .38$

Figure 30. Half-body computational domain, model sizing and boundary conditions................. 40

Figure 31. Descent velocity sweep with applied forward velocity, rotor performance................ 42

Figure 32. Quadrotor model with pressure port locations. ............................................................ 44

Figure 33. Pressure differential analysis for early on-set vortex-ring state warning system........ 45

Figure 34. Quadrotor model, pressure contour plane locations.................................................. 47

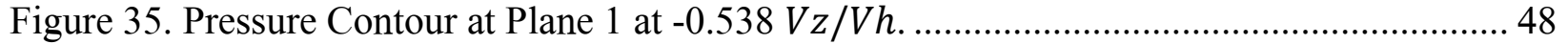

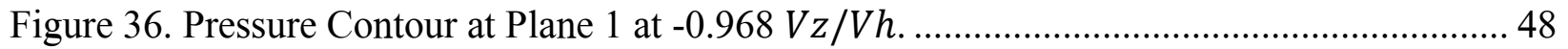

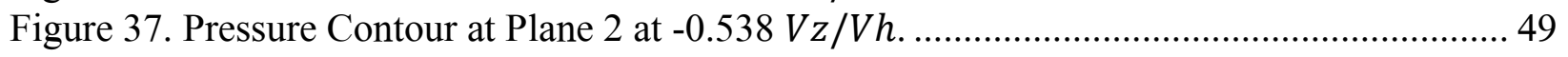

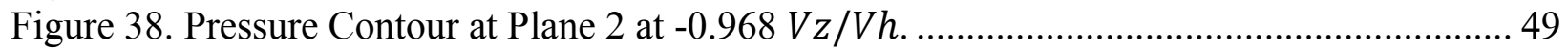




\section{List of Appendices}

Table A-1. T-motor rotor validation study geometric and speed data.................................. 54

Table A-2. T-motor rotor experimental data at 3000 RPM for force and moment loading. ........ 55

Table A-3. T-motor rotor numerical grid specifications................................................... 55

Table A-4. Experimental and numerical results for the T-motor rotor validation study............ 56

Table A-5. VAPTOR pitch corrected model comparison to experimental results. .................... 56

Table B-1. Quarter body quadrotor numerical grid specifications. ..................................... 57

Table B-2. Aeryon 185 rotor descent velocity sweep geometric and speed data...................... 58

Table B-3. Quadrotor descent velocity sweep. Rotor aerodynamic loading. ............................ 59

Table B-4. Quadrotor descent velocity sweep. Full body aerodynamic loading....................... 59

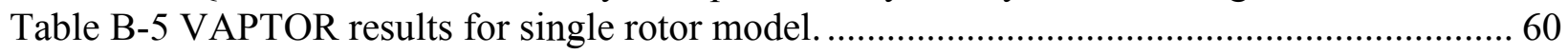

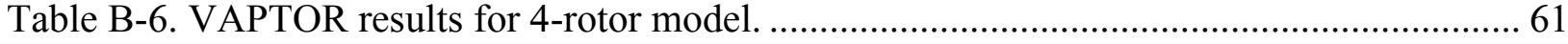

Table C-1. Half-body quadrotor numerical grid specifications. ............................................. 63

Table C-2. Quadrotor model flight maneuver, velocity decomposition. ................................ 63

Table C-3. OpenFOAM flight maneuvers, aerodynamic loading on 2-rotor model. .................. 64

Table D-1. OpenFOAM differential pressure port measured values....................................... 65 


\section{Nomenclature}

The following symbols are used in this thesis:

$$
\begin{aligned}
& A \quad=\text { Rotor disk area } \\
& A O A=\text { Angle of attack } \\
& C_{P} \quad=\text { Power coefficient } \\
& C_{P_{\text {avg }}}=\text { Average power coefficient } \\
& C_{T} \quad=\text { Thrust coefficient } \\
& C_{T_{\text {avg }}}=\text { Average thrust coefficient } \\
& C_{\mu, s t d}=\text { Model constant } \\
& D \quad=\text { Drag } \\
& F_{X} \quad=\text { Force loading in X-direction } \\
& F_{Y} \quad=\text { Force loading in Y-direction } \\
& F_{Z} \quad=\text { Force loading in Z-direction } \\
& J \quad=\text { Advance ratio, propeller convention } \\
& k_{T_{\infty}} \quad=\text { Turbulent frequency } \\
& L \quad=\text { Lift } \\
& M_{X} \quad=\text { Moment loading about X-axis } \\
& M_{Y} \quad=\text { Moment loading about } \mathrm{Y} \text {-axis } \\
& M_{Z} \quad=\text { Moment loading about Z-axis } \\
& P_{i} \quad=\text { Measured static pressure at probe } i \\
& Q \quad=\text { Torque } \\
& R \quad=\text { Rotor radius } \\
& r=\text { Distance from airfoil section to axis of rotation }
\end{aligned}
$$




$$
\begin{aligned}
& T \quad=\text { Thrust } \\
& T u_{\infty} \quad=\text { Freestream turbulent intensity } \\
& V_{h} \quad=\text { Induced velocity at hover } \\
& V_{R} \quad=\text { Resultant velocity } \\
& V_{X} \quad=\text { Forward/horizontal velocity } \\
& V_{Z} \quad=\text { Rotor climb/descent velocity } \\
& V_{\infty} \quad=\text { Freestream velocity } \\
& w \quad=\text { Induced velocity } \\
& \alpha \quad=\text { Freestream angle of attack } \\
& \alpha_{i} \quad=\text { Induced angle of attack } \\
& \alpha_{e f f} \quad=\text { Effective freestream angle of attack } \\
& \alpha_{0} \quad=\text { Freestream angle of attack without induced effects } \\
& \beta=\text { Rotor/airfoil pitch angle } \\
& \gamma \quad=\text { Descent angle } \\
& \Delta P_{i j} \quad=\text { Pressure difference between port } i \text { and probe } j \\
& \epsilon \quad=\text { Induced angle due to downwash } \\
& \theta \quad=\text { Quadrotor pitch angle } \\
& \mu_{\infty} \quad=\text { Freestream advance ratio, rotor convention } \\
& v \quad=\text { Freestream kinematic viscosity } \\
& v_{T} \quad=\text { Turbulent kinematic viscosity } \\
& \rho \quad=\text { Density of air } \\
& \Omega \quad=\text { Rotor rotation speed } \\
& \omega_{\infty} \quad=\text { Freestream turbulent kinetic energy }
\end{aligned}
$$




\section{Chapter 1}

\section{Introduction}

Vortex-ring state is a highly unsteady and turbulent flight regime that rotors experience when they descend into their own downwash. Descending into a rotors own downwash causes the stable helical vortex structure to collapse into a single strong vortex that encompasses the rotor tips $[1,2]$. A reduction in the effective angle of attack of the rotor in combination with an increased inflow velocity into the rotor plane causes reductions in thrust forces and an increase in thrust force oscillations about a mean thrust value $[3,4,5,6]$. Figure 1 shows the strong vortex-ring around a rotor in vortex-ring state which causes the reduction in the effective angle of attack. A visualization of the more stable helical wake shedding may be seen in Figure 2 which occurs during the windmill brake state. 


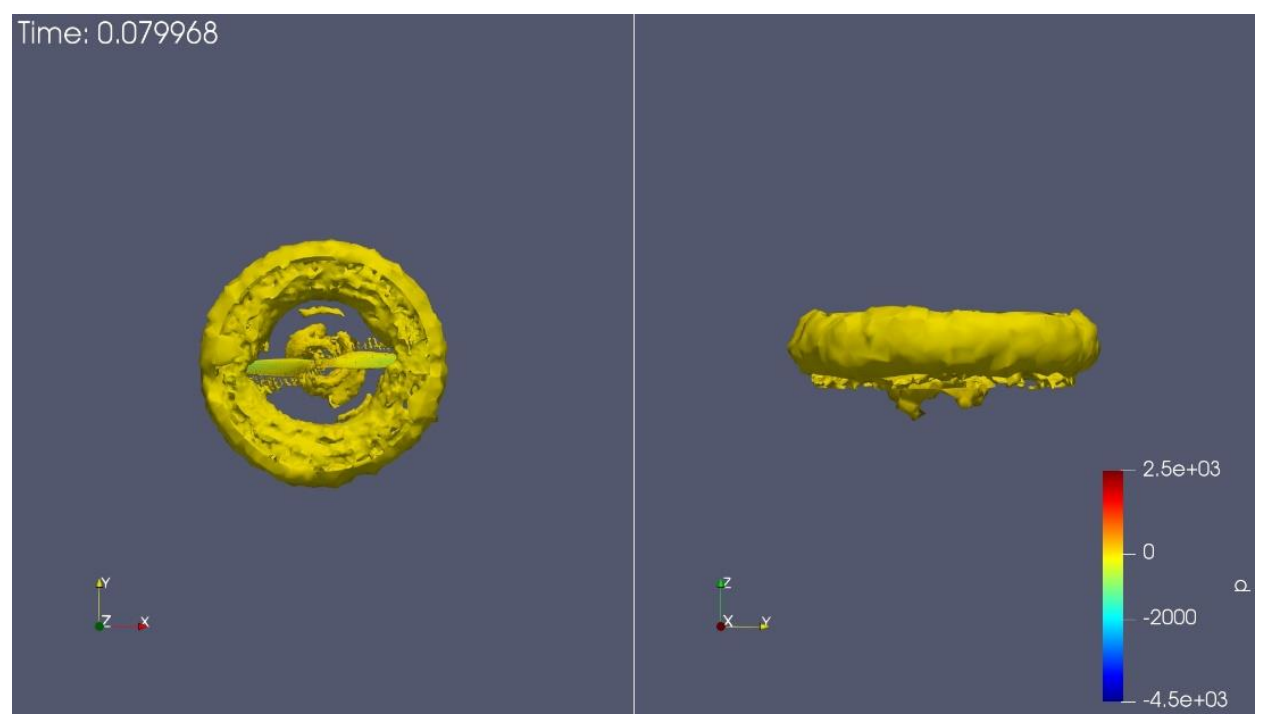

Figure 1. Rotor wake structure during vortex-ring state shown by Q-criterion.

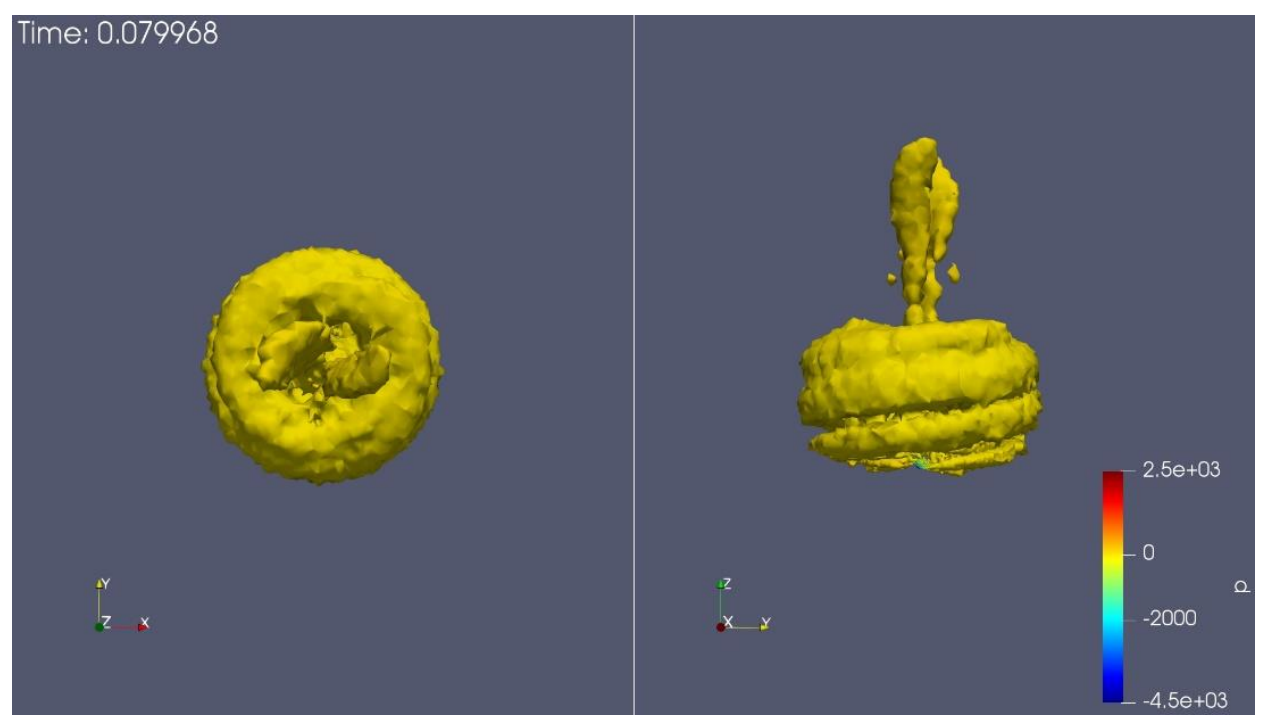

Figure 2. Rotor wake structure in the windmill brake state shown by Q-criterion.

When entering vortex-ring state, the operation of rotorcraft becomes unpredictable and dangerous because of inadequate thrust production as well as imbalanced thrust loads across multiple rotors causing significant stability concerns. A multitude of experimental studies have been performed into the vortex-ring state flight regime with an emphasis placed on flow visualization of the flow structure itself $[7,8]$. The ability to effectively model vortex-ring state using numerical approaches is an on-going research field. Furthermore, the study of flight 
maneuvers to minimize the impact of vortex-ring state as well as early warning systems to predict the vortex-ring state boundaries remains to be an important research venture in both the computational and experimental fields of rotor aerodynamics. However, avoiding vortex-ring state in rotorcraft currently requires either generous safety margins placed around a vehicle's descentvelocity range or an extremely comprehensive set of experimental data over a range of flight maneuvers in order to better predict this phenomena [9]. Even these results are susceptible to experimental errors or deviations in flight, for example when wind is present. Also, the use of flight maneuvers is situationally dependent, such that they may not always be effective or appropriate. Therefore, being able to predict the on-set of vortex-ring state via an in-flight monitoring system would provide a significant benefit to the safety of rotorcraft operators and the flight vehicles themselves.

The unsteady nature of vortex-ring state renders the use of classical momentum theory approaches for modelling of this state to be ineffective [10]. Descent velocities lying in the range of hovering up to about twice the rotor induced velocity at hover, $V_{h}$, can be difficult to investigate since the traditional momentum theory approach is no longer valid $[11,12,13]$. As the rotorcraft goes beyond this lower boundary, it enters the post-vortex-ring state flight regime commonly referred to as the windmill brake state and momentum theory can be applied again [10].

Based on the work of experimental Wolkovitch (1972), it was shown that the lower vortexring state boundary was $0.707 V_{h}$. Vortex-ring state may be identified through flow visualization of the rotor wake structure or by investigating rotor thrust. In terms of flow visualization, a breakdown of the stable helical rotor wake vortex may be seen to shift into a single donut-shaped wake vortex that is trapped around the rotor-plane tip. Thrust trends show a significant degradation of thrust performance due to vortex-ring state as well as possible thrust oscillations indicative of 
the unsteady nature of this flight regime. Thrust oscillations in the range of $12-20 \%$ of the mean thrust coefficient have been shown both experimentally and numerically $[14,10,15,5]$. Rotor geometry characteristic, such as collective pitch angle, have some effect on the magnitude of the thrust oscillations. Shetty and Selig (2011) showed thrust oscillation changes of $\pm 30 \%$ in relation to an increased collective pitch angle as well as a decrease in the freestream advance ratio at which the minimum thrust point occurs [16]. Thrust oscillations may also translate to power oscillations if the collective pitch angle of the rotor is high enough [4]. The magnitude to which vortex-ring state will affect the thrust of a rotor and the velocity in which it begins is dependent on the rotor's blade loading and its spanwise blade twist distribution [17].

Mitigation and avoidance strategies for vortex-ring state continues to be an advancing field of study both experimentally and numerically. Current measures are limited to avoiding purely descending flight and/or employing alternate flight maneuvers that assist in keeping the shed wake vortex away from the rotor plane during descent. If descent angles are minimized, such as less than or equal to 30-degree descent angles, vortex-ring state is non-existent at virtually all descent speeds [10]. This is due to the forward velocity preventing wake vortex build-up in the rotor plane. Betzina's (2001) work supports this claim by showing that entering vortex-ring state is not possible at descent angles less than 20 degrees. The authors used a tiltrotor in helicopter mode in the NASA Ames wind tunnel [5] to present this conclusion.

Currently, the best way to avoid vortex-ring state is through flight maneuvers. A possible maneuver is to descend in the windmill brake state through a rapid increase in descent speed, which requires sufficient ground clearance. Dziubinski and Stalewski (2007) used flow visualization of their results to show that this maneuver effectively pushes the vortex ring above the rotor plane and consequently allows for thrust to recover [8]. Vice versa, a decrease in descent speed is also 
capable of helping a rotorcraft exit vortex-ring state as shown by Grzegorczyk (2013). The vortexring strongly dominates the nearby flow structure, which results in a slower thrust recovery via this method [7]. Spiraled flight patterns or increased forward speed maneuvers are two other approaches that may be used $[10,18]$. Mullen and Bernini (2016) used a descent velocity sweep to study the rapid thrust reduction experienced by the rotor upon entering vortex-ring state followed by the steady thrust recovery in the post-vortex-ring state regime [6]. Ahlin and Brown (2005) demonstrated that rotor thrust recovery begins to occur before the rotor wake stabilizes fully into its windmill brake state structure [19]. Other means of predicting or avoiding vortex-ring state have been limited to computer software running simplified algorithms through inputted aircraft performance data to warn operators only after they have penetrated the vortex-ring state boundary [9].

The herein presented research involved a quadrotor drone model that was run through a vertical descent velocity sweep. Thrust and power coefficient trends versus descent velocity normalized with the hover downwash velocity were sought to determine the impact of vortex-ring state on the aerodynamic performance. The model used the Aeryon 185 rotor mounted on a drone body that resembled the SkyRanger R70 of Aeryon Labs Inc. Vortex-ring state boundaries were determined based on the thrust profile and through flow visualization of the wake structure that surrounded the rotor. Follow-up investigations involved the application of forward speeds to the quadrotor model to mimic non-vertical descent flight paths. The reduction in thrust loss was studied using these simplified flight maneuvers. Further investigations via pressure analysis of the rotors flow structure at different descent speeds showed that it may be possible to predict the onset of vortex-ring state prior to any thrust loss occurring. 
A numerical model capable of analyzing the unsteady aerodynamics of a quadrotor was formulated in OpenFOAM with a sliding mesh interface to allow for rotor rotation. A Reynolds Averaged Navier Stokes (RANS) formulation has been shown to be unsuitable for modelling temporal aerodynamic phenomena based on the work by Westbrook-Netherton and Toomer (2015) [20]. Therefore, a Detached Eddy Simulation (DES) approach was used in combination with RANS modelling to capture any transient effects occurring during vortex-ring state $[21,22]$. This provides a more computationally efficient approach since RANS modelling is used in the nearwall treatment while Large Eddy Simulation (LES) modelling is used in the freestream region to better capture the wake structure. This helps to maintain better usage of computational resources versus a full LES model while providing better accuracy than a purely RANS model. Momentum theory is another potential approach to modelling vortex-ring state that could have been used. Dziubinski and Stalewski (2007) have employed an actuator disk model into a CFD program to replicate the effects of rotor rotation through an imposed pressure jump across the rotor plane [8]. This helps save computational resources by avoiding the need to model the vehicles rotor, however, the model now requires extensive calibrating in combination with the time-consuming numerical formulation to accurately reproduce realistic flight performance. Seeing as majority of the computational grid is located within the freestream region as opposed to on the rotor surface, setting up a conventional model with a appropriately meshed rotor may prove easier and more accurate by negating the need to include assumptions into the numerical model. A potential flow model is also a possible approach to vortex-ring state that is currently used by other researchers as well as briefly within the work presented in Chapter 3 and 4. Potential flow is generally an effective and computationally inexpensive practice for rotor performance predictions. Difficulty arises within the vortex-ring state flight regime due to the non-linearity experience within the vortex-ring 
and surrounding freestream. The unpredictable and chaotic nature of the rotor wake makes the computation of rotor thrust and power loading to be less accurately predicted by governing first and second order equations. 


\section{Chapter 2}

\section{Rotor Aerodynamics}

Chapter 2 covers the fundamentals of rotor aerodynamics including sign convention, rotor convention equations, and the definition of other important parameters. The principles of momentum theory as it applies to calculating a rotor's downwash and the mechanics of vortexring state will also be shown. VAPTOR was one of the numerical codes used within this report for investigation of vortex-ring state. VAPTOR is a higher order potential flow model, which has its own formulation briefly explained here.

\subsection{Rotor Aerodynamics}

Results presented in this report have been non-dimensionalized using standard rotor convention. Rotor velocities are based on the freestream advance ratio, $\mu$, defined as follows: 


$$
\mu=\frac{V_{\infty} \cos (\alpha)}{\Omega R}
$$

$\Omega$ is the rotor rotational speed ( $\mathrm{rads} / \mathrm{sec}$ ), and alpha is the freestream angle of attack (degrees) and $R$ is the rotor radius (m). Figure 3 below depicts the relationship between the rotor-tip path plane and the incoming freestream air's relative direction as related through $\theta$. Based on the figure, a $\theta$ of 0 degrees represents fully edgewise flow, 90 degrees represents climbing flight, and -90 degrees represents descending flight. The thrust vector is defined as being perpendicular to the rotor plane.

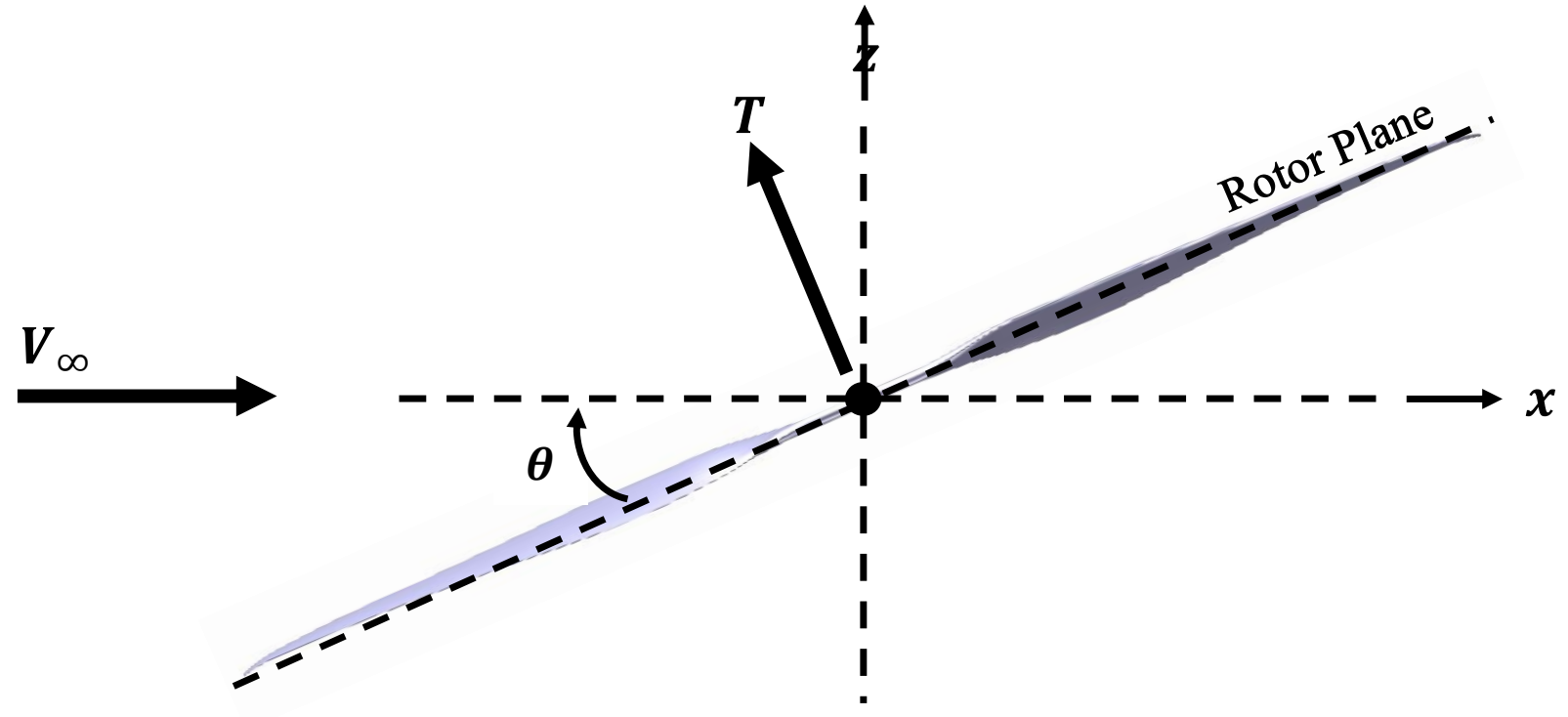

Figure 3. Rotor inflow velocity sign convention.

OpenFOAM presents force calculations in Newtons and Newton-metres for force and moment loadings, respectively, which can be non-dimensionalized into thrust and power coefficients [23]:

$$
\begin{gathered}
C_{T}=\frac{2 T}{\rho A(\Omega R)^{2}} \\
C_{P}=\frac{2 Q}{\rho A R(\Omega R)^{2}}
\end{gathered}
$$


where $T$ is the thrust force $(\mathrm{N}), Q$ is the torque on the rotor due to the generated thrust in the direction of the thrust vector $(\mathrm{N}-\mathrm{m}), \rho$ the air density $\left(\mathrm{kg} / \mathrm{m}^{3}\right)$, and $A$ the rotor disk area $\left(\mathrm{m}^{2}\right)$. Figure 4 defines the velocity components and directions experienced by a given airfoil section. The horizontal velocity component is due to the rotor speed and is a function of the measured distance from the rotor airfoil to the axis of rotation, $r(\mathrm{~m})$. The vertical component is due to the climb or descent velocity of the flight vehicle. The airfoil then sees the resultant velocity, $V_{R}$ at the freestream angle of attack $\alpha$. AC defines the airfoil sections aerodynamic center at which the thrust, lift and force vectors act.

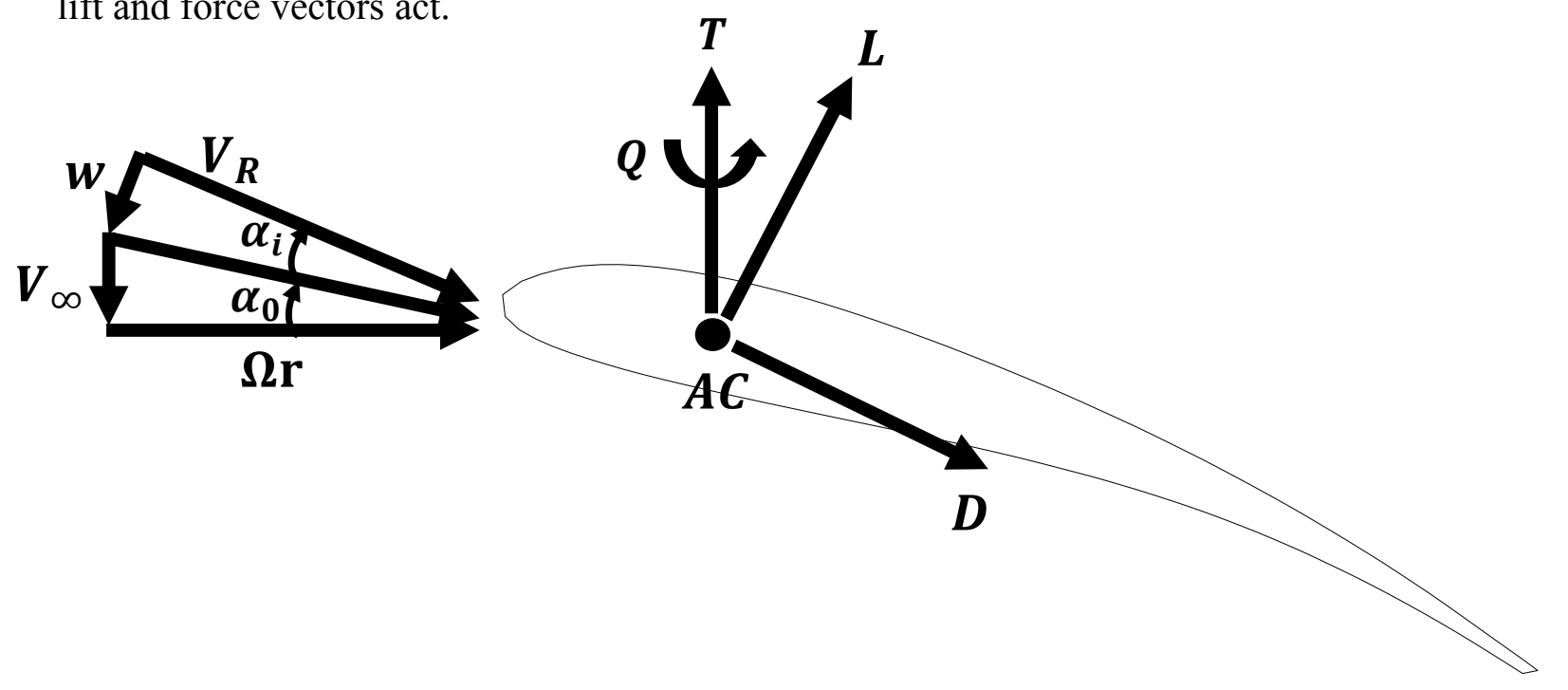

Figure 4. Rotor cross-section incoming flow schematic.

\subsection{Momentum Theory}

Momentum theory is a simplified mathematical model used to formulate a first-order approximation for rotor thrust and power [11]. This approach, sometimes referred to as disk actuator theory, assumes that the rotor is an infinitely thin plane where incoming airflow sees a pressure change across the plane. This in turn generates a prediction for the thrust and power of a 
rotor depending on the magnitude of the velocity change across the rotor plane. Figure 5 outlines the schematic for disk actuator theory. Disk actuator theory assumes the flow is one dimensional, quasi-steady, incompressible and inviscid [11]. Plane 0 is the plane far upstream of the rotor plane, plane 1 is located just above the rotor plane, plane 2 is located just below the rotor plane, and plane $\infty$ is located far downstream of the rotor plane. Flow properties are assumed to be uniform across each defined plane. At hover conditions, $V_{\infty}=0$ such that the induced velocity at hover is equal to $V_{h}$ based on momentum theory which is defined as:

$$
V_{h}=\sqrt{\frac{T_{h}}{\rho A}}
$$

where $T_{h}$ is the thrust at hover $(\mathrm{N})$. A more detailed proof of the disk actuator method can be found in the work of Leishman [11].

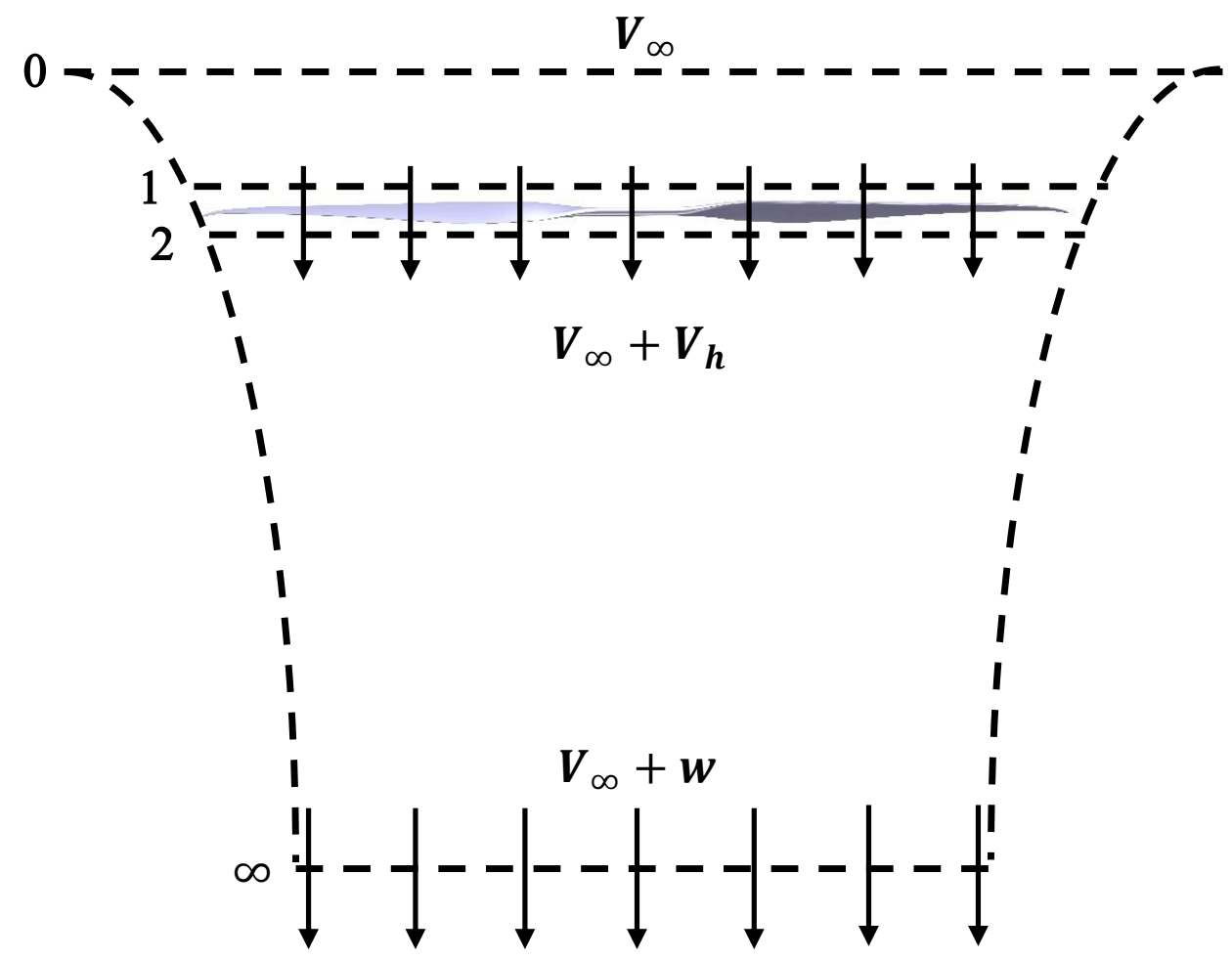

Figure 5. Disk actuator theory model schematic. 
Using momentum theory during axial descent is not possible due to the shift in flow structure within this flight regime. Based on the work of Leishman (2000), when $-2 \leq V_{\infty} / V_{h} \leq$ 0 , momentum theory is invalid [11]. This is because at any cross-sectional plane, the flow velocity is unsteady and can be moving both upward and downward across the plane requiring the inclusion of fluid recirculation within the formulation. Velocities starting from hover and increasing into climb flight is the normal working state of a rotor. Velocities below $V_{\infty} / V_{h}=-2$ are within the windmill brake state where momentum theory may be used again with some manipulation to account for the slipstream going in the opposite direction.

\subsection{Vortex-Ring State}

Vortex-ring state boundaries, as defined by momentum theory, is presumed to occur within the range of $-2 \leq V_{\infty} / v_{h} \leq 0$. Entering vortex-ring state causes a breakdown of the stable helical vortex structure that is shed by a rotor into a single, strong vortex-ring that encapsulates the rotor tip. This vortex-ring remains trapped in the rotor plane unless evasive maneuvers are employed to escape. This vortex-ring decreases the effective angle of attack seen by incoming flow to the rotor resulting in diminished thrust production by the rotor as well as thrust oscillations about a mean thrust value. The vortex-ring effective angle of attack can be roughly defined as follows:

$$
\alpha_{e f f}=\alpha-\epsilon
$$

Equation 5

Where $\alpha_{e f f}$ is the effective angle of attack seen by a rotor airfoil section and $\epsilon$ is the reduction in the angle of attack due to the downwash of the rotor. This aperiodic thrust loading leads to severe flight upsets and flight vehicle control issues and thrust load imbalances for multirotor configurations. 


\subsection{VAPTOR Formulation}

This numerical model has been formulated as a higher-order potential flow model in MATLAB to predict the aerodynamic performance of isolated rotors or multiple rotors that are in close proximity. This work was formulated and validated by Bramesfeld and Maughmer (2008) [24] and Barcelos et al. (2017) [25, 26] and was used by the author to obtain numerical results from a lower order aerodynamic model as they are presented in this thesis. It models a rotor's bound spanwise circulation using a second-order spline and the subsequent wake shedding using a first-order continuous vortex sheet. Lifting surfaces are discretized using distributed vorticity elements (DVEs), which contain leading and trailing edge vortex filaments with parabolic changing strength and a vortex sheet with a linearly changing spanwise strength. The model is numerically robust in allowing for both fixed wake and relaxed wake solution algorithms. The results shown from VAPTOR here used a steady, relaxed wake model to better account for the complicated flow structure that is to be expected in vortex-ring state. Further details regarding the numerical formulation as well as the validation of this model can be found in the work of Barcelos et al. (2017) [25]. Figure 6 and Figure 7 show the rotor configuration for both the single and 4rotor models used in VAPTOR as well as the rotor rotation directions. Inter-rotor spacing, direction and speed were set identically to the CFD model. 


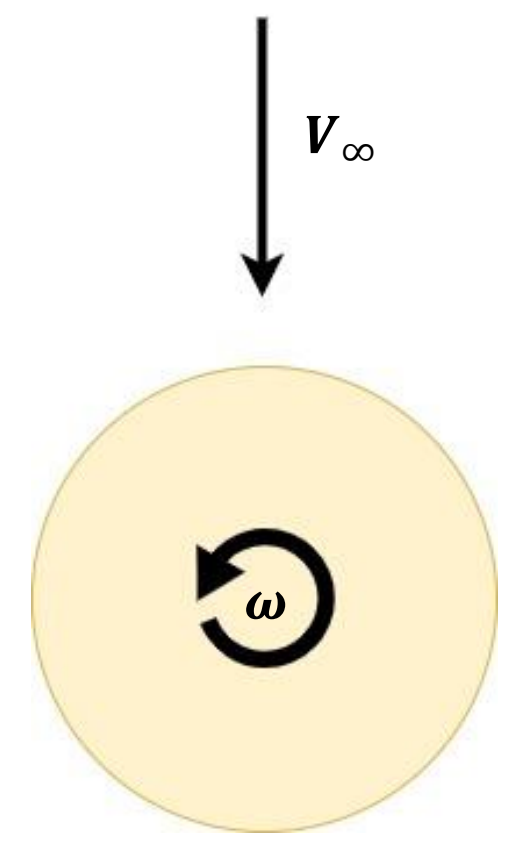

Figure 6. VAPTOR single rotor model schematic.

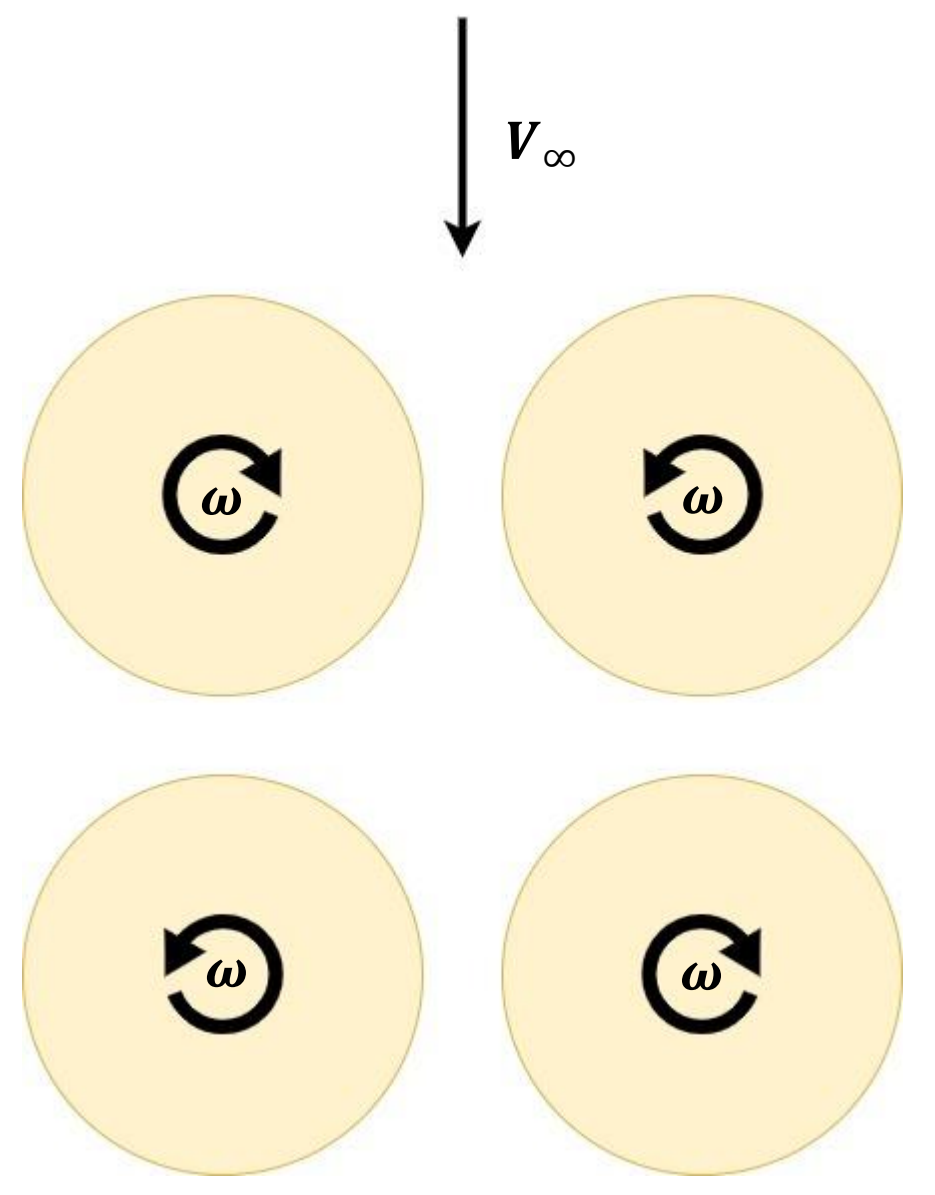

Figure 7. VAPTOR 4-rotor model schematic. 


\section{Chapter 3}

\section{Validation Study}

The numerical grids that were used for all Computational Fluid Dynamics (CFD) models were meshed using ANSYS v18.2 using an unstructured algorithm. The simulations were run using OpenFOAM v5.0 on the Compute Canada HPC Clusters (Niagara, Cedar, and Graham) and IBM BlueGene/Q HPC Cluster. The presented numerical results are based on an unsteady simulation run for 5 revolutions for a total of 1800 timesteps ( 1 timestep per 1 degree of rotor rotation). The numerical results were validated using a comparison to experimental results that were obtained in the large subsonic wind tunnel of Ryerson University.

Chapter 3 also outlines the validation procedure for VAPTOR, which is a higher-order potential flow model, that was used to compare solutions in the vortex-ring flight regime to CFD solutions. This was done to test the robust nature of this solver which was formulated by Bramesfeld and Maughmer (2008) and Barcelos et al. (2017) [25, 26], in terms of both results and computational efficiency [24]. Both single and 4-rotor models were tested using a steady state, relaxed wake formulation. Models were evaluated at 30 timesteps per revolution for 7 revolutions 
equating to a total of 210 timesteps. Raw data for all presented plots and figures in Chapter 3 can be found in Appendix A.

\subsection{Geometric Model}

A 1-rotor 46-cm (18-inch) T-motor rotor geometry was used as the validation model. Figure 8 shows the T-motor geometry that was used in the validation study. Three cases were modelled with a 90-degree angle of attack, which is purely axial freestream flow like it is encountered during climbing flight [27].

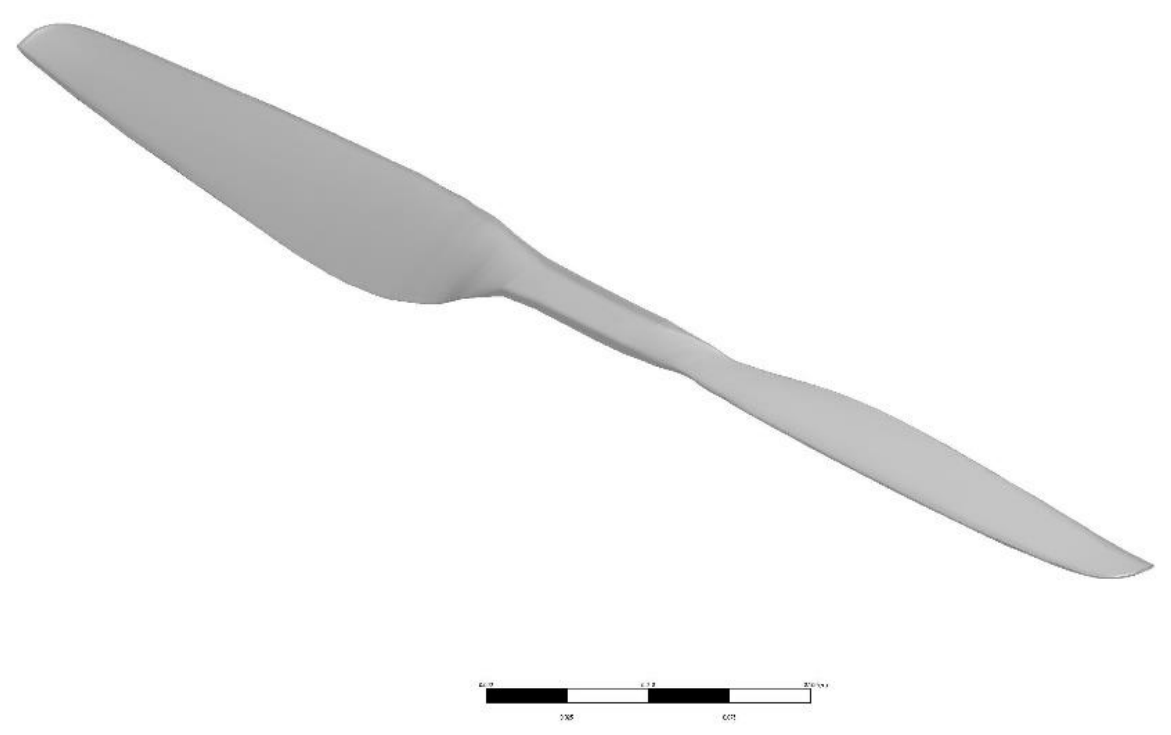

Figure 8. Isometric T-motor rotor rendering.

A 3-D geometric scan of the T-motor rotor was used to remodel the rotor in CATIA V5R2017 for use in the numerical models shown here. The 3-D laser scanning provided an STL file for use within the CAD software. An STL file is a file containing a network of points that create a mesh in a similar sense to how a CFD program uses a mesh for the control volume. Importing this 
STL file provides a means of replicating the rotor geometry, although somewhat imperfectly due to the thin nature of the rotor geometry. Kolaei et al. (2018) present the exact rotor geometry in their work [27].

The control volume that was used had 3 subregions, as shown in Figure 9, in order to better control grid spacing and element size transition rates. These subregions are purely to assist meshing operations and do not affect the numerical solution. Body sizing shown Figure 9 is normalized using the rotor radius, $R$. Boundary conditions are located 20-blade radii away from the model's origin, which is at the rotors center of rotation, in order to limit the interference between the rotor flow structure and the prescribed boundaries.

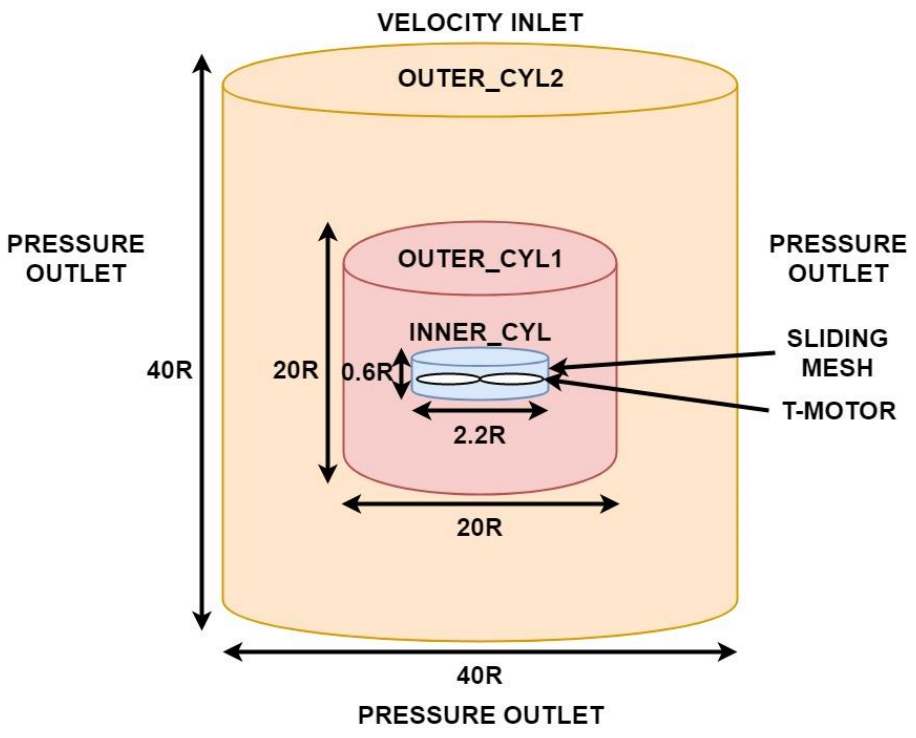

Figure 9. T-motor computational domain, model sizing and boundary conditions.

\subsection{OpenFOAM Numerical Model}

OpenFOAM v5.0 has a library of CFD solvers that may be used for a multitude of applications. The PimpleDyMFoam solver is a transient and incompressible flow solver for sliding 
mesh applications. Figure 10 depicts an isometric view of the control volume and Figure 11 shows the grid transition rates between model subregions. With a rotor rotation speed of 3000 RPM, tip speeds were estimated to be no higher than Mach 0.23 , thus rendering compressibility effects to be negligible. Model patches surrounding the T-motor rotor were set as Arbitrary Mesh Interfaces (AMI), which allowed the modelling of the rotor's rotation and served as an interpolation interface between the rotor and the remainder of the freestream gas path. Boundary patches at the model's extremities were set to velocity-inlet and pressure-outlet conditions depending on the need to model climbing or descending cases.

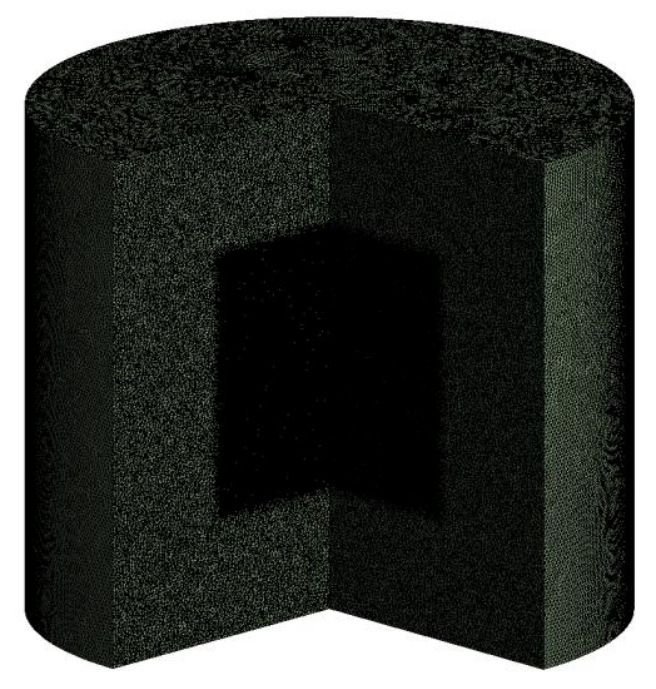

Figure 10. T-motor rotor computational domain overview. 


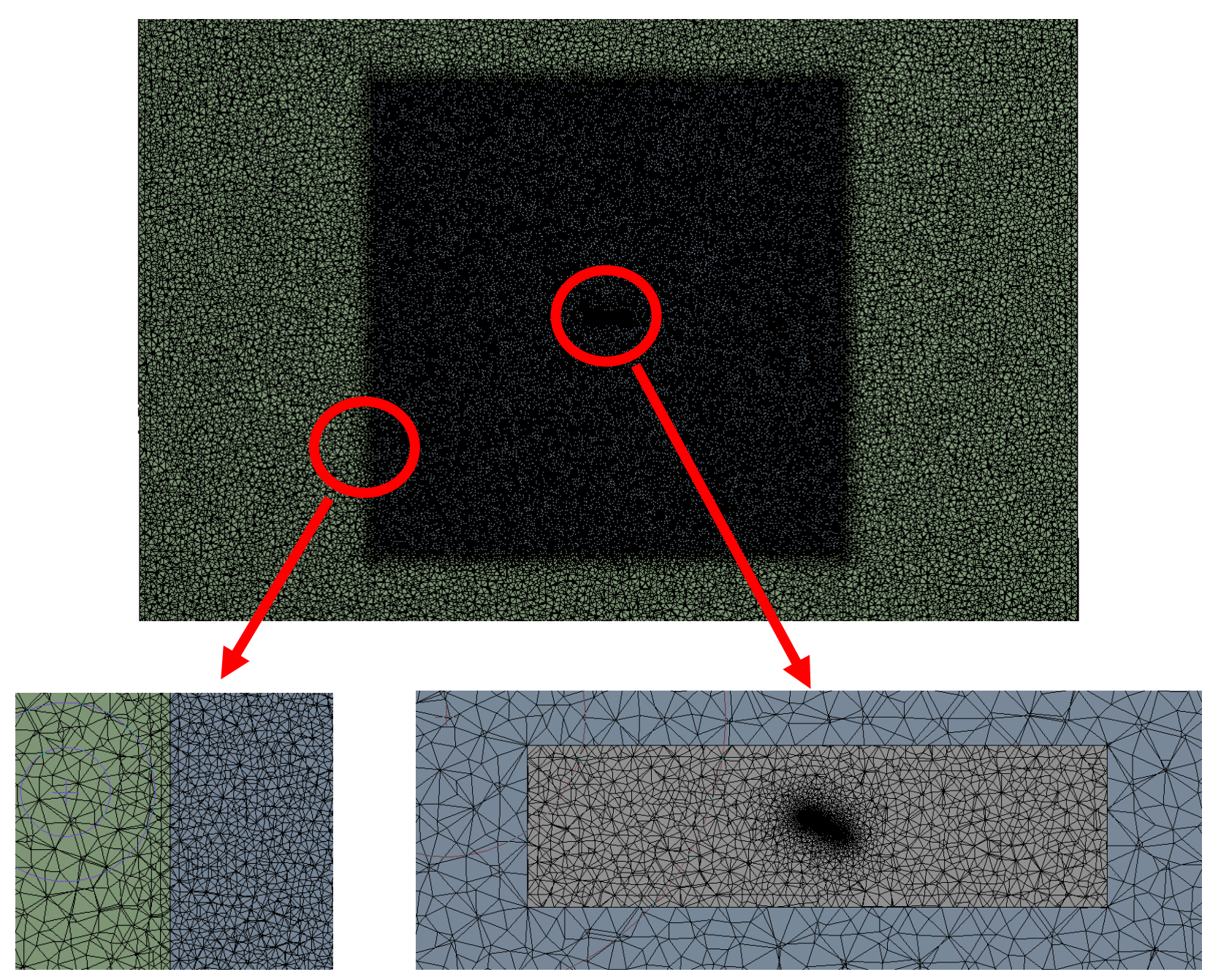

Figure 11. T-motor model, control volume grid transition spacing between subregions.

Element sizing is maximum at the outermost subregion and grows steadily more refined towards the rotor itself in order to better predict viscous interactions within the boundary layer as well as complex flow structures that are expected to occur during vortex-ring state. Boundary layer meshing involves 20 layers of structured prism elements that are normal to the wall surface as shown in Figure 12. Total grid refinement of all subregions was 40 million elements. All results from this numerical model were validated against experimental results obtained by Kolaei et al. (2018) [27]. 


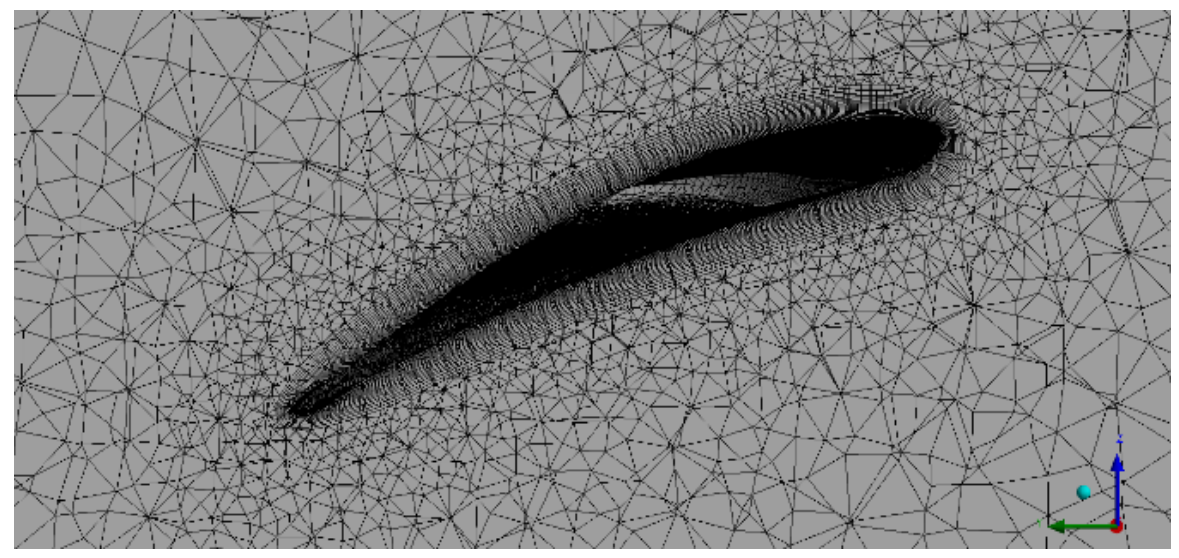

Figure 12. T-motor rotor boundary layer mesh.

The two-equation, first-order $k-\omega$ Shear Stress Transport (SST) was implemented for predicting viscous interactions while also tuning the turbulent frequency $\left(k_{T_{\infty}}\right)$ and turbulent kinetic energy $\left(\omega_{\infty}\right)$ to get good agreement with the experimental results. These parameters were matched to those that could be expected in the wind tunnel, which based on hotwire anemometry tests, is around $0.25 \%$ turbulence intensity based on the results reported by Kolaei et al. (2018) $[27,26]$. The turbulent frequency and turbulent kinetic energy are functions of turbulent intensity, $T u_{\infty}$, freestream velocity $\left(V_{\infty}\right)$, kinematic viscosity $(v)$ and turbulent kinematic viscosity $\left(v_{T}\right)$ :

$$
\begin{array}{cc}
k_{T_{\infty}}=1.5\left(T u_{\infty} V_{\infty}\right)^{2} & \text { Equation 6 } \\
\omega_{\infty}=C_{\mu, s t d}\left(\frac{k_{T_{\infty}}}{v}\right)\left(\frac{v_{T}}{v}\right)^{-1} & \text { Equation 7 }
\end{array}
$$

$C_{\mu, s t d}$ is a model constant used for tuning the turbulent kinetic energy. Based on the work in the field of turbulent flows by Pope (2000) [28], a value of 0.09 was used. All other variables were set to match sea level conditions and the turbulent viscosity ratio $\left(v_{T} / v\right)$ was set to 100 [28]. 


\subsection{Numerical and Experimental Results}

Ryerson University's large subsonic closed-circuit wind tunnel has three anti-turbulence screens in the settling chamber upstream of the test section to decrease the turbulence intensity within incoming air flow which is around $0.25 \%$ [27]. The test stand has a fiberglass cowling that encompasses the rotor's speed controller, 6-DOF load cell, an electric motor and other components. The rotor test stand is shown in Figure 13 where the cowling that encloses the previously mentioned components may be seen downstream of the rotor.

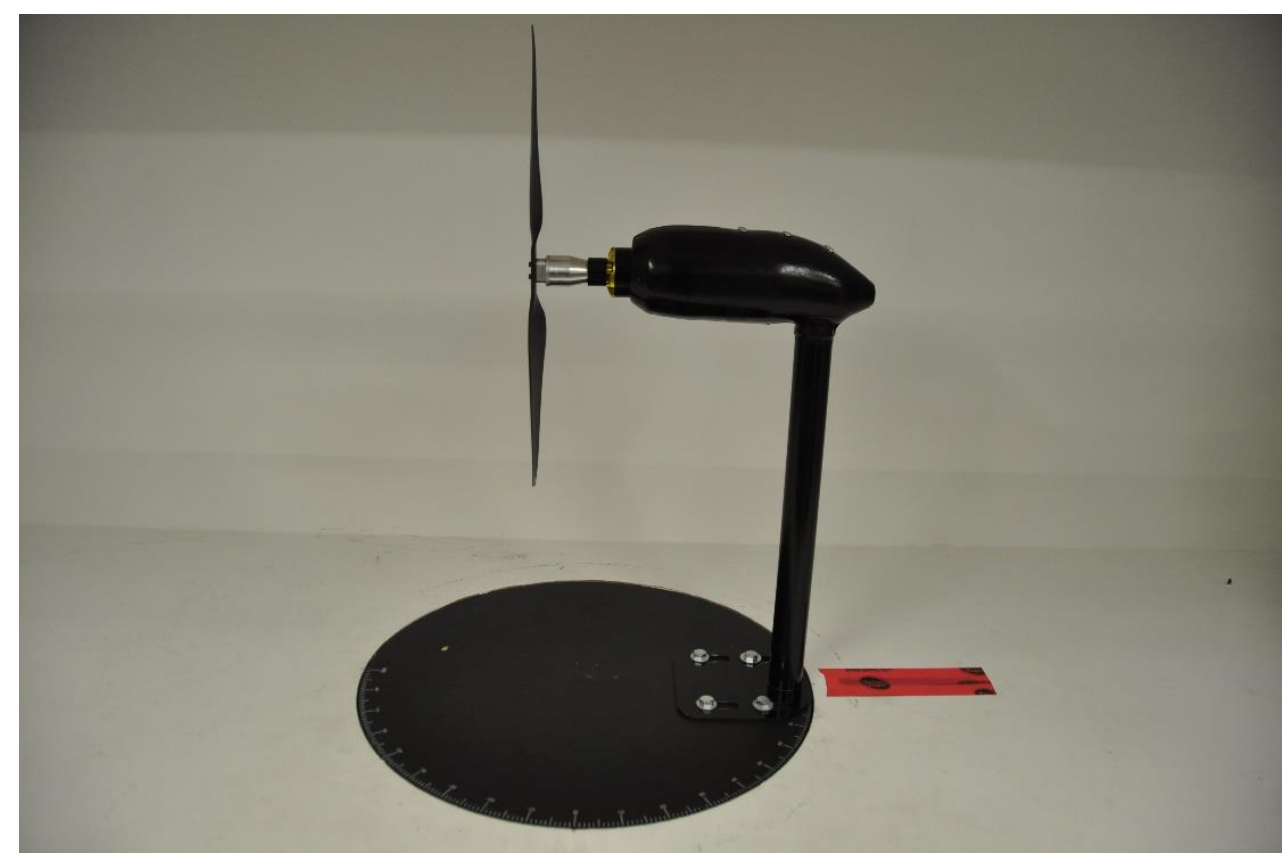

Figure 13. Rotor test stand within large subsonic wind tunnel of Ryerson University.

Solid blockage corrections are applied to measured results due to the presence of the test stand, base loads of the test stand, and due to wall interference effects. Through Taylor Series Method (TSM) uncertainty analysis, accuracy in thrust and power measurements were estimated to be around $1.78 \%$ and $2.15 \%$ respectively. A more detailed description of the experimental 
setup can be found in the work of Kolaei et al. (2018) [27]. Figure 14 outlines the comparison of experimental and numerical results. The experimental results presented herein were collected and analyzed by Kolaei et al. (2018) [27].
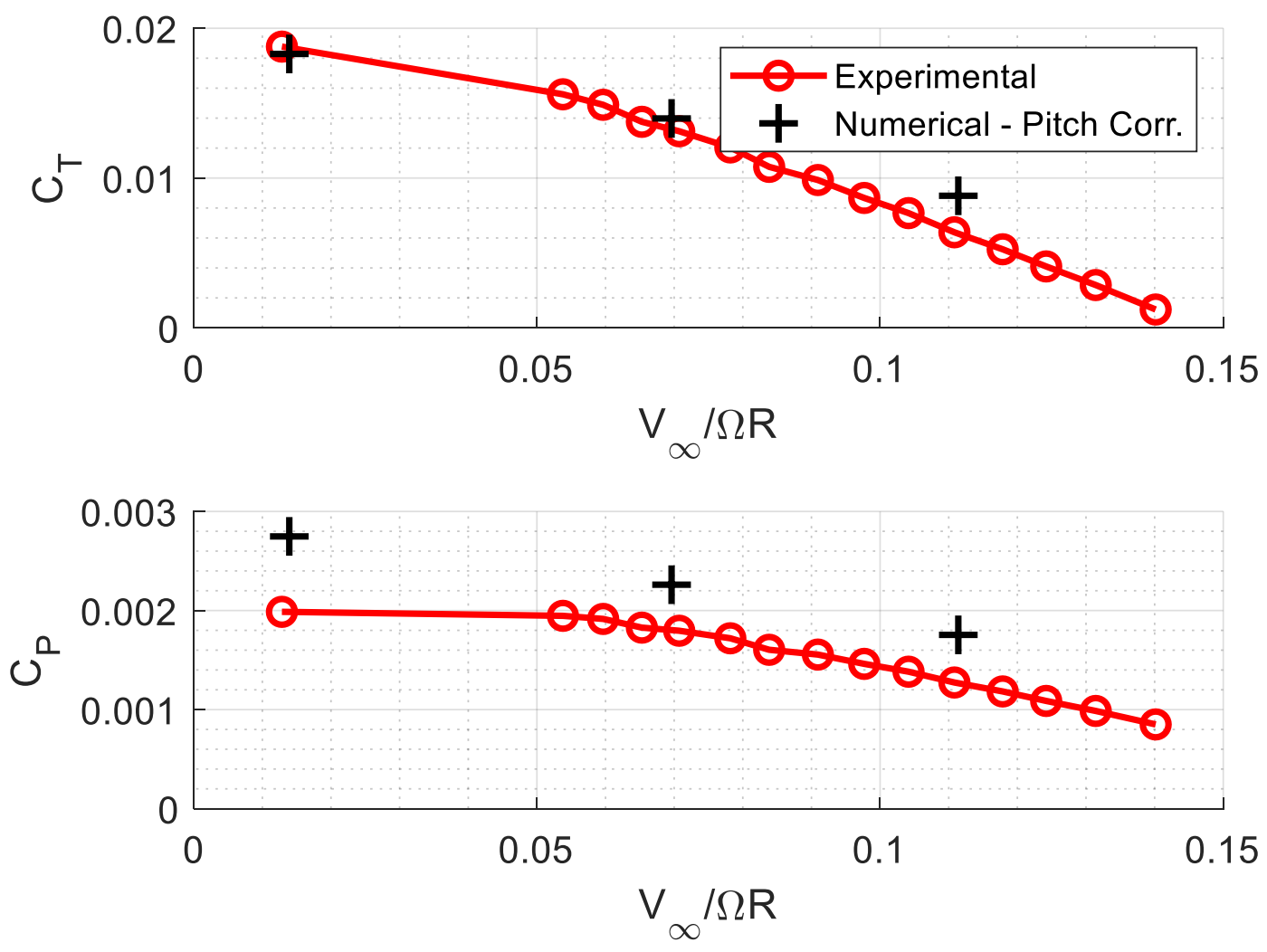

Figure 14. T-motor rotor numerical and experimental results [27].

Validation tests were performed at non-dimensional freestream velocities, $V_{\infty} / \Omega R$, of $0.014,0.070$, and $0.111(1 \mathrm{~m} / \mathrm{s}, 5 \mathrm{~m} / \mathrm{s}$, and $8 \mathrm{~m} / \mathrm{s})$. The comparisons with the numerical results are summarized in Figure 14. Numerical thrust and power coefficients were time-averaged over the last revolution for 360 timesteps (one revolution) through post-processing of results in MATLAB. 
The simulations consisted of 1800 timesteps and 5 revolutions which equated to one timestep per 1-deg of rotor rotation iterative scheme.

At the $5 \mathrm{~m} / \mathrm{s}$ axial freestream velocity, differences of $18.05 \%$ and $23.71 \%$ are observed for the thrust and power coefficients, respectively. This deviation is due to the $3 \mathrm{D}$ geometry scan being unable to correctly capture the collective pitch because of the thin rotor geometry. Unfortunately, this issue was not discovered until late in the computational investigation. To demonstrate this, the rotor's collective pitch angle was iteratively adjusted about the mid-chord line until the thrust coefficient matched well with experimental data. Comparisons were then made between the numerical and experimental power coefficients to determine the accuracy of the numerical model. A final collective pitch increase of 4 degrees was made to converge the error to $5.28 \%$ and $24.42 \%$ on the thrust and power coefficient which is identified by the "plus" sign in Figure 14. This new rotor geometry was then re-simulated at both $1 \mathrm{~m} / \mathrm{s}$ and $8 \mathrm{~m} / \mathrm{s}$ axial freestream velocities. At $1 \mathrm{~m} / \mathrm{s}$, the error is $3.77 \%$ and $36.71 \%$ on the thrust and power coefficients respectively and at $8 \mathrm{~m} / \mathrm{s}$ the error is $36.61 \%$ and $35.84 \%$. The pitch correction helps improve thrust predictions at the lower freestream advance ratios, however, it is ineffective at the upper end of the rotor velocity profile. The power coefficient is consistently over-predicted at all speeds likely due to the strong dependence it has on replicating the exact rotor geometry as well as inaccuracies in predicting turbulent transition points. Additional sources of error for the power coefficient are due to remodeled rotor in CATIA not being perfectly identical and the unstructured mesh not fully capturing the curvature of the rotors leading edge. 


\subsection{VAPTOR Numerical Model}

The VAPTOR model utilized the Aeryon 185 rotor provided by Aeryon Labs Inc. (now part of FLIR systems). Table 1 lists the rotor geometry data that was used in VAPTOR and Figure 15 depicts the geometry data graphically. The data was extracted from the CATIA model that was created from the scanned rotor STL file and was based on 20 airfoil stations equidistantly taken from the Aeryon 185 rotor from hub to rotor tip. Airfoil sections were extracted from stations 1 through 19 and are presented in Figure 16 to Figure 19. Column 2 represents the radial location of the airfoil section with respect to the origin (rotor hub). Column 3 non-dimensionalized the airfoil sections chord with the rotor radius. Column 4 gives the pitch angle of the airfoil with reference to the horizontal axis. Column 5 gives the horizontal displacement of the leading-edge point of each airfoil versus the leading-edge point of the airfoil section at the rotation axis with a negative displacement representing a shift towards the trailing edge. 

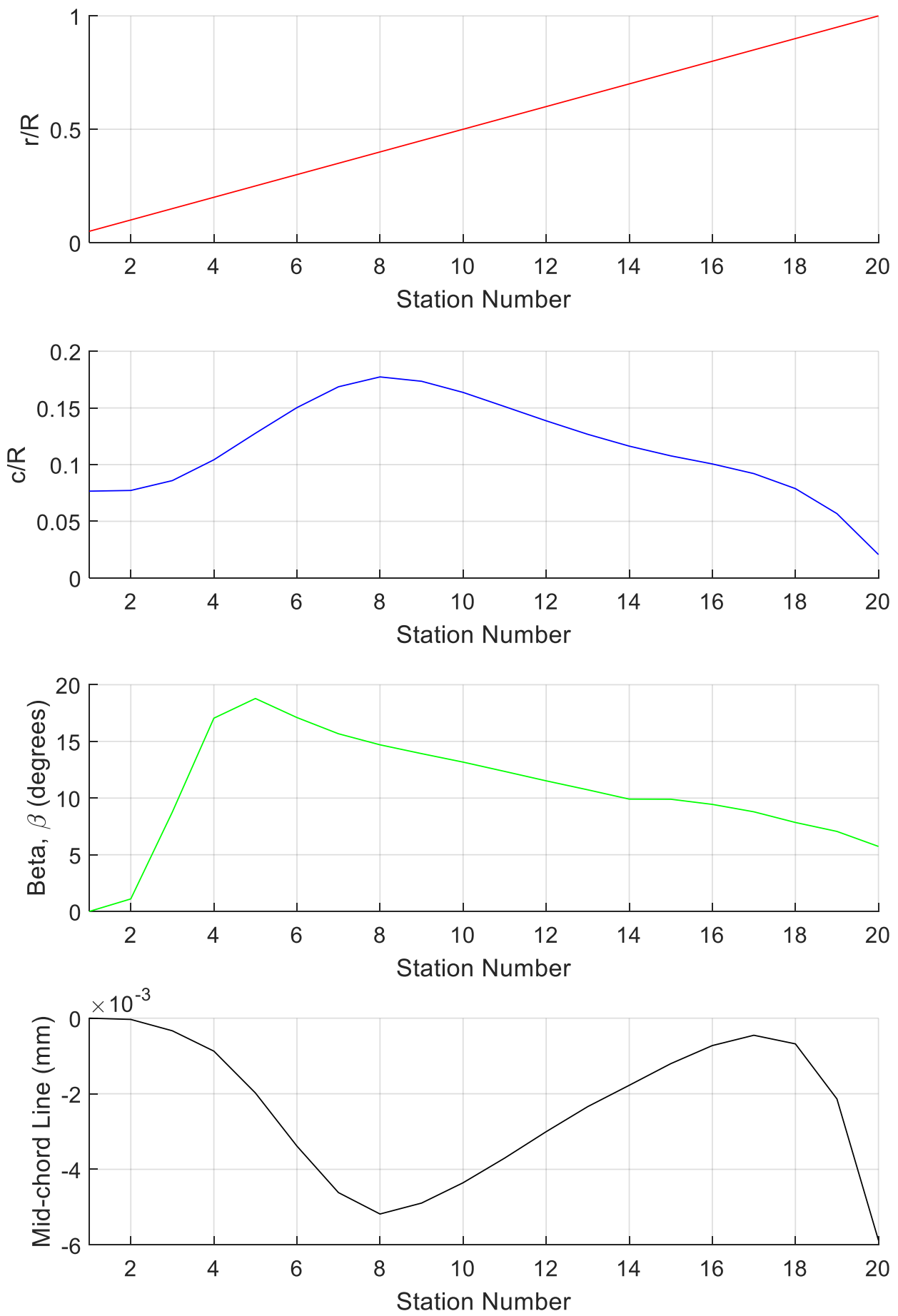

Figure 15. Aeryon 185 rotor geometric data. 
Table 1. VAPTOR Aeryon185 rotor geometric specifications.

\begin{tabular}{c|cccc} 
Station & $\boldsymbol{r} / \boldsymbol{R}$ & $\boldsymbol{c} / \boldsymbol{R}$ & $\begin{array}{c}\boldsymbol{\beta} \\
\text { (degrees) }\end{array}$ & $\begin{array}{c}\text { Mid-chord line } \\
(\mathbf{m})\end{array}$ \\
\hline $\mathbf{1}$ & 0.05 & 0.0766 & 0.0030 & $0.000 \mathrm{E}+00$ \\
\hline $\mathbf{2}$ & 0.10 & 0.0772 & 1.1050 & $-3.300 \mathrm{E}-05$ \\
\hline $\mathbf{3}$ & 0.15 & 0.0859 & 8.7660 & $-3.340 \mathrm{E}-04$ \\
\hline $\mathbf{4}$ & 0.20 & 0.1043 & 17.0480 & $-8.720 \mathrm{E}-04$ \\
\hline $\mathbf{5}$ & 0.25 & 0.1276 & 18.7850 & $-1.979 \mathrm{E}-03$ \\
\hline $\mathbf{6}$ & 0.30 & 0.1503 & 17.1030 & $-3.385 \mathrm{E}-03$ \\
\hline $\mathbf{7}$ & 0.35 & 0.1687 & 15.6750 & $-4.616 \mathrm{E}-03$ \\
\hline $\mathbf{8}$ & 0.40 & 0.1774 & 14.6990 & $-5.182 \mathrm{E}-03$ \\
\hline $\mathbf{9}$ & 0.45 & 0.1735 & 13.9220 & $-4.893 \mathrm{E}-03$ \\
\hline $\mathbf{1 0}$ & 0.50 & 0.1637 & 13.1740 & $-4.355 \mathrm{E}-03$ \\
\hline $\mathbf{1 1}$ & 0.55 & 0.1512 & 12.3530 & $-3.703 \mathrm{E}-03$ \\
\hline $\mathbf{1 2}$ & 0.60 & 0.1387 & 11.5220 & $-3.004 \mathrm{E}-03$ \\
\hline $\mathbf{1 3}$ & 0.65 & 0.1268 & 10.7300 & $-2.341 \mathrm{E}-03$ \\
\hline $\mathbf{1 4}$ & 0.70 & 0.1163 & 9.9080 & $-1.776 \mathrm{E}-03$ \\
\hline $\mathbf{1 5}$ & 0.75 & 0.1077 & 9.9000 & $-1.204 \mathrm{E}-03$ \\
\hline $\mathbf{1 6}$ & 0.80 & 0.1006 & 9.4440 & $-7.250 \mathrm{E}-04$ \\
\hline $\mathbf{1 7}$ & 0.85 & 0.0921 & 8.7910 & $-4.520 \mathrm{E}-04$ \\
\hline $\mathbf{1 8}$ & 0.90 & 0.0789 & 7.8490 & $-6.800 \mathrm{E}-04$ \\
\hline $\mathbf{1 9}$ & 0.95 & 0.0568 & 7.0600 & $-2.137 \mathrm{E}-03$ \\
\hline $\mathbf{2 0}$ & 1.00 & 0.0207 & 5.7360 & $-5.878 \mathrm{E}-03$ \\
\hline
\end{tabular}

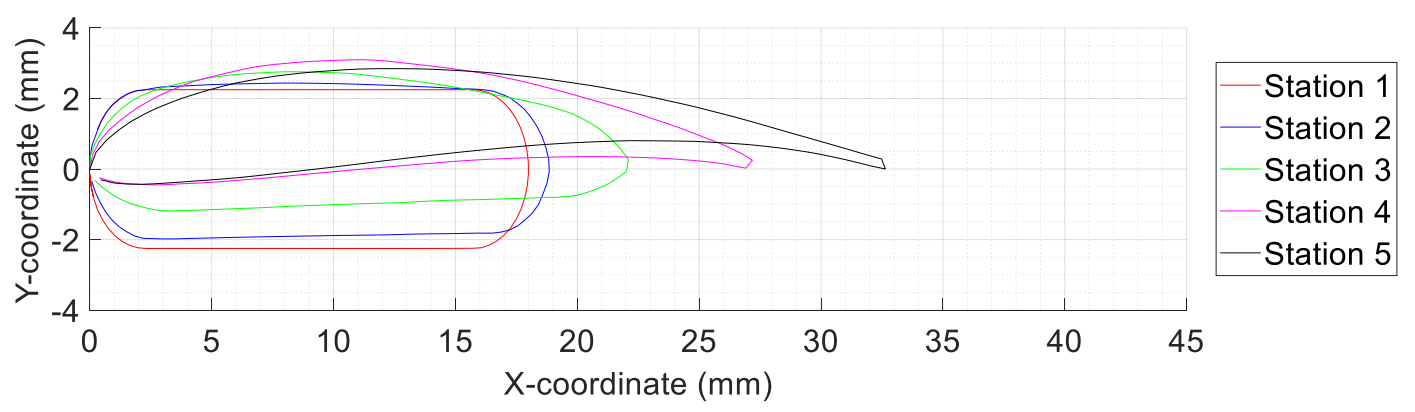

Figure 16. Aeryon185 airfoil sections for stations 1 to 5. 


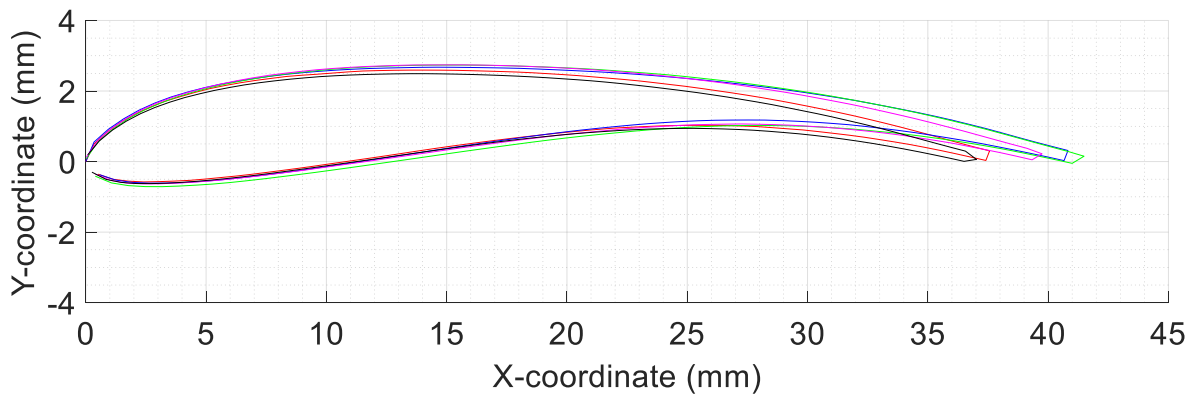

Station 6 Station 7

Station 8

Station 9

Station 10

Figure 17. Aeryon185 airfoil sections for stations 6 to 10 .

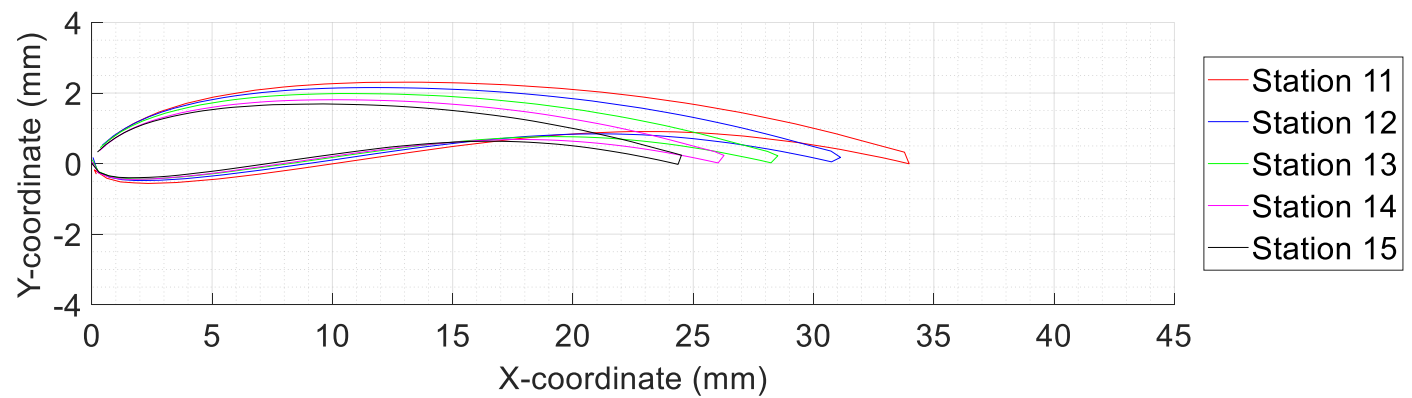

Figure 18. Aeryon185 airfoil sections for stations 11 to 15.

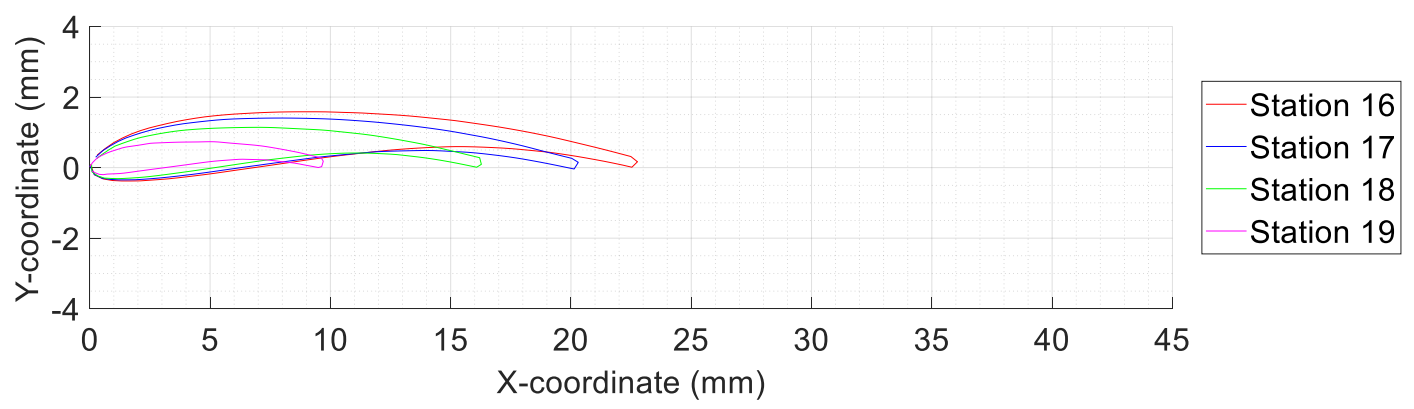

Figure 19. Aeryon185 airfoil sections for stations 16 to 19. 


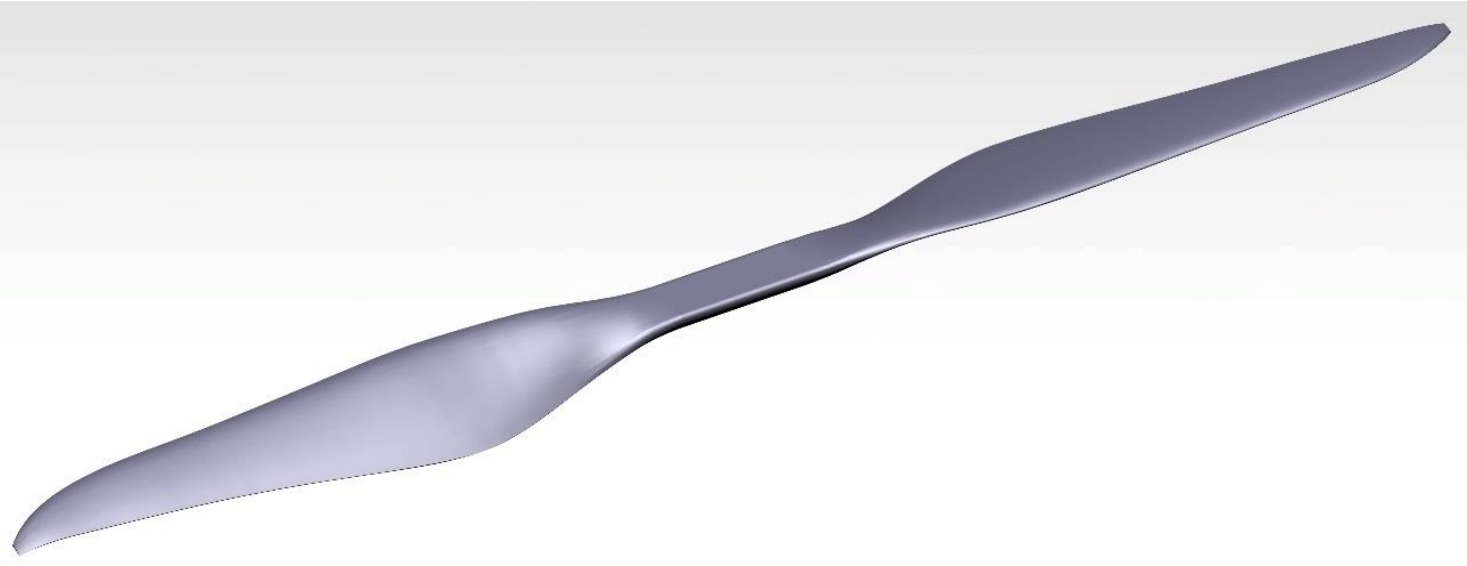

Figure 20. Isometric Aeryon185 rendering.

The single rotor model in VAPTOR was simulated for 30 azimuth locations per rotation for a total of 5 rotations whereas the 4-rotor model was simulated for 7 rotations to ensure a converged solution was achieved. It is important to know that the VAPTOR model was formulated using propeller convention, but the results were converted to rotor convention format to compare experimental and numerical results.

\subsection{VAPTOR Results}

To match VAPTOR data to experimental results, a 4-degree pitch correction was applied to the rotor geometry to better replicate actual rotor performance. Like the CFD model for the Tmotor rotor, the collective pitch was adjusted at a single non-dimensional freestream velocity to match the thrust coefficient values of the VAPTOR model and experimental results. Figure 21 outlines the comparison between VAPTOR results and obtained experimental results in the subsonic wind tunnel at Ryerson University for the Aeryon 185 rotor. The plots show the comparison of thrust and power coefficients over increasing non-dimensional velocity, $V_{\infty} / \Omega R$. 
Good agreement in terms of both performance trends and force magnitudes is seen between VAPTOR and the experimental results with an average deviation of around $13.51 \%$ and $11.69 \%$ on thrust and power coefficients respectively. OpenFOAM results for a single Aeryon185 rotor were not compared to VAPTOR and experimental data due to computational resource limitations. Due to the increase in grid density with the Aeryon 185 rotor model in comparison to the T-motor rotor model (single-rotor models), the available servers were either unable to run the model or the queue time necessary to fully simulate the case was too resource intensive.
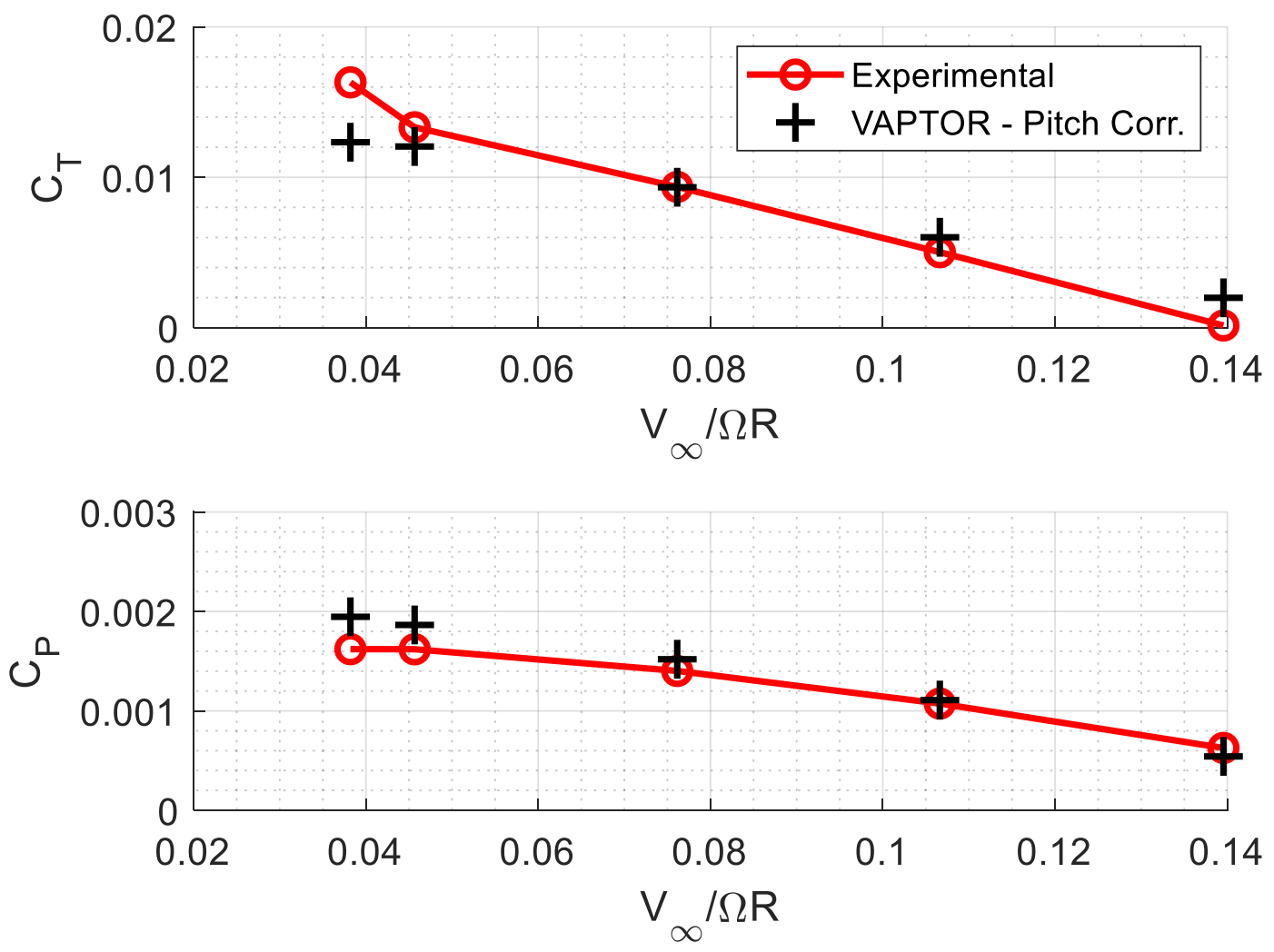

Figure 21. Aeryon185 VAPTOR and experimental results. 


\section{Chapter 4}

\section{Descent Velocity Sweep}

An axisymmetric axial freestream angle of attack model for a quadrotor drone was used to simulate a descent velocity sweep to better understand the relationship between descent velocity and rotor thrust as the rotor enters vortex-ring state. The sweep ranged from a climbing velocity ratio of 0.22 to a 4.30 descent-velocity ratio. The velocity ratio is defined as the ratio between rotor climb/descent speed versus the rotor induced velocity at hover based on momentum theory, $V_{h}$ [11]. The rotor having entered vortex-ring state was located by observing thrust and power coefficient trends over the descent velocity sweep. Vortex-ring state was identified by its characteristic reduction in rotor thrust. CFD and VAPTOR results are compared in terms of results and computational efficiency. Raw data for all presented plots and figures in Chapter 4 can be found in Appendix B. 


\subsection{Geometric Model}

A computational model was made to resemble a typical quadrotor configuration. Geometric files for the quadrotor were provided by Aeryon Labs Inc. (now part of FLIR systems). A finalized model rendering from CATIA is shown in Figure 22. The body has a diameter of approximately $24-\mathrm{cm}$ (9.5 inches) and the rotors have a $47-\mathrm{cm}$ (18.5-inch) diameter.

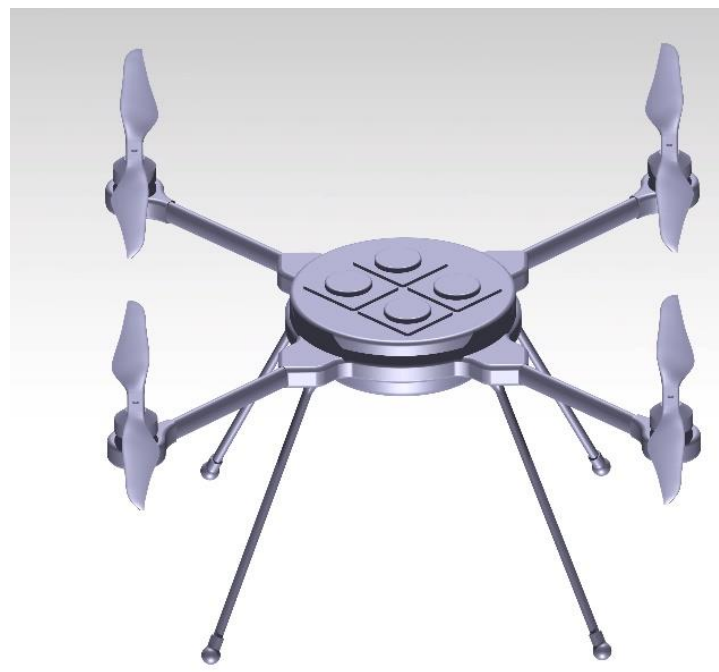

Figure 22. Quadrotor drone CAD model.

Only purely climbing and descending flights with axial inflow were modelled for this vortex-ring state study. An axisymmetric, 90-degree section model was used in order to increase computational efficiency with two symmetry boundary conditions being used to capture the full flow structure of the quadrotor. Figure 23 shows a schematic for the computational model and presents model sizing based on the rotor radius, $R$, and the boundary conditions. Model sizing was 
made relative to the quadrotors center of geometry. This model was made to be comparable to the validated T-motor rotor with a minor increase in model sizing.

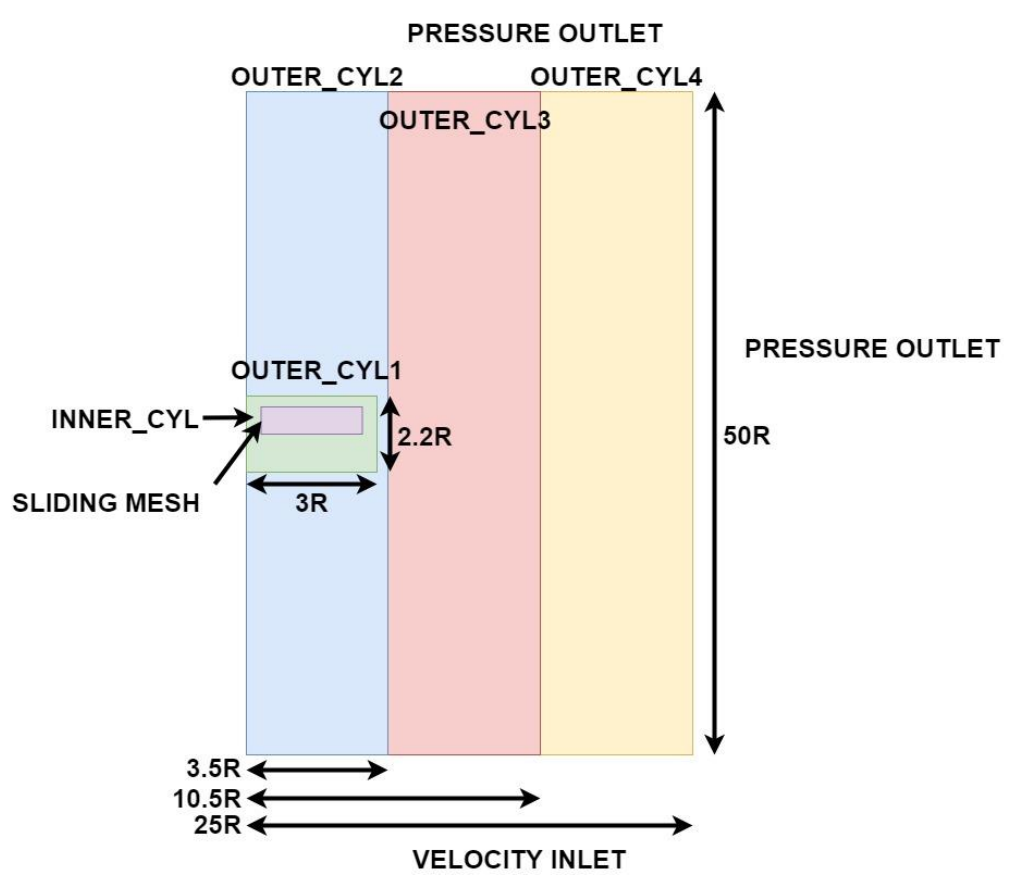

Figure 23. Computational domain, model sizing and boundary conditions of quadrotor.

\subsection{OpenFOAM Numerical Model}

Additional subregions were modelled into the computational schematic in order to better control grid density and more gradual grid spacing that allows for a more effective Detached Eddy Simulation (DES). Due to tight geometric clearances, the boundary layer prism meshing was reduced from 20 layers to 15 layers. The quadrotor uses an Aeryon 185 rotor from Aeryon Labs Inc. that was mounted to the drone arm as seen in Figure 24. The interface between the two-colored regions indicates the location of the AMI patch for the sliding mesh interface. 


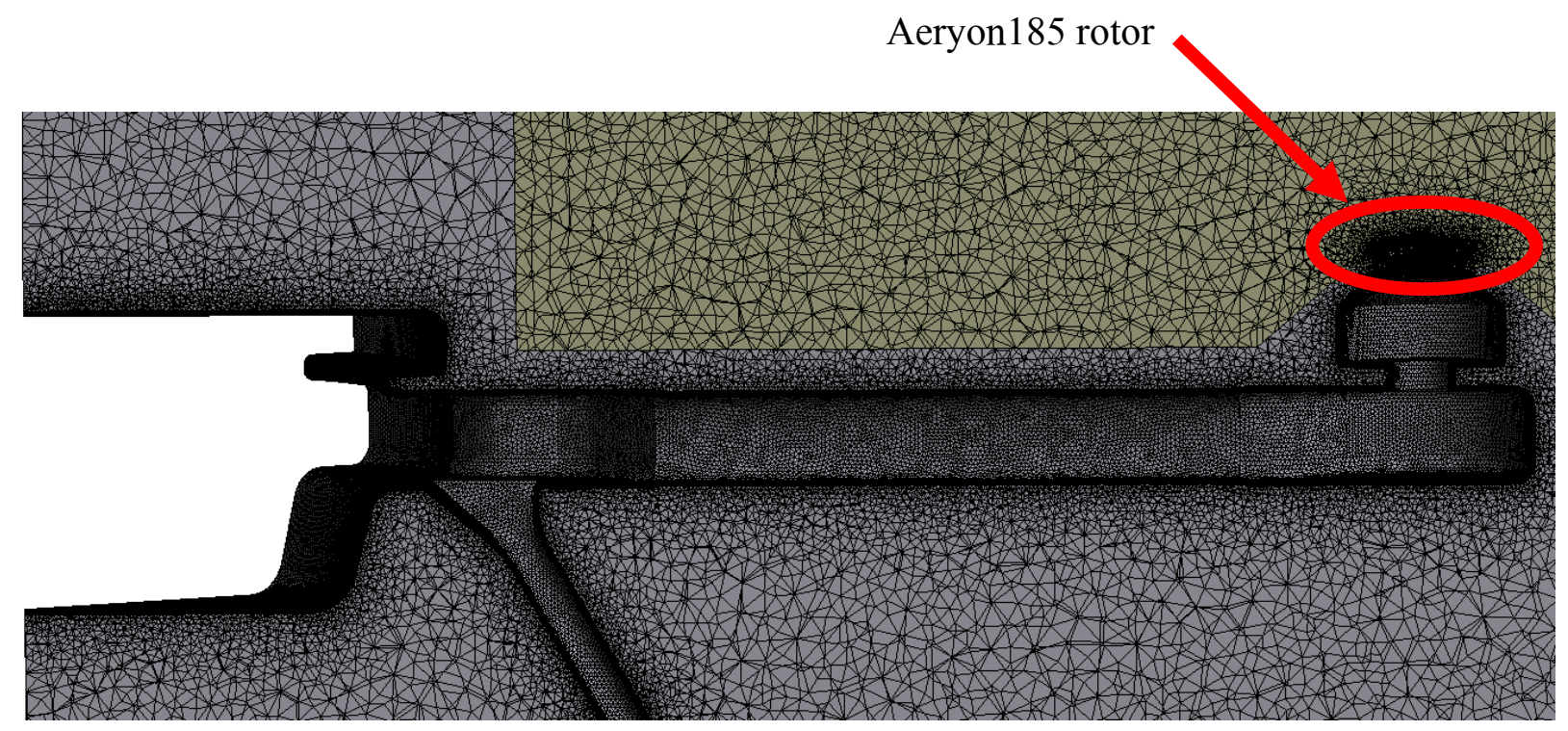

Figure 24. Quadrotor drone computational grid, 2D section plane.

The downwash at hover conditions was determined using momentum theory. The thrust at hover was approximated by simulation at near hover conditions of 0.22 climbing velocity ratio, which equates to $1 \mathrm{~m} / \mathrm{s}$ climb rate. Boundary conditions were set to replicate sea level conditions and the rotor speed was 3000 RPM. A velocity ratio of 0 (hover model) was not investigated due to numerical instability caused by no initial inflowing velocity. With the computed numerical solution for thrust, the rotor hover induced velocity, $V_{h}$, can be calculated using momentum theory. A rotor induced velocity at the near-hover condition was found to be $4.65 \mathrm{~m} / \mathrm{s}$.

\subsection{Results}

The vortex-ring state flight regime was identified using the thrust profile with respect to the descent-velocity ratio. Figure 25 shows the descent velocity sweep results for thrust coefficient, $C_{T}$, versus the velocity ratio, $V_{Z} / V_{h}$, which is the climbing/descending velocity normalized with the rotor induced velocity at hover. Results are shown for aerodynamic loading only on the rotor 
and loading on the entire quadrotor. The numerical model simulates the flow effects of a four-rotor quadrotor configuration via dual symmetry planes, however, aerodynamic performance presented is for a single-rotor. A rapid degradation in rotor thrust generating potential marks the beginning of this aerodynamic phenomena, which, as expected, occurred close to the rotor induced velocity at hover.
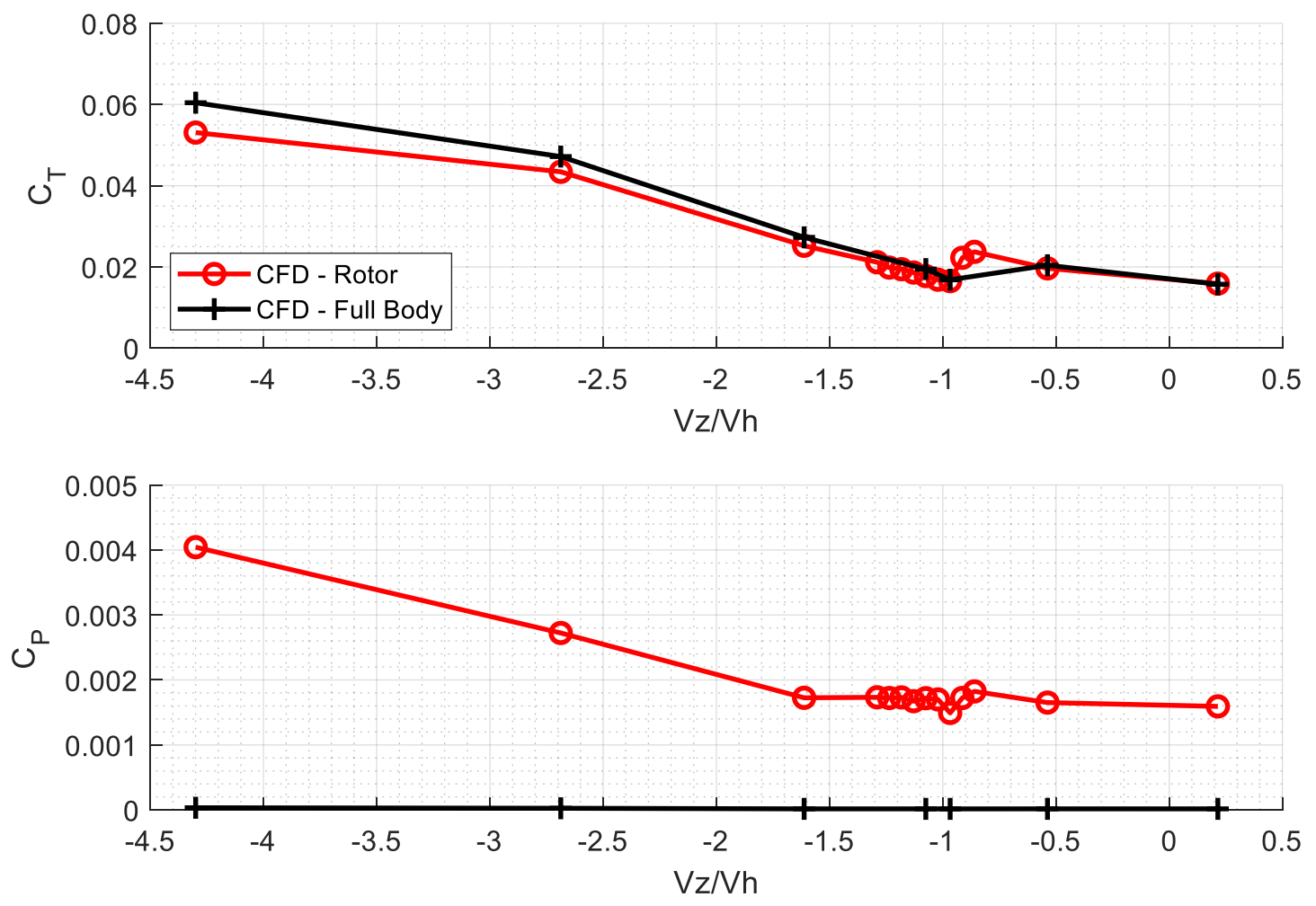

Figure 25. Quadrotor drone descent velocity sweep, rotor performance.

Vortex-ring state is identified by the characteristic loss in rotor thrust performance, which occurs as expected at a descent velocity close to the momentum theory-based downwash at hover, $V_{h}$. Figure 25 shows a sudden thrust loss around $V_{Z} / V_{h}=-0.97$, which implies that the rotor has 
entered vortex-ring state at higher, but not at lower descent rates. Based on the simulation results, very little variation in required rotor power was observed when the rotor was in the vortex-ring state flight regime. Based on this conclusion, it is then possible to state that the vortex-ring state flight regime of the current configuration occurs from about -0.9 to $-1.1 V_{Z} / V_{h}$.

For purposes of comparison between CFD and VAPTOR, the descent velocity sweep was run through a single and 4-rotor model in VAPTOR as well. It is important to note that the VAPTOR models only include the rotor dynamics and not any fuselage effects on the flow structure whereas the OpenFOAM model does include the fuselage geometry into the computational grid. Figure 25 shows that the effect of the fuselage is minimal until higher descent rates are reached within the windmill brake state. Each CFD data point required 96 cores for 96 hours of simulation time (4 days) to reach a converged solution. In comparison to VAPTOR which required 85 hours using a single core (with $400 \mathrm{~Gb}$ of memory).

Figure 26 shows the results of the two numerical models. The dataset marked by an "o" represents CFD aerodynamic loading of the rotors only, “+” represents CFD aerodynamic loading of the rotors and fuselage combined, "*" represents the VAPTOR single rotor model and " $\mathrm{x}$ " represents the VAPTOR 4-rotor model. The results show that all models have good agreement pre and post vortex-ring state with regards to both thrust and power coefficients, however, within vortex-ring state, the magnitude of thrust loss as well as the power predictions are noticeably different between CFD and VAPTOR. This may be attributable to difficulties in modelling this unsteady flight regime, especially with the VAPTOR models relaxed wake numerical scheme as the program attempts to calculate each timesteps wake elements as the rotor is trapped within its own wake. 

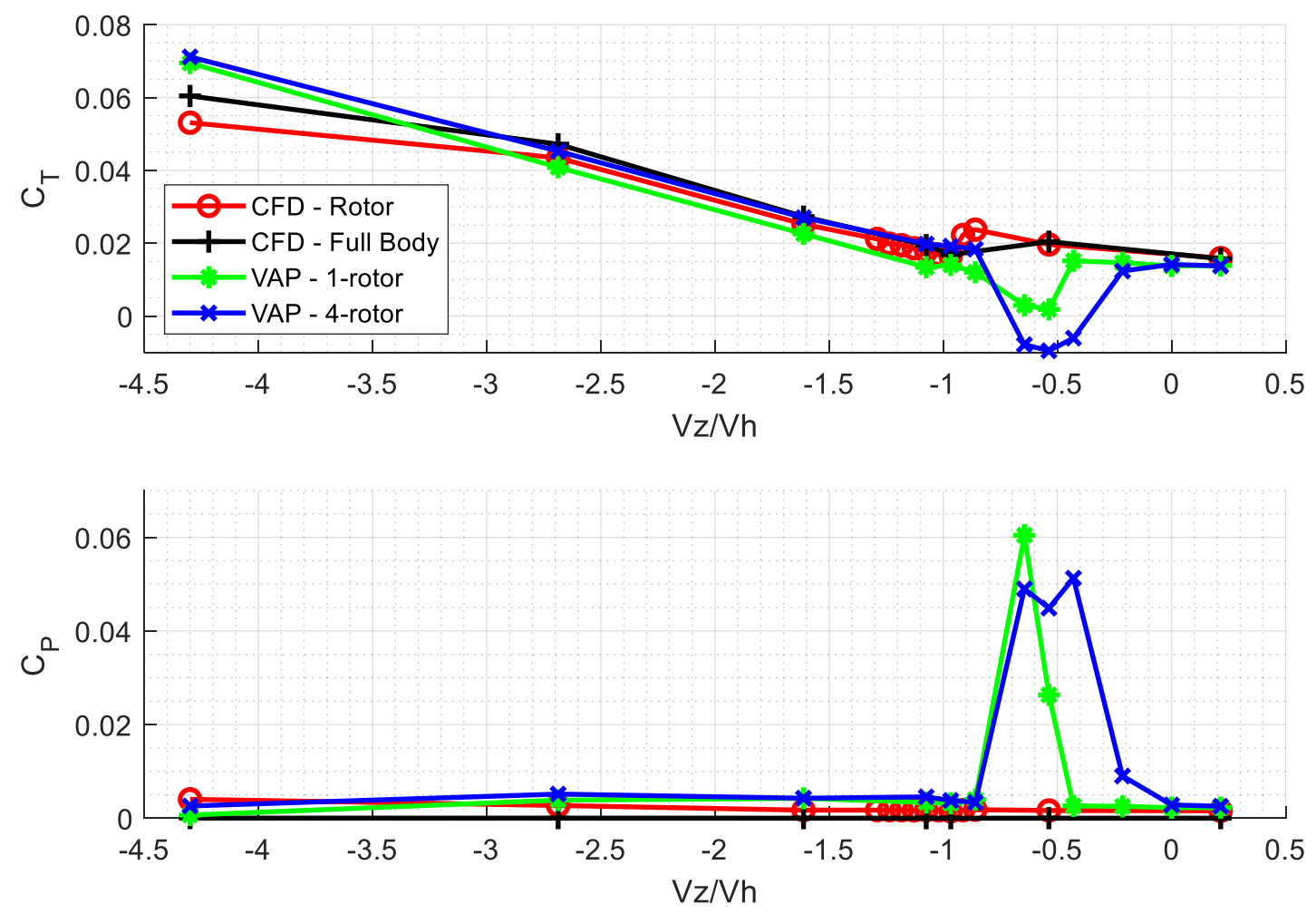

Figure 26. Descent velocity sweep, numerical model comparison of rotor performance.

Differences in flow structure between the minimum thrust point of vortex-ring state and higher descent speeds is clearly visible through vorticity contour plots around the quadrotor. Figure 27 shows a vorticity contour on a 2D plane through the rotors center of rotation for a simulation where the quadrotor is descending at $4.5 \mathrm{~m} / \mathrm{s}$. Vortex-ring state flow structure, as previously mentioned, is representative of the collapse of the helical vortex structure being shed by the rotor into a more unstable and chaotic nature. Once the descent rate is increased beyond the minimum thrust point, the flow re-stabilizes into the more desirable helical vortex. This can be clearly seen in Figure 28 and Figure 29 (right) where the descent rate of the quadrotor was $5 \mathrm{~m} / \mathrm{s}$ and $7.5 \mathrm{~m} / \mathrm{s}$ respectively. The rotor wake is more aptly seen through a 3D visualization of the Q-criterion seen in Figure 29 (left) where three concentric vortex rings have been created downstream of the rotor 
plane. Animations of Q criterion at a $7.5 \mathrm{~m} / \mathrm{s}$ descent and vorticity at near-hover $(1 \mathrm{~m} / \mathrm{s}$ climb), 2.5 $\mathrm{m} / \mathrm{s}, 4.5 \mathrm{~m} / \mathrm{s}, 5 \mathrm{~m} / \mathrm{s}$, and $7.5 \mathrm{~m} / \mathrm{s}$ descent have been made available at the following google drive link: https://drive.google.com/open?id=1d2H5Mgy0i4EmWnJaeVyE_4NZKYEXT2LW.

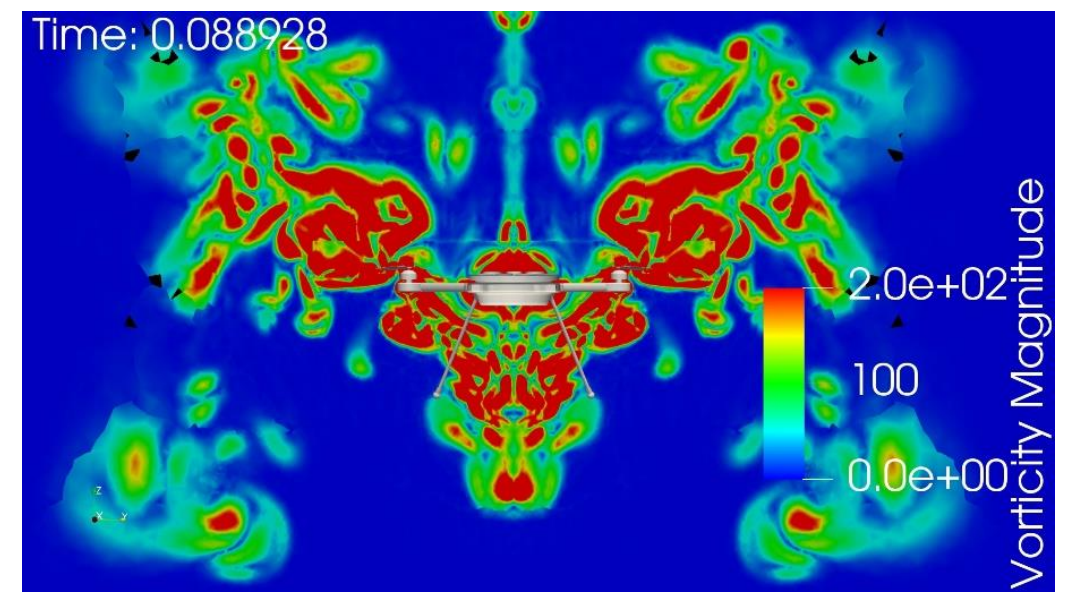

Figure 27. Unstable rotor wake vortex shown with vorticity at $-0.968 V_{z} / V_{h}$.

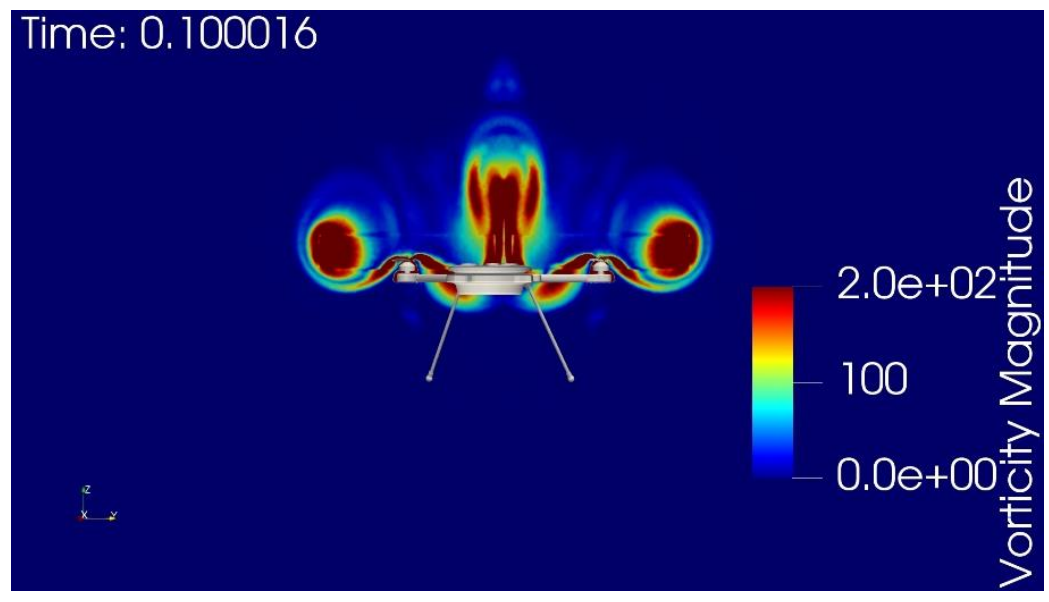

Figure 28. Stable rotor wake vortex shown with vorticity at $-1.075 V_{z} / V_{h}$. 


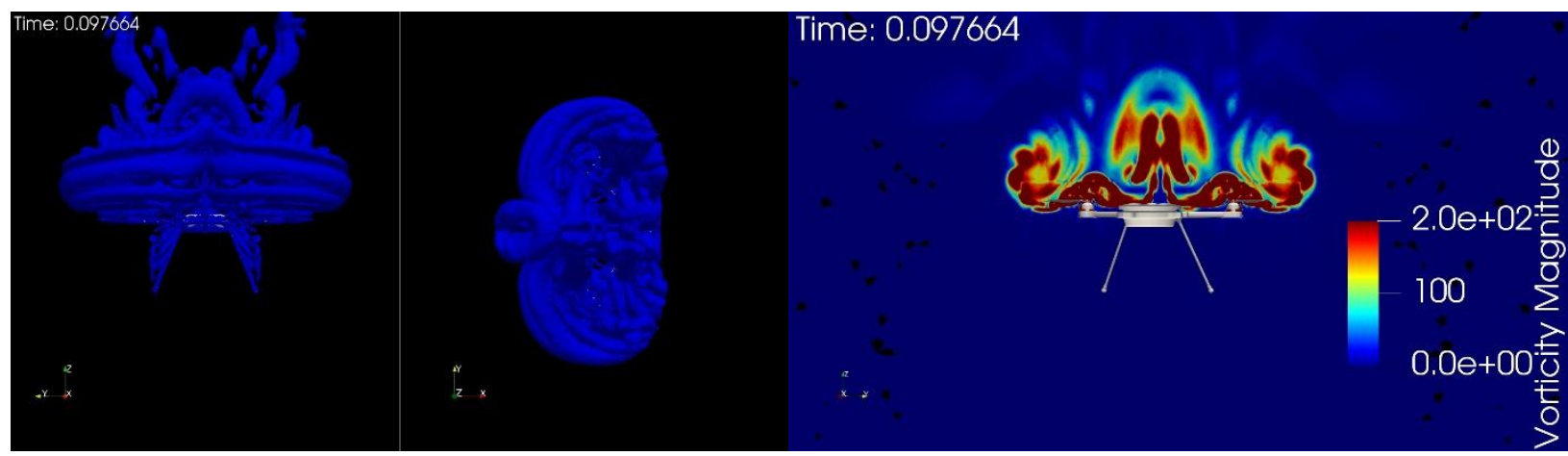

Figure 29. Rotor wake shown with Q-criterion (left) and Vorticity (right) at -1.613 $V_{z} / V_{h}$. 


\section{Chapter 5}

\section{Vortex-Ring State Flight Maneuvers}

Mitigation strategies of vortex-ring state via flight maneuvers are investigated in Chapter 5. Using a half-body model of the same quadrotor from Chapter 3, various forward speeds are applied in combination with the descent velocity sweep to explore non-vertical flight paths. Rotor thrust trends are shown again to demonstrate how the use flight maneuvers can be employed to reduce the magnitude of thrust loss due to vortex-ring state. Power trends are not shown since the two rotors are counter-rotating, resulting in the averaged power coefficient between the two rotors to be zero. Raw data for all presented plots and figures in Chapter 5 can be found in Appendix C.

\subsection{Geometric Model}

The quadrotor configuration used here was the same geometric model as the one used in Chapter 3 for the vertical descent velocity sweep. This 2-rotor model uses a half-body 
configuration with a single symmetry plane to allow for application of a forward velocity in combination with the descent velocity component. Figure 30 details the model schematic and boundary conditions of the flight maneuver model. The body sizing shown on the schematic is with respect to the rotor radius, which is $0.47 \mathrm{~m}$ (18.5-inch).

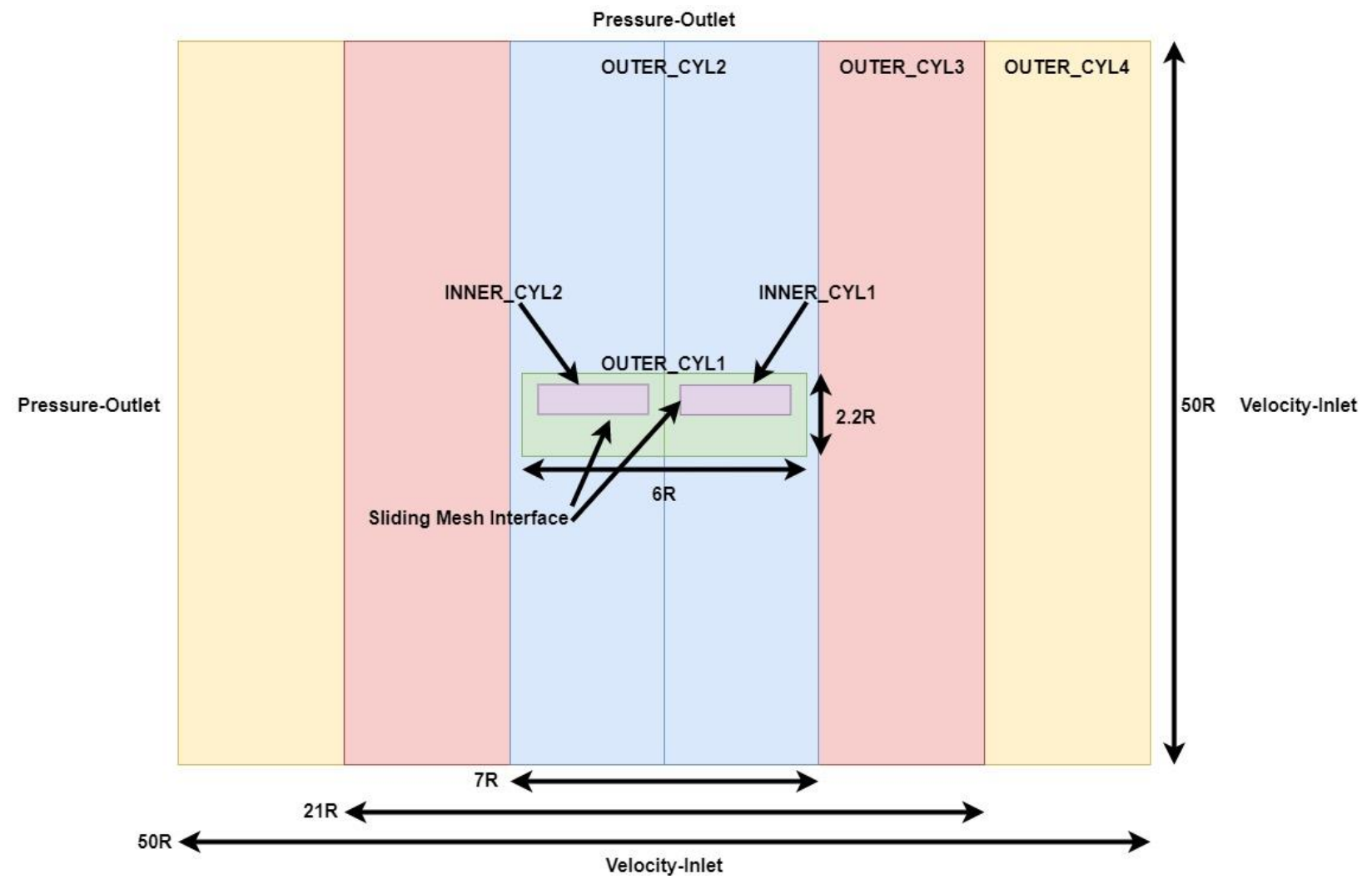

Figure 30. Half-body computational domain, model sizing and boundary conditions.

\subsection{Results}

Figure 31 shows the results for three forward velocities, namely $1 \mathrm{~m} / \mathrm{s}, 2 \mathrm{~m} / \mathrm{s}$ and $3 \mathrm{~m} / \mathrm{s}$. The thrust coefficients were plotted against the descent velocity ratio, $V_{Z} / V_{h}$ for each forward speed. Aerodynamic loadings presented here were taken as an average load between both rotors 
and neglected the force and moment loadings on the fuselage itself. Due to significant computational resource requirements for a half-body model, the descent velocities performed here were plotted using less data points since these models require 96 cores for nearly 8 days of run time to reach a converged solution. At a $1 \mathrm{~m} / \mathrm{s}$ forward velocity, the rotors entering vortex-ring state can be seen to occur somewhere in the range of $V_{Z} / V_{h}=-0.538$ and $V_{Z} / V_{h}=-0.860$. The thrust loss from the on-set of vortex-ring state is reduced from about $30 \%$ to $26 \%$ because of the applied forward velocity pushing some of the vortex ring away from the rotor tips. At a $2 \mathrm{~m} / \mathrm{s}$ forward velocity, a thrust loss of around $1 \%$ is observed. This shows that with only a small addition to the forward velocity, vortex-ring state is almost non-existent. This is because the forward velocity is of sufficient magnitude to prevent the rotors wake from building up around the rotor tip. This is further shown at the highest forward speed where no thrust loss was found. The thrust loss experienced by the rotors when the quadrotor enters the vortex-ring state flight regime appears to be non-linearly related to the forward velocity. It may be concluded that employing flight maneuvers such as a non-zero forward velocity can be an effective countermeasure to vortex-ring state. However, should a quadrotor already be in vortex-ring state, this strategy may not be an immediate solution because of the strength of the vortex-ring around the rotor tip. It would likely take time to break away from the vortex-ring before thrust recovery could occur [7]. For multirotor rotorcraft, thrust imbalances would likely cause an uncontrolled flight maneuver that would pull the vehicle out of vortex-ring state. 


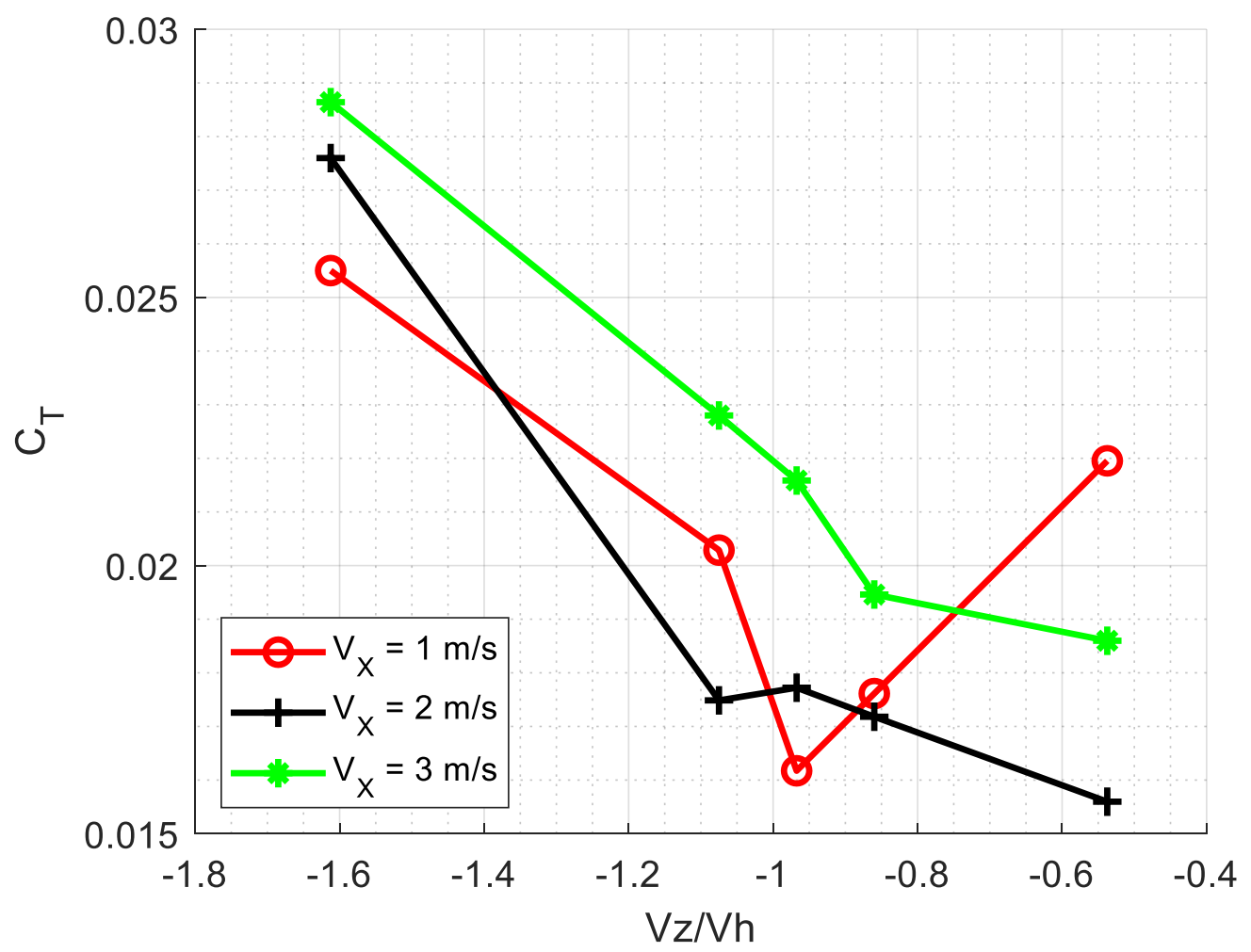

Figure 31. Descent velocity sweep with applied forward velocity, rotor performance.

Additional flight maneuver investigations are recommended to further investigate this approach. Future studies should be performed with a similar descent velocity sweep with more data points as well as each trend line should be held at a constant descent angle. This would assist in better understanding which flight maneuvers would be suitable for helping a quadrotor exit vortex-ring state. 


\section{Chapter 6}

\section{Vortex-Ring State Prediction Methods}

An early-onset vortex-ring state warning system is proposed for a quadrotor drone using pressure ports to monitor differential pressures. This system shows promising data for descending flight based on acquired CFD results and is recommended for further investigation and testing. Flow visualizations of $2 \mathrm{D}$ pressure contours at the locations of these pressure ports assist in showing the results of the differential pressure measurement system. Raw data for all presented plots and figures in Chapter 6 can be found in Appendix D.

\subsection{Results}

A thrust loss of about $30 \%$ occurs when the quadrotor penetrates the vortex-ring state flight regime boundary based on the previously shown numerical results in Figure 25. This thrust loss has been known to cause significant control issues and flight-path upsets for rotorcraft. The ability to predict the early on-set of vortex-ring state becomes critical for the safe operation of 
these vehicles when descending. One proposed method is to use pressure differentials between different locations of the quadrotor fuselage as a warning sign when approaching vortex-ring state during descent. Two differential pressures were investigated with the quadrotor model from Chapter 4. The locations for the three pressure-ports that were assessed, are shown in Figure 32. Port 1 is located at the top of the quadrotor fuselage and is aligned with a vertical axis that passes through the body's centroid. Port 1 is approximately $5-\mathrm{cm}$ above the fuselage surface, conceivably mounted on a sting. Port 2 is located $5-\mathrm{cm}$ below the quadrotor fuselage, also in alignment with the same vertical axis through the body's centroid. Port 3 is located just at the button of one of the legs of the quadrotor's landing gear. The pressure differential between Ports 1 and 2 and Ports 2 and 3 were assessed. The notation for the measured pressure difference, $\Delta P_{i j}$, between point $i$ and $j$ is:

$$
\Delta P_{i j}=P_{i}-P_{j}
$$

Equation 8

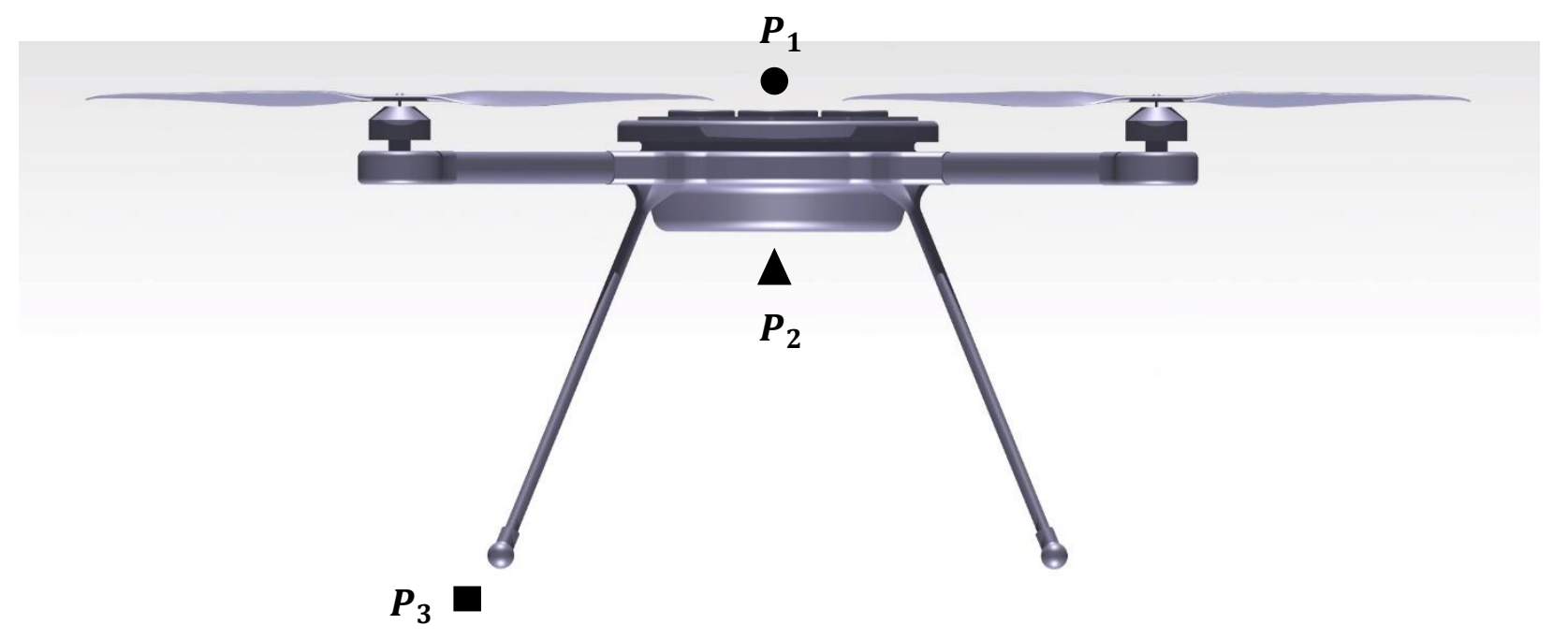

Figure 32. Quadrotor model with pressure port locations.

Figure 33 shows the results for pressure differentials $\Delta P_{12}$ and $\Delta P_{13}$ across the previously tested descent velocity sweep. $\Delta P_{12}$ does pick up a pressure drop of about $40 \mathrm{~Pa}$ when the aircraft 
is in vortex-ring state; however, minimal pressure shifts are seen before vortex-ring state takes effect. This proves problematic as the indicative pressure drop only recognizes once the aircraft has already entered the vortex-ring state, and it may already be too late for evasive maneuvers. Alternatively, $\Delta P_{13}$ shows a more significant pressure drop that occurs at descent velocities before vortex-ring state begins, that is about a $30 \mathrm{~Pa}$ drop between $V_{Z} / V_{h}=-0.538$ and -0.968 , followed by a sudden $20 \mathrm{~Pa}$ drop when entering vortex ring state. The $\Delta P_{13}$ pressure differential presents a potentially viable option for predicting vortex-ring state in a purely descending flight maneuver.

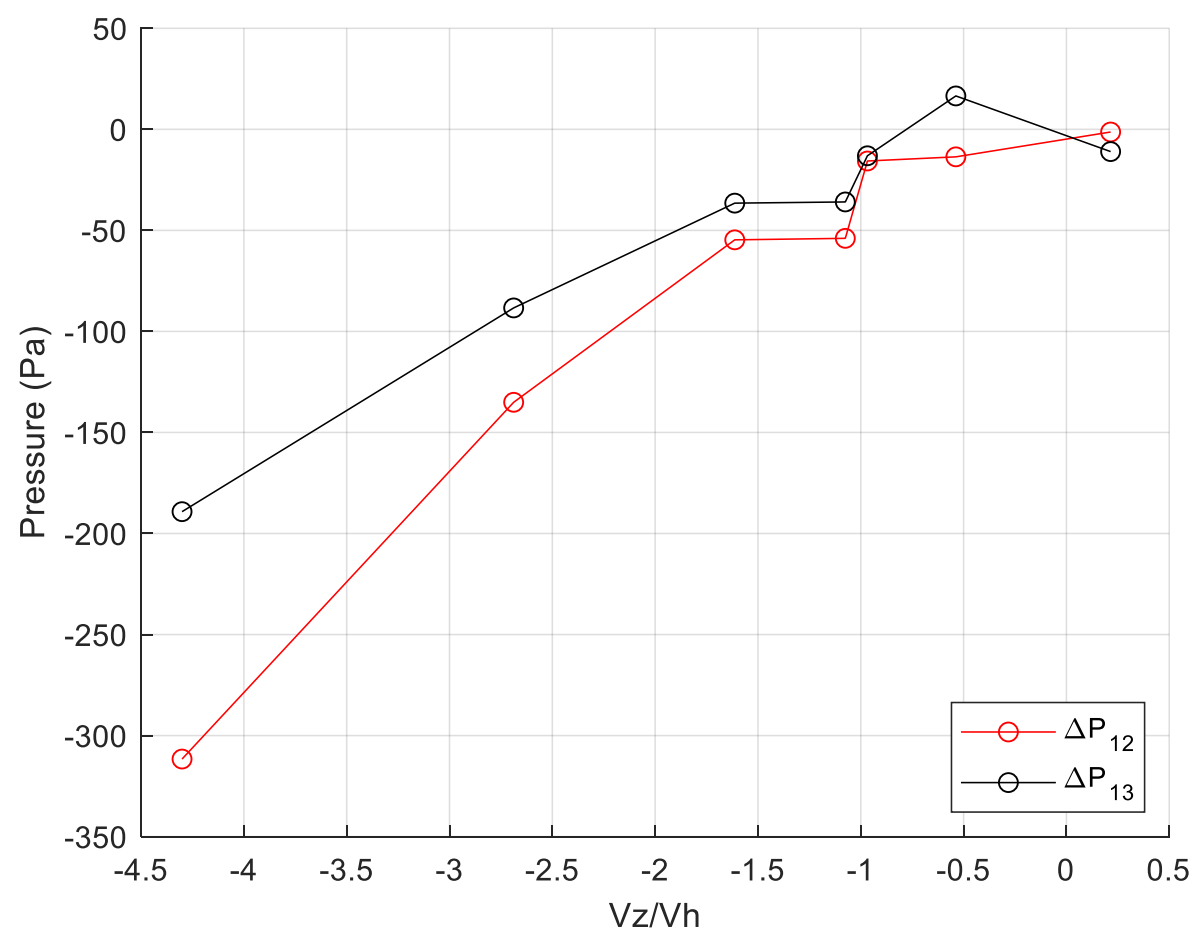

Figure 33. Pressure differential analysis for early on-set vortex-ring state warning system.

The flow conditions of the quadrotor in vortex-ring state were visualized using contoured planes of static pressure with respect to sea-level atmospheric pressure at two different crosssectional locations which, in Figure 34, are defined as Plane 1 and Plane 2. Plane 1 intersects the 
quadrotor fuselage body where the symmetry boundary condition is located, and Plane 2 intersects through the middle of the end of the quadrotor's legs. Pressure contours at these locations are shown for a descent rate of $V_{\mathrm{Z}} / \mathrm{V}_{\mathrm{h}}=-0.538$ in Figure 35 and Figure 37 and $\mathrm{V}_{\mathrm{Z}} / \mathrm{V}_{\mathrm{h}}=-0.968$ in Figure 36 and Figure 38. In these figures, the locations of pressure ports have been marked using a "circle" for $\mathrm{P}_{1}$, a "triangle" for $\mathrm{P}_{2}$ and a "rectangle" for $\mathrm{P}_{3}$. The contours show that the pressures at Port 1 and 2 are both affected by the shift into the vortex-ring state flight regime due to their proximity to the rotor's and see comparable pressure values. Consequently, both see a very similar pressure drop as the vortex-ring state boundary is penetrated and therefore the differential between them is difficult to pick up on. The differential pressure between Port 1 and 3 is more effective since Port 1 will see a large pressure drop as the quadrotor enters vortex-ring state while Port 3 is sufficiently far away from the rotor and thus it is less impacted by the vortex-ring state so the pressure differential between both Ports is more significant. This then allows the $\Delta P_{13}$ differential pressure to be a potential method of predicting the on-set of vortex-ring state because of the different rates at which each port sees their respective pressure drop. Further testing along different flight plans is required to determine whether this pressure measurement is unanimously effective in all other flight conditions. 


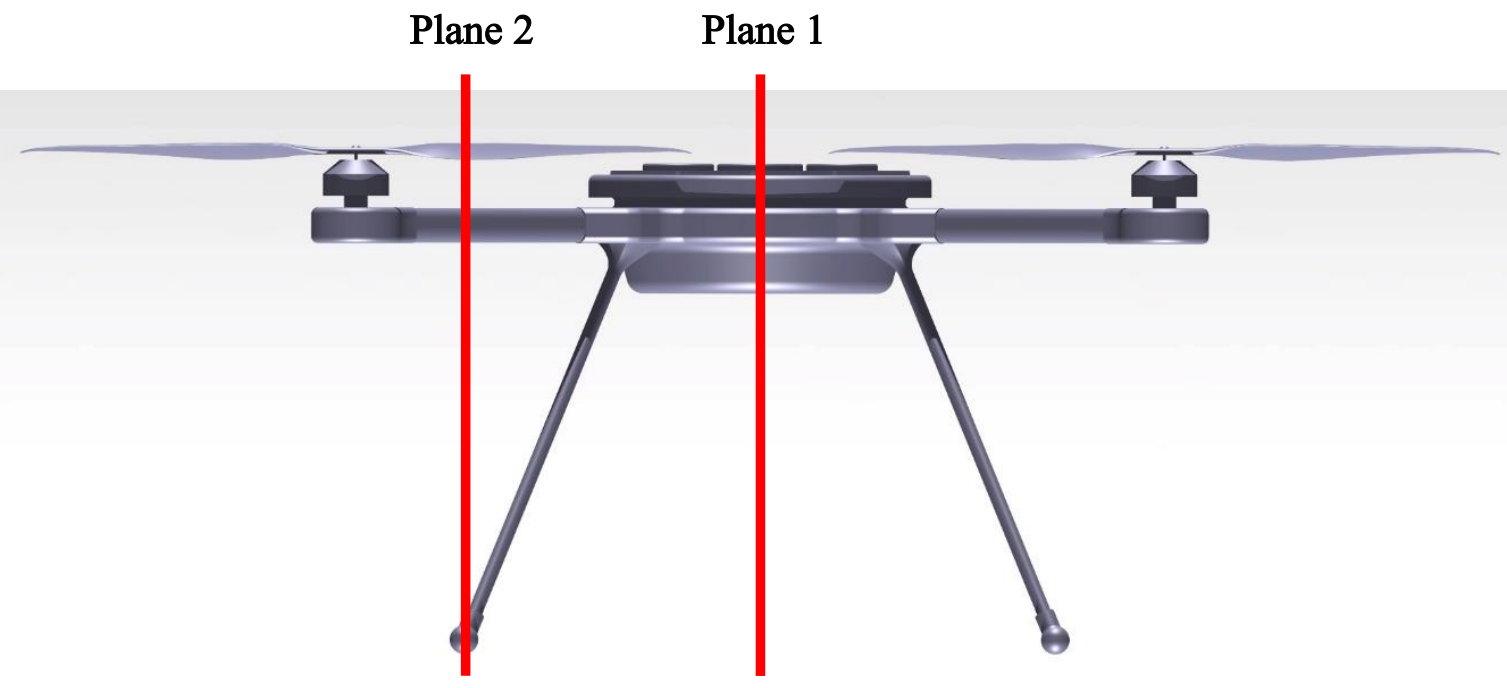

Figure 34. Quadrotor model, pressure contour plane locations. 


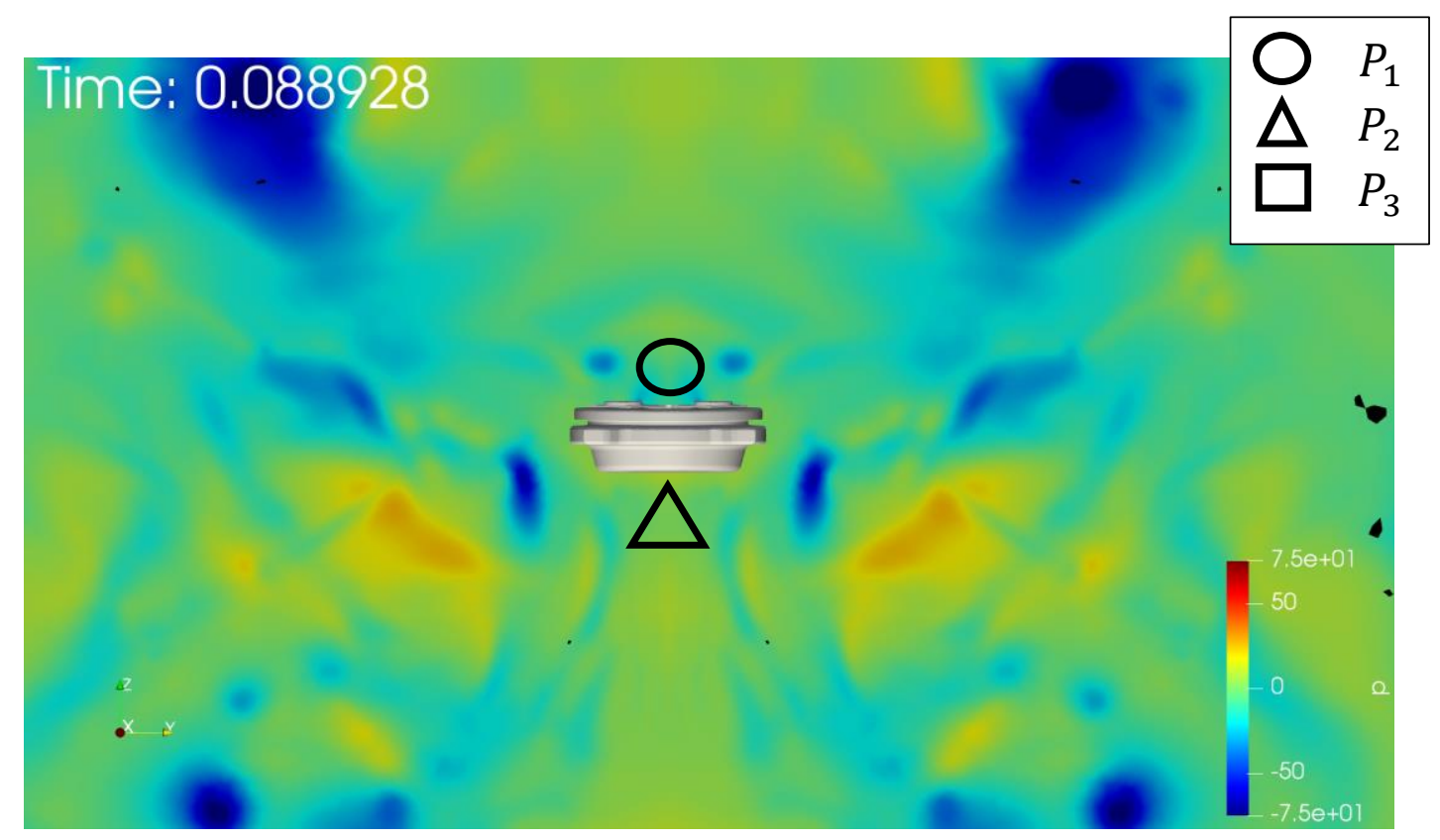

Figure 35. Pressure Contour at Plane 1 at $-0.538 V_{z} / V_{h}$.

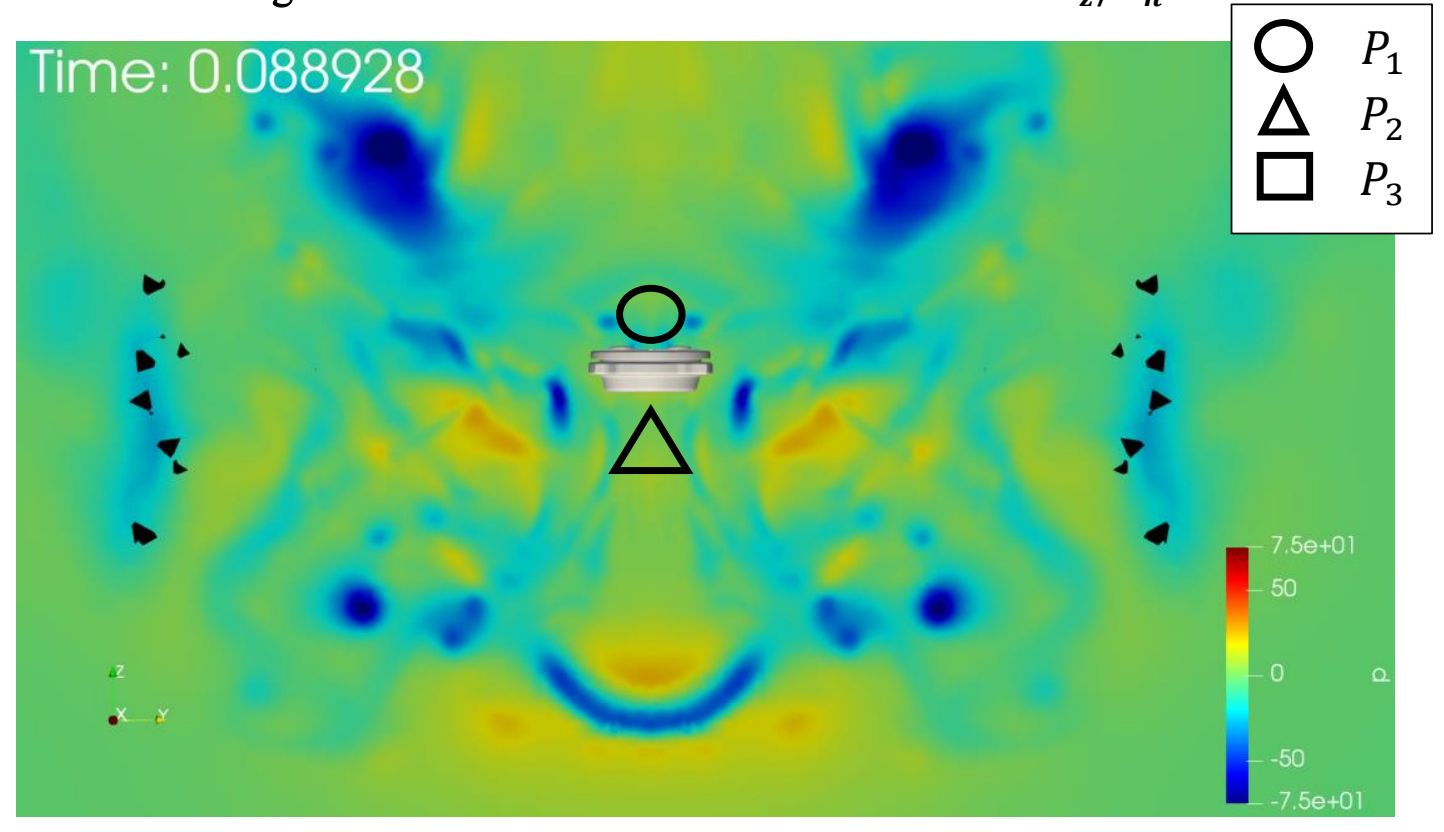

Figure 36. Pressure Contour at Plane 1 at $-0.968 V_{z} / V_{h}$. 


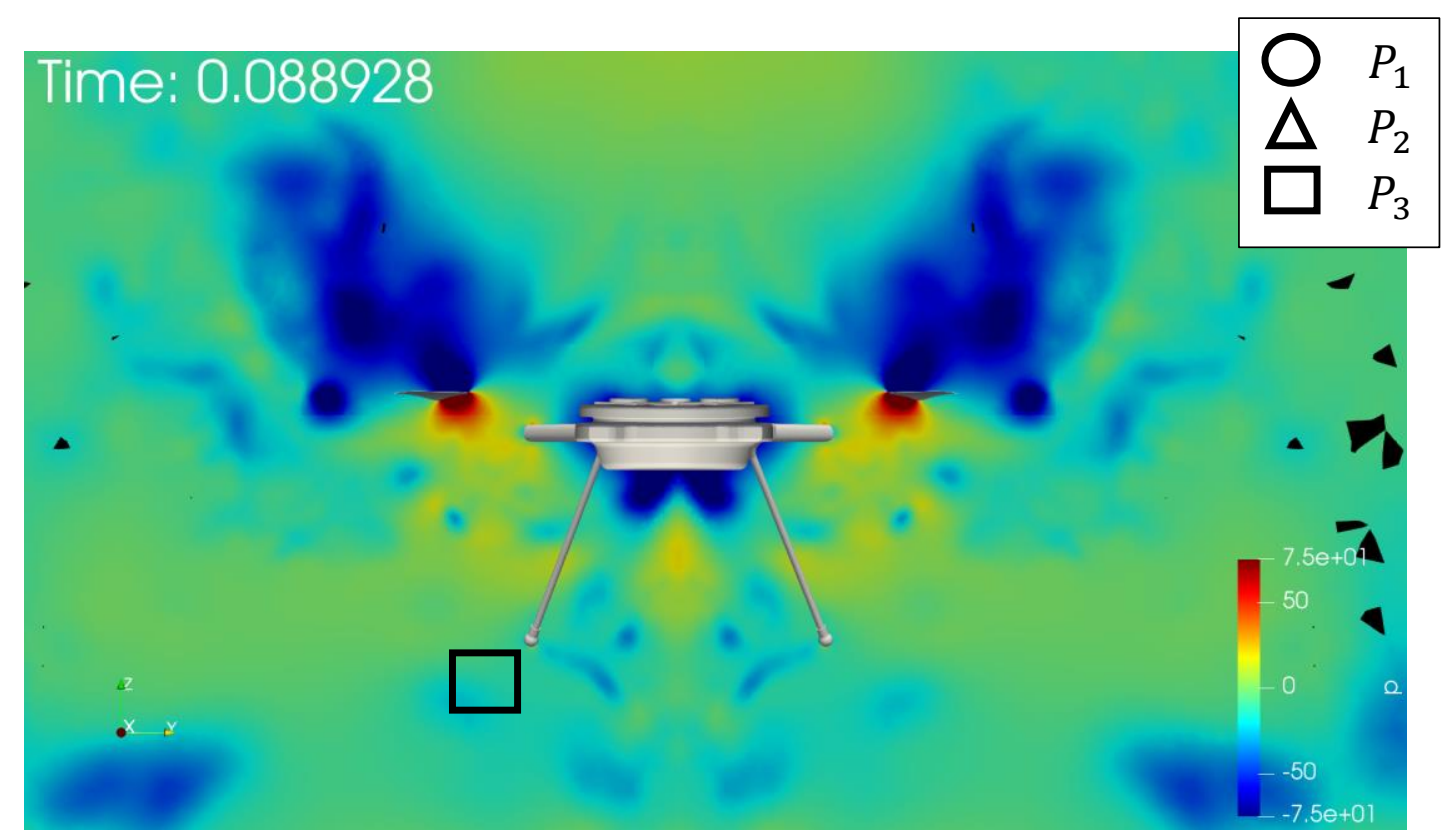

Figure 37. Pressure Contour at Plane 2 at $-0.538 V_{z} / V_{h}$.

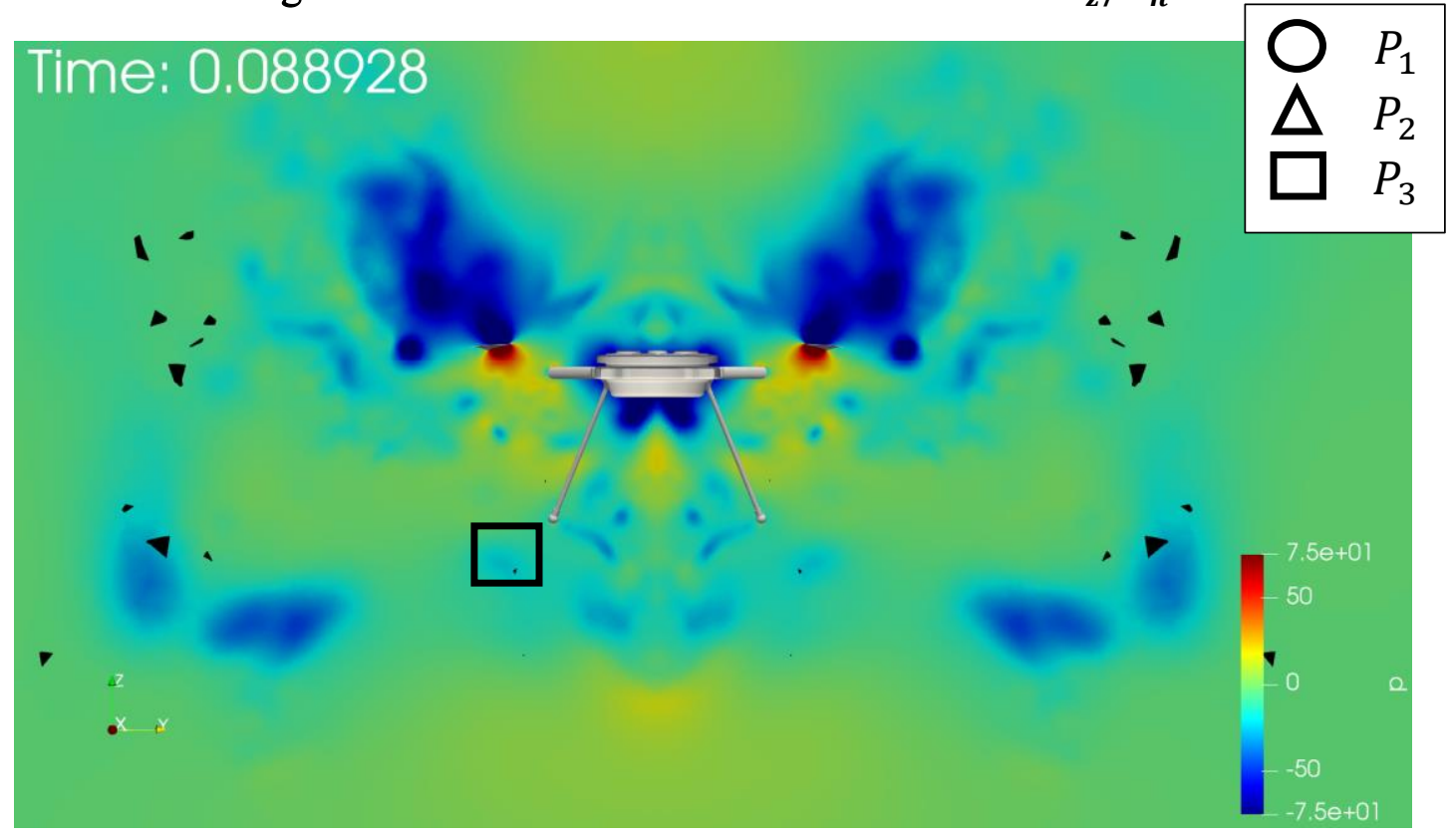

Figure 38. Pressure Contour at Plane 2 at $-0.968 V_{z} / V_{h}$. 


\section{Chapter 7}

\section{Conclusions}

\subsection{Conclusions}

A quadrotor configuration was modelled to investigate the vortex-ring state flight regime and its impacts on a rotor thrust and power. The numerical model was validated via a single rotor numerical study for axial freestream flight with the results being compared to experimental data obtained from a subsonic wind tunnel. The results showed good agreement with experimental thrust and power trends. Power predictions of the rotor remain relatively inaccurate due to issues surrounding $\mathrm{CAD}$ modelling, meshing of the rotor, and predictions of laminar-turbulent transition. By running a descent velocity sweep for the multirotor drone model, it was found that peak thrust loss in vortex-ring state occurs at descent speeds around the rotor hovering induced velocity of $4.65 \mathrm{~m} / \mathrm{s}$. This is due to the breakdown of the stable rotor helical vortex structure into a more chaotic flow phenomenon as demonstrated through flow visualization. Comparisons were made between the CFD and VAPTOR numerical models. Both models showed good agreement pre and post vortex-ring state; however, some deviations were seen in terms of the magnitude of thrust 
loss, the lower boundary of vortex-ring state, and the power predictions in vortex-ring state. The VAPTOR model required less computational resources to run each simulation, but some difficulties were experienced in calculating a relaxed wake vorticity sheet when the rotor descended into its own downwash. The VAPTOR model proves to be fairly accurate and less computationally intensive, especially for descending forward flight cases where a CFD model would require twice the grid size and a VAPTOR model would require no increase in resources.

Vortex-ring state mitigation strategies were initially studied using flight maneuvers and then the relative effect on thrust loss was studied. Using various applied forward velocities to replicate non-vertical descent flight paths, three additional descent velocity sweeps were investigated. It was shown that as the forward velocity of the quadrotor was increased, less thrust was lost when the quadrotor's descent rate was increased. Once a forward velocity of $3 \mathrm{~m} / \mathrm{s}$ was applied, no evidence of vortex-ring state occurring was present in the performance trends.

Additional investigations were performed using a quadrotor configuration that was at various descent velocities in order to investigate early on-set vortex-ring state prediction methods. A pressure differential probe between the top and bottom of the quadrotor body showed no indication of vortex-ring state until the quadrotor had already entered this flight regime. However, a differential pressure measurement between a probe that was located at the top of the drone body and one that is located at the bottom of one of the quadrotor landing gear shows a pressure drop well before vortex-ring state takes effect. This result shows that an early warning system of vortexring state for quadrotors may be possible by measuring pressure differentials in this setup. Continued study of different flight paths must also be performed to determine if the proposed system is suitable for other flight conditions. Furthermore, the implemented system would need to recognize the difference between a pressure drop due to changes in airflow conditions versus a 
pressure drop caused by the on-set of vortex-ring state. This could be done by correlating a measured pressure drop with the vertical velocity component of the quadrotor such that vortexring state is predicted only if the drone is descending in combination with a measured pressure drop.

The flow structure calculated by the CFD model may not necessarily match realistic flight conditions. It is important to note that the inlet velocity magnitude is in full effect from the start of the simulations that were run which is representative of a quadrotor instantaneously accelerating to a given descent velocity. A quadrotor that experiences wind conditions of varying magnitudes will significantly affect the quadrotor's thrust and power performance as well as the vortex-ring state boundaries. Wind conditions could adjust the effective airflow direction and velocity such that vortex-ring state effects are delayed or prematurely started.

\subsection{Future Work}

The work presented in this report opens the way for numerous future investigations to expand on the conclusions that were presented. In terms of the VAPTOR model, improvements could be made into its approach of descending flight by first starting a rotor in hover to generate the initial wake elements before allowing it to descent into its wake structure. By implementing a parallelized numerical scheme, the computational runtime could be shortened, or potentially multiple advance ratios can be computed simultaneously. The flight maneuver study could benefit from running additional cases where the flight path angle is held constant over increasing resultant velocity to study vortex-ring state impacts. Comparisons to actual flight performance data would be ideal in this scenario as well. With respect to the differential pressure warning system, more simulations must be run across varying descent angles and in different wind conditions. This 
system should be tested both numerically and experimentally to determine the system's viability under alternative flight conditions to those presented here. 


\section{Appendix A}

\section{Validation Study - Aerodynamic Data}

The numerical and experimental results as well as rotor geometric and speed data that were used for the validation study of the T-motor rotor in Chapter 2, are outlined in Appendix A.

\section{A.1. T-motor Rotor Experimental Results}

Error! Reference source not found. presents the T-motor rotor geometric and speed data used in the validation study shown in Chapter 2.

Table A-1. T-motor rotor validation study geometric and speed data.

\begin{tabular}{c|c|c}
\multicolumn{2}{c}{ Parameter } & Value \\
\hline \multirow{2}{*}{ Rotor Diameter } & Inches & 18 \\
\cline { 2 - 3 } & Metres & 0.4572 \\
\hline \multirow{2}{*}{ Rotor Speed } & RPM & 3000 \\
\cline { 2 - 3 } Rotor Area & $\mathrm{R}$ & 314 \\
\hline \multirow{2}{*}{ Density } & $\mathrm{m}^{2}$ & 0.1642 \\
\hline & Numerical Tests $\left(\mathrm{kg} / \mathrm{m}^{3}\right)$ & 1.00 \\
\hline
\end{tabular}

Error! Reference source not found. outlines the side and axial force loading on the rotor as well as the moment loadings for increasing tunnel airspeed. 
Table A-2. T-motor rotor experimental data at 3000 RPM for force and moment loading.

\begin{tabular}{ccccccccc}
$\begin{array}{c}\text { Tunnel } \\
\text { RPM } \\
\mathbf{R P M})\end{array}$ & $\begin{array}{c}\text { Mean } \\
\text { Velocity } \\
(\mathbf{m} / \mathbf{s})\end{array}$ & $\begin{array}{c}\text { Temperature } \\
\mathbf{( K )}\end{array}$ & $\begin{array}{c}\boldsymbol{F}_{\boldsymbol{X}} \\
\mathbf{( N )}\end{array}$ & $\begin{array}{c}\boldsymbol{F}_{\boldsymbol{y}} \\
\mathbf{( N )}\end{array}$ & $\begin{array}{c}\boldsymbol{F}_{\boldsymbol{z}} \\
(\mathbf{N})\end{array}$ & $\begin{array}{c}\boldsymbol{M}_{\boldsymbol{X}} \\
(\mathbf{N})\end{array}$ & $\begin{array}{c}\boldsymbol{M}_{\boldsymbol{y}} \\
(\mathbf{N})\end{array}$ & $\begin{array}{c}\boldsymbol{M}_{\boldsymbol{z}} \\
(\mathbf{N})\end{array}$ \\
\hline $\mathbf{0}$ & 0.923 & 295.74 & -0.0259 & -0.0330 & 9.3309 & -0.0175 & -0.0107 & -0.2257 \\
\hline $\mathbf{2 0 0}$ & 3.863 & 297.82 & 0.0117 & -0.0309 & 7.7556 & -0.0048 & 0.0040 & -0.2214 \\
\hline $\mathbf{2 2 0}$ & 4.284 & 297.76 & 0.0110 & -0.0306 & 7.4086 & -0.0050 & 0.0042 & -0.2178 \\
\hline $\mathbf{2 4 0}$ & 4.689 & 297.85 & 0.0184 & -0.0295 & 6.8455 & -0.0048 & 0.0049 & -0.2078 \\
\hline $\mathbf{2 6 0}$ & 5.080 & 297.80 & 0.0180 & -0.0279 & 6.5330 & -0.0049 & 0.0052 & -0.2043 \\
\hline $\mathbf{2 8 0}$ & 5.615 & 297.85 & 0.0185 & -0.0179 & 5.9977 & -0.0051 & 0.0063 & -0.1956 \\
\hline $\mathbf{3 0 0}$ & 6.021 & 298.06 & 0.0164 & -0.0134 & 5.3557 & -0.0047 & 0.0068 & -0.1824 \\
\hline $\mathbf{3 2 0}$ & 6.531 & 297.85 & 0.0141 & 0.0001 & 4.9209 & -0.0041 & 0.0074 & -0.1770 \\
\hline $\mathbf{3 4 0}$ & 7.016 & 297.85 & 0.0096 & -0.0026 & 4.3285 & -0.0040 & 0.0079 & -0.1663 \\
\hline $\mathbf{3 6 0}$ & 7.479 & 297.85 & 0.0062 & 0.0005 & 3.8280 & -0.0039 & 0.0082 & -0.1573 \\
\hline $\mathbf{3 8 0}$ & 7.959 & 297.90 & -0.0029 & 0.0054 & 3.1934 & -0.0043 & 0.0085 & -0.1450 \\
\hline $\mathbf{4 0 0}$ & 8.464 & 297.90 & -0.0077 & 0.0104 & 2.6335 & -0.0041 & 0.0090 & -0.1347 \\
\hline $\mathbf{4 2 0}$ & 8.919 & 298.12 & -0.0136 & 0.0131 & 2.0671 & -0.0040 & 0.0095 & -0.1238 \\
\hline $\mathbf{4 4 0}$ & 9.438 & 299.19 & -0.0193 & 0.0170 & 1.4535 & -0.0040 & 0.0101 & -0.1123 \\
\hline $\mathbf{4 6 0}$ & 10.065 & 301.05 & -0.0271 & 0.0195 & 0.6468 & -0.0040 & 0.0106 & -0.0969 \\
\hline
\end{tabular}

\section{A.2. T-motor Rotor Numerical Grid Specifications}

Error! Reference source not found. outlines the grid element sizing's, boundary layer meshing details, and the element count for the T-motor rotor numerical model employed in OpenFOAM. Refer to Figure 9 for subregion descriptions and locations.

Table A-3. T-motor rotor numerical grid specifications.

\begin{tabular}{|c|c|c|}
\hline Subregion & Average Element Size (in) & Number of Elements $\mathbf{( 1 0}^{\mathbf{6}}$ ) \\
\hline OUTER_CYL2 & 3.00 & 13 \\
\hline OUTER_CYL1 & 1.25 & 22 \\
\hline INNER_CYL* & 0.50 & 5 \\
\hline TOTAL & N/A & 40 \\
\hline
\end{tabular}

*Note: Boundary layer meshing utilized 20 layers of structured prism elements normal to the wall surface. 


\section{A.3. T-motor Rotor Numerical Results}

Error! Reference source not found. outlines the data comparison between the experimental and numerical results that was shown in Chapter 2. The deviation percent shows the difference between the experimental and numerical results.

Table A-4. Experimental and numerical results for the T-motor rotor validation study.

\begin{tabular}{|c|c|c|c|c|c|}
\hline $\begin{array}{c}\text { AOA } \\
\text { (degrees) }\end{array}$ & $\begin{array}{c}\text { Velocity } \\
(\mathrm{m} / \mathrm{s})\end{array}$ & Parameter & Experimental & CFD & $\begin{array}{c}\text { Deviation } \\
(\%)\end{array}$ \\
\hline \multirow{6}{*}{90} & \multirow[b]{2}{*}{1} & $C_{T}$ & 0.01902 & 0.01830 & 3.77 \\
\hline & & $C_{P}$ & 0.00201 & 0.00275 & 36.71 \\
\hline & \multirow{2}{*}{5} & $C_{T}$ & 0.01329 & 0.01399 & 5.28 \\
\hline & & $C_{P}$ & 0.00182 & 0.00226 & 24.42 \\
\hline & \multirow{2}{*}{8} & $C_{T}$ & 0.00646 & 0.00883 & 36.61 \\
\hline & & $C_{P}$ & 0.00129 & 0.00176 & 35.84 \\
\hline
\end{tabular}

\section{A.4. VAPTOR Numerical Results}

Error! Reference source not found. shows the comparison of experimental results to VAPTOR results for the Aeryon185 rotor validation study under a 4-degree pitch correction as detailed in Chapter 2.

Table A-5. VAPTOR pitch corrected model comparison to experimental results.

\begin{tabular}{c|cc|c|c|c|c|c}
$\begin{array}{c}\text { Velocit } \\
\mathbf{y}\end{array}$ & $\begin{array}{c}\text { Advance ratio, } \\
\boldsymbol{\mu}\end{array}$ & \multicolumn{2}{c}{ Experimental } & \multicolumn{2}{c}{ VAPTOR } & \multicolumn{2}{c}{$\begin{array}{c}\text { Deviation } \\
(\%)\end{array}$} \\
\cline { 3 - 9 }$(\mathbf{m} / \mathbf{s})$ & & $\boldsymbol{C}_{\boldsymbol{T}}$ & $\boldsymbol{C}_{\boldsymbol{P}}$ & $\boldsymbol{C}_{\boldsymbol{T}}$ & $\boldsymbol{C}_{\boldsymbol{P}}$ & $\boldsymbol{C}_{\boldsymbol{T}}$ & $\boldsymbol{C}_{\boldsymbol{P}}$ \\
\hline $\mathbf{2 . 8 2}$ & 0.0382 & 0.01632 & -0.00162 & 0.01233 & 0.00195 & 24.41 & 20.08 \\
\hline $\mathbf{3 . 3 7}$ & 0.0457 & 0.01333 & -0.00162 & 0.01205 & 0.00186 & 9.58 & 15.08 \\
\hline $\mathbf{5 . 6 2}$ & 0.0761 & 0.00936 & -0.00140 & 0.00934 & 0.00152 & 0.26 & 8.37 \\
\hline $\mathbf{7 . 8 7}$ & 0.1066 & 0.00502 & -0.00107 & 0.00601 & 0.00111 & 19.79 & 3.24 \\
\hline $\mathbf{1 0 . 3 0}$ & 0.1395 & 0.00015 & -0.00063 & 0.00199 & 0.00054 & 1258.22 & 13.58 \\
\hline
\end{tabular}




\section{Appendix B}

\section{Descent Velocity Sweep - Numerical Data}

The data that was plotted in Chapter 3 for the quadrotor descent velocity sweep are presented in Appendix B. This data includes numerical data tables of rotor loading, rotor and fuselage loading, single-rotor VAPTOR loading, and multirotor VAPTOR loading.

\section{B.1. OpenFOAM Numerical Grid Specifications}

Error! Reference source not found. outlines the grid element sizing's, boundary layer meshing details, and the element count for the T-motor rotor numerical model employed in OpenFOAM. Refer to Figure 23 for subregion descriptions and locations.

Table B-1. Quarter body quadrotor numerical grid specifications.

\begin{tabular}{c|c|c} 
Subregion & Average Element Size (in) & Number of Elements $\mathbf{( 1 0}^{\mathbf{6}}$ ) \\
\hline OUTER_CYL4 & 4.00 & 2 \\
\hline OUTER_CYL3 & 2.00 & 6 \\
\hline OUTER_CYL2 & 0.60 & 16 \\
\hline OUTER_CYL1 & 0.30 & 7 \\
\hline
\end{tabular}




\begin{tabular}{c|c|c|}
\hline INNER_CYL* & 0.25 & 4 \\
\hline TOTAL & N/A & 35 \\
\hline
\end{tabular}

${ }^{*}$ Note: Boundary layer meshing utilized 15 layers of structured prism elements normal to the wall surface.

\section{B.2. OpenFOAM Numerical Results}

Error! Reference source not found. presents Aeryon 185 rotor geometric and speed data used in the validation study shown in Chapter 2.

Table B-2. Aeryon 185 rotor descent velocity sweep geometric and speed data.

\begin{tabular}{c|c|c}
\multicolumn{2}{c}{ Parameter } & Value \\
\hline \multirow{2}{*}{ Rotor Diameter } & Inches & 18.5 \\
& Metres & 0.4699 \\
\hline \multirow{2}{*}{ Rotor Speed } & RPM & 3000 \\
\hline Rotor Area & $\mathrm{R}$ & 314 \\
\hline Density & $\mathrm{m}^{2}$ & 0.1734 \\
\hline
\end{tabular}

Error! Reference source not found. and Error! Reference source not found. tabulates all numerical results obtained from OpenFOAM over the descent velocity sweep shown in Chapter 3 for a given $V_{Z} / V_{h}$. 
Table B-3. Quadrotor descent velocity sweep. Rotor aerodynamic loading.

\begin{tabular}{|c|c|c|c|c|c|c|c|c|c|c|}
\hline $\begin{array}{c}\text { AOA } \\
\text { (degrees) }\end{array}$ & $\begin{array}{c}\text { Velocity } \\
(\mathrm{m} / \mathrm{s})\end{array}$ & $\frac{V_{Z}}{V_{h}}$ & $\begin{array}{l}\boldsymbol{F}_{\boldsymbol{X}} \\
(\mathrm{N})\end{array}$ & $\begin{array}{l}\boldsymbol{F}_{\boldsymbol{y}} \\
(\mathrm{N})\end{array}$ & $\begin{array}{c}\boldsymbol{F}_{\boldsymbol{Z}} \\
(\mathrm{N})\end{array}$ & $\begin{array}{l}M_{X} \\
(\mathrm{~N})\end{array}$ & $\begin{array}{l}M_{y} \\
(\mathrm{~N})\end{array}$ & $\begin{array}{l}M_{z} \\
(\mathrm{~N})\end{array}$ & $C_{T}$ & $C_{P}$ \\
\hline 90 & 1 & 0.215 & 0.015 & -0.010 & 7.504 & -0.001 & 0.025 & 0.177 & 0.0159 & 0.00159 \\
\hline-90 & -2.5 & -0.538 & 0.042 & 0.075 & 9.281 & 0.101 & -0.148 & 0.183 & 0.0196 & 0.00165 \\
\hline-90 & -4 & -0.860 & -0.136 & 0.003 & 11.203 & 0.174 & 0.089 & 0.202 & 0.0237 & 0.00182 \\
\hline-90 & -4.25 & -0.914 & -0.054 & 0.044 & 10.511 & 0.064 & 0.060 & 0.191 & 0.0223 & 0.00172 \\
\hline-90 & -4.5 & -0.968 & -0.021 & 0.025 & 7.798 & -0.003 & 0.049 & 0.166 & 0.0165 & 0.00149 \\
\hline-90 & -4.75 & -1.021 & 0.060 & 0.001 & 7.963 & -0.045 & 0.027 & 0.189 & 0.0169 & 170 \\
\hline-90 & -5 & -1.075 & 0.042 & 0.003 & 8.383 & -0.030 & 0.031 & 0.191 & 0.0177 & 0.00172 \\
\hline-90 & -5.25 & -1.129 & 0.043 & 0.020 & 8.795 & -0.035 & 0.022 & 0.186 & 0.0186 & 0.00167 \\
\hline-90 & -5.5 & -1.183 & 0.000 & 0.036 & 9.182 & 0.052 & 0.071 & 0.192 & 0.0194 & 0.00173 \\
\hline-90 & -5.75 & -1.236 & 0.001 & 0.013 & 9.371 & 0.024 & 0.040 & 0.191 & 0.0198 & 0.00172 \\
\hline-90 & -6 & -1.290 & -0.008 & 0.011 & 9.994 & 0.027 & 0.054 & 0.192 & 0.0212 & 0.00173 \\
\hline-90 & -7.5 & -1.613 & -0.025 & -0.004 & 11.910 & 0.006 & 0.012 & 0.192 & 0.0252 & 0.00173 \\
\hline-90 & -12.5 & -2.688 & -0.001 & -0.015 & 20.512 & 0.020 & -0.036 & 0.302 & 0.0434 & 0.00272 \\
\hline-90 & -20 & -4.301 & -0.016 & 0.066 & 25.080 & 0.028 & -0.052 & 0.449 & 0.0531 & 0.00404 \\
\hline
\end{tabular}

Table B-4. Quadrotor descent velocity sweep. Full body aerodynamic loading.

\begin{tabular}{|c|c|c|c|c|c|c|c|c|c|c|c|c|c|c|c|}
\hline \multirow{2}{*}{$\begin{array}{c}\text { AOA } \\
\text { (degrees } \\
\text { ) }\end{array}$} & \multirow{2}{*}{$\frac{V_{Z}}{V_{h}}$} & \multicolumn{2}{|c|}{$\begin{array}{c}\boldsymbol{F}_{\boldsymbol{X}} \\
(\mathrm{N})\end{array}$} & \multicolumn{2}{|c|}{$\begin{array}{l}\boldsymbol{F}_{\boldsymbol{y}} \\
(\mathrm{N})\end{array}$} & \multicolumn{2}{|c|}{$\begin{array}{c}\boldsymbol{F}_{\boldsymbol{Z}} \\
(\mathrm{N})\end{array}$} & \multicolumn{2}{|c|}{$\begin{array}{r}M_{X} \\
(\mathrm{~N})\end{array}$} & \multicolumn{2}{|c|}{$\begin{array}{l}M_{y} \\
(\mathrm{~N})\end{array}$} & \multicolumn{2}{|c|}{$\begin{array}{l}M_{z} \\
(\mathrm{~N})\end{array}$} & \multirow{2}{*}{$C_{T}$} & \multirow{2}{*}{$C_{P}$} \\
\hline & & Rotor & Fuse. & Rotor & Fuse. & Rotor & Fuse. & Rotor & Fuse. & Rotor & Fuse. & $\begin{array}{c}\text { Roto } \\
\mathbf{r}\end{array}$ & Fuse. & & \\
\hline 90 & 0.22 & 0.015 & -0.116 & -0.010 & 0.032 & 7.504 & -0.073 & -0.001 & -0.018 & 0.025 & -0.018 & 0.177 & 0.018 & 0.0157 & 0.0018 \\
\hline-90 & -0.54 & 0.042 & 0.272 & 0.075 & -0.369 & 9.281 & 0.361 & 0.101 & 0.021 & -0.148 & 0.021 & 0.183 & 0.013 & 0.0204 & 0.0018 \\
\hline-90 & -0.97 & -0.021 & -0.155 & 0.025 & -0.028 & 7.798 & 0.154 & -0.003 & 0.019 & 0.049 & 0.015 & 0.166 & 0.023 & 0.0168 & 0.0017 \\
\hline-90 & -1.08 & 0.042 & 0.165 & 0.003 & -0.182 & 8.383 & 0.811 & -0.030 & 0.050 & 0.031 & 0.048 & 0.191 & 0.004 & 0.0195 & 0.0018 \\
\hline-90 & -1.61 & -0.025 & 0.066 & -0.004 & -0.074 & 11.910 & 0.980 & 0.006 & 0.074 & 0.012 & 0.074 & 0.192 & 0.002 & 0.0273 & 0.0017 \\
\hline-90 & -2.69 & -0.001 & -0.150 & -0.015 & 0.120 & 20.512 & 1.777 & 0.020 & 0.143 & -0.036 & 0.142 & 0.302 & 0.002 & 0.0472 & 0.0027 \\
\hline-90 & -4.30 & -0.016 & 0.510 & 0.066 & -0.149 & 25.080 & 3.470 & 0.028 & 0.297 & -0.052 & 0.309 & 0.449 & -0.048 & 0.0604 & 0.0036 \\
\hline
\end{tabular}




\section{B.3. VAPTOR Numerical Results}

Error! Reference source not found. and Error! Reference source not found. present the results for thrust and power coefficients of the single and 4-rotor VAPTOR models respectively.

Table B-5 VAPTOR results for single rotor model.

\begin{tabular}{|c|c|c|c|c|}
\hline \multirow{2}{*}{$\begin{array}{c}\text { AOA } \\
\text { (degrees) }\end{array}$} & \multirow{2}{*}{$\begin{array}{c}\text { Velocity } \\
(\mathrm{m} / \mathrm{s})\end{array}$} & \multirow{2}{*}{$\frac{V_{Z}}{V_{h}}$} & \multicolumn{2}{|c|}{ Rotor } \\
\hline & & & $C_{T}$ & $C_{P}$ \\
\hline 90 & 1 & 0.215 & 0.0139 & 0.0023 \\
\hline-90 & 0 & 0.000 & 0.0137 & 0.0023 \\
\hline-90 & -1 & -0.215 & 0.0146 & 0.0025 \\
\hline-90 & -2 & -0.430 & 0.0152 & 0.0026 \\
\hline-90 & -2.5 & -0.538 & 0.0018 & 0.0263 \\
\hline-90 & -3 & -0.645 & 0.0029 & 0.0604 \\
\hline-90 & -4 & -0.860 & 0.0120 & 0.0040 \\
\hline-90 & -4.5 & -0.968 & 0.0140 & 0.0032 \\
\hline-90 & -5 & -1.075 & 0.0134 & 0.0034 \\
\hline-90 & -7.5 & -1.613 & 0.0226 & 0.0043 \\
\hline-90 & -12.5 & -2.688 & 0.0408 & 0.0039 \\
\hline-90 & -20 & -4.301 & 0.0694 & 0.0007 \\
\hline
\end{tabular}


Table B-6. VAPTOR results for 4-rotor model.

\begin{tabular}{|c|c|c|c|c|c|c|c|c|c|c|c|c|}
\hline \multirow{2}{*}{$\begin{array}{c}\mathrm{AOA} \\
\text { (degrees) }\end{array}$} & \multirow{2}{*}{$\begin{array}{c}\text { Velocity } \\
(\mathrm{m} / \mathrm{s})\end{array}$} & \multirow{2}{*}{$\frac{V_{Z}}{V_{h}}$} & \multicolumn{2}{|c|}{ Rotor 1} & \multicolumn{2}{|c|}{ Rotor 2} & \multicolumn{2}{|c|}{ Rotor 3} & \multicolumn{2}{|c|}{ Rotor 4} & \multirow{2}{*}{$C_{T_{a v g}}$} & \multirow{2}{*}{$C_{P_{a v g}}$} \\
\hline & & & $C_{T}$ & $C_{P}$ & $C_{T}$ & $C_{P}$ & $C_{T}$ & $C_{P}$ & $C_{T}$ & $C_{P}$ & & \\
\hline 90 & 1 & 0.215 & 0.0138 & 0.0027 & 0.0137 & 0.0025 & 0.0136 & 0.0025 & 0.0139 & 0.0025 & 0.0137 & 0.0026 \\
\hline 90 & 0 & 0.000 & 0.0139 & 0.0028 & 0.0140 & 0.0026 & 0.0145 & 0.0030 & 0.0142 & 0.0030 & 0.0142 & 0.0028 \\
\hline-90 & -1 & -0.215 & 0.0139 & 0.0081 & 0.0106 & 0.0061 & 0.0137 & 0.0148 & 0.0112 & 0.0070 & 0.0124 & 0.0090 \\
\hline-90 & -2 & -0.430 & -0.0042 & 0.0420 & -0.0058 & 0.0477 & 0.0030 & 0.0514 & -0.0173 & 0.0639 & 061 & 0.0513 \\
\hline-90 & -2.5 & -0.538 & 0.0012 & 0.0299 & 0.0046 & 0.0339 & -0.0123 & 0.0562 & -0.0318 & 0.0755 & -0.0095 & 0.0488 \\
\hline-90 & -3 & -0.645 & 0.0155 & 0.0168 & -0.0565 & 0.0844 & 0.0158 & 0.0388 & -0.0062 & 0.0560 & -0.0079 & 0.0490 \\
\hline-90 & -4 & -0.860 & 0.0147 & 0.0036 & 0.0194 & 0.0032 & 0.0220 & 0.0023 & 0.0173 & 0.0043 & 0.0183 & 0.0034 \\
\hline-90 & -4.5 & -0.968 & 0.0178 & 0.0032 & 0.0187 & 0.0036 & 0.0204 & 0.0047 & 0.0199 & 0.0037 & 0.0192 & 0.0038 \\
\hline-90 & -5 & -1.075 & 0.0189 & 0.0048 & 0.0192 & 0.0039 & 0.0202 & 0.0048 & 0.0208 & 0.0047 & 0.0198 & 0.0046 \\
\hline-90 & -7.5 & -1.613 & 0.0262 & 0.0045 & 0.0328 & 0.0036 & 0.0263 & 0.0045 & 0.0228 & 0.0045 & 0.0270 & 0.0043 \\
\hline-90 & -12.5 & -2.688 & 0.0460 & 0.0046 & 0.0460 & 0.0053 & 0.0442 & 0.0055 & 0.0449 & 0.0052 & 0.0453 & 0.0052 \\
\hline-90 & -20 & -4.301 & 0.0716 & 0.0026 & 0.0716 & 0.0027 & 0.0711 & 0.0024 & 0.0703 & 0.0028 & 0.0711 & 0.0026 \\
\hline
\end{tabular}




\section{Appendix C}

\section{Vortex-Ring Flight Maneuvers - Numerical Data}

In this section, all data that was plotted in Chapter 4 for the quadrotor descent velocity sweep with applied forward speeds is presented. This data includes numerical results for each of the three forward velocities that were tested along with their corresponding descent velocity sweep.

\section{C.1. OpenFOAM Numerical Grid Specifications}

Error! Reference source not found. outlines the grid element sizing's, boundary layer meshing details, and the element count for the T-motor rotor numerical model employed in OpenFOAM. Refer to Figure 30 for subregion descriptions and locations. 
Table C-1. Half-body quadrotor numerical grid specifications.

\begin{tabular}{|c|c|c|}
\hline Subregion & Average Element Size (in) & Number of Elements $\mathbf{( 1 0}^{\mathbf{6}}$ ) \\
\hline OUTER_CYL4 & 4.00 & 4 \\
\hline OUTER_CYL3 & 2.00 & 12 \\
\hline OUTER_CYL2 & 0.60 & 32 \\
\hline OUTER_CYL1 & 0.30 & 14 \\
\hline INNER_CYL2* & 0.25 & 4 \\
\hline INNER_CYL1 & 0.25 & 4 \\
\hline TOTAL & N/A & 70 \\
\hline
\end{tabular}

*Note: Boundary layer meshing utilized 15 layers of structured prism elements normal to the wall surface.

\section{C.2. OpenFOAM Numerical Results}

Error! Reference source not found. gives the velocity component breakdown for each simulation that was studied in the flight maneuver investigation. Cases 1 through 5, 6 through 10 , and 11 through 15 were for a $1 \mathrm{~m} / \mathrm{s}, 2 \mathrm{~m} / \mathrm{s}$, and $3 \mathrm{~m} / \mathrm{s}$ forward velocity respectively.

Table C-2. Quadrotor model flight maneuver, velocity decomposition.

\begin{tabular}{c|cccccc} 
Case & $\begin{array}{c}\text { AOA } \\
\text { degrees) }\end{array}$ & $\begin{array}{c}\boldsymbol{V}_{\boldsymbol{Z}} \\
(\mathrm{m} / \mathrm{s})\end{array}$ & $\begin{array}{c}\boldsymbol{V}_{\boldsymbol{X}} \\
(\mathrm{m} / \mathrm{s})\end{array}$ & $\begin{array}{c}\boldsymbol{V}_{\boldsymbol{R}} \\
(\mathrm{m} / \mathbf{s})\end{array}$ & $\begin{array}{c}\text { Descent Angle, } \boldsymbol{\gamma} \\
(\mathrm{degrees})\end{array}$ & \begin{tabular}{c}
$\boldsymbol{V}_{\boldsymbol{Z}}$ \\
\hline $\mathbf{V}$
\end{tabular} \\
\hline $\mathbf{1}$ & -90 & -2.5 & 1 & 2.693 & 68.20 & -0.538 \\
\hline $\mathbf{2}$ & -90 & -4 & 1 & 4.123 & 75.96 & -0.860 \\
\hline $\mathbf{3}$ & -90 & -4.5 & 1 & 4.610 & 77.47 & -0.968 \\
\hline $\mathbf{4}$ & -90 & -5 & 1 & 5.099 & 78.69 & -1.075 \\
\hline $\mathbf{5}$ & -90 & -7.5 & 1 & 7.566 & 82.41 & -1.613 \\
\hline $\mathbf{6}$ & -90 & -2.5 & 2 & 3.202 & 51.34 & -0.538 \\
\hline $\mathbf{7}$ & -90 & -4 & 2 & 4.472 & 63.44 & -0.860 \\
\hline $\mathbf{8}$ & -90 & -4.5 & 2 & 4.924 & 66.04 & -0.968 \\
\hline $\mathbf{9}$ & -90 & -5 & 2 & 5.385 & 68.20 & -1.075 \\
\hline $\mathbf{1 0}$ & -90 & -7.5 & 2 & 7.762 & 75.07 & -1.613 \\
\hline $\mathbf{1 1}$ & -90 & -2.5 & 3 & 3.905 & 39.81 & -0.538 \\
\hline $\mathbf{1 2}$ & -90 & -4 & 3 & 5.000 & 53.13 & -0.860 \\
\hline $\mathbf{1 3}$ & -90 & -4.5 & 3 & 5.408 & 56.31 & -0.968 \\
\hline $\mathbf{1 4}$ & -90 & -5 & 3 & 5.831 & 59.04 & -1.075 \\
\hline $\mathbf{1 5}$ & -90 & -7.5 & 3 & 8.078 & 68.20 & -1.613 \\
\hline
\end{tabular}


Table C-3. OpenFOAM flight maneuvers, aerodynamic loading on 2-rotor model.

\begin{tabular}{|c|c|c|c|c|c|c|c|c|c|c|c|c|c|c|}
\hline \multirow[b]{2}{*}{ Case } & \multicolumn{6}{|c|}{ Rotor 1} & \multicolumn{6}{|c|}{ Rotor 2} & \multirow[b]{2}{*}{$C_{T_{a v g}}$} & \multirow[b]{2}{*}{$C_{P_{a v g}}$} \\
\hline & $\begin{array}{l}\boldsymbol{F}_{\boldsymbol{X}} \\
(\mathrm{N})\end{array}$ & $\begin{array}{l}\boldsymbol{F}_{\boldsymbol{y}} \\
(\mathrm{N})\end{array}$ & $\begin{array}{c}\boldsymbol{F}_{\boldsymbol{Z}} \\
(\mathrm{N})\end{array}$ & $\begin{array}{c}M_{X} \\
(\mathrm{~N})\end{array}$ & $\begin{array}{l}M_{y} \\
(\mathrm{~N})\end{array}$ & $\begin{array}{l}M_{z} \\
(\mathrm{~N})\end{array}$ & $\begin{array}{c}\boldsymbol{F}_{\boldsymbol{X}} \\
(\mathrm{N})\end{array}$ & $\begin{array}{c}\boldsymbol{F}_{\boldsymbol{y}} \\
(\mathrm{N})\end{array}$ & $\begin{array}{c}\boldsymbol{F}_{\boldsymbol{Z}} \\
(\mathrm{N})\end{array}$ & $\begin{array}{l}M_{X} \\
(\mathrm{~N})\end{array}$ & $\begin{array}{l}M_{y} \\
(\mathrm{~N})\end{array}$ & $\begin{array}{l}M_{z} \\
(\mathrm{~N})\end{array}$ & & \\
\hline 1 & -0.025 & -0.031 & 9.594 & 0.140 & 0.089 & 0.196 & 0.066 & 0.019 & 11.145 & 0.180 & -0.083 & -0.195 & 0.0220 & $1 \mathrm{E}-08$ \\
\hline 2 & 0.037 & -0.006 & 8.864 & 0.085 & 0.146 & 0.189 & 0.031 & -0.024 & 7.775 & -0.003 & 0.009 & -0.160 & 0.0176 & $4 \mathrm{E}-07$ \\
\hline 3 & -0.040 & 0.032 & 8.290 & 0.131 & 0.053 & 0.189 & -0.039 & -0.047 & 6.988 & 0.089 & 0.035 & -0.149 & 0.0162 & $6 \mathrm{E}-07$ \\
\hline 4 & 0.006 & 0.042 & 10.910 & 0.151 & 0.027 & 0.201 & -0.029 & -0.003 & 8.256 & -0.039 & 0.043 & -0.175 & 0.0203 & $4 \mathrm{E}-07$ \\
\hline 5 & -0.046 & 0.019 & 13.098 & 0.151 & 0.046 & 0.209 & -0.020 & 0.076 & 10.992 & 0.076 & 0.110 & -0.175 & 0.0255 & $5 \mathrm{E}-07$ \\
\hline 6 & 0.041 & -0.095 & 8.599 & 0.078 & 0.164 & 0.175 & 0.013 & -0.065 & 6.135 & 0.039 & -0.073 & -0.145 & 0.0156 & 4E-07 \\
\hline 7 & 0.007 & 0.010 & 9.293 & 0.090 & 0.038 & 0.195 & 0.012 & -0.054 & 6.937 & 0.007 & 0.088 & -0.149 & 0.0172 & 7E-07 \\
\hline 8 & & & 10.526 & & -0.027 & & & & 6.216 & 0.057 & & & 77 & $5 \mathrm{E}-07$ \\
\hline 9 & -0.012 & 0.022 & 8.519 & 0.137 & 0.110 & 0.176 & -0.068 & -0.017 & 8.000 & 0.089 & -0.016 & -0.166 & 0.0175 & $1 \mathrm{E}-07$ \\
\hline 10 & -0.035 & 0.015 & 13.925 & 0.129 & 0.021 & 0.214 & -0.018 & 0.062 & 12.147 & 0.136 & -0.038 & -0.186 & 0.0276 & $4 \mathrm{E}-07$ \\
\hline 11 & -0.049 & -0.067 & 10.072 & 0.258 & 0.152 & 0.203 & 0.028 & -0.129 & 7.496 & 0.034 & -0.100 & -0.182 & 0.0186 & $3 \mathrm{E}-07$ \\
\hline 12 & -0.080 & -0.010 & 10.882 & 0.223 & 0.027 & 0.220 & -0.034 & -0.063 & 7.502 & 0.041 & -0.104 & -0.173 & 0.0195 & 7E-07 \\
\hline 13 & -0.004 & 0.000 & 11.537 & 0.175 & -0.004 & 0.207 & -0.073 & -0.129 & 8.855 & -0.020 & -0.130 & -0.178 & 0.0216 & 4E-07 \\
\hline 14 & -0.055 & -0.008 & 12.548 & 0.198 & 0.054 & 0.220 & -0.054 & -0.146 & 8.990 & 0.029 & -0.100 & -0.177 & 0.0228 & $6 \mathrm{E}-07$ \\
\hline 15 & -0.050 & 0.014 & 14.410 & 0.112 & -0.004 & 0.228 & 0.059 & 0.029 & 12.646 & 0.112 & -0.101 & -0.192 & 0.0286 & $5 \mathrm{E}-07$ \\
\hline
\end{tabular}




\section{Appendix D}

\section{Vortex-Ring State Prediction Methods}

Appendix D presents measured pressure port values across all three pressure port locations that were presented in Chapter 5.

\section{D.1. OpenFOAM Numerical Results}

Error! Reference source not found. presents measured pressure port values across all three locations and the respective pressure differentials over the entire descent velocity sweep in Chapter 5.

Table D-1. OpenFOAM differential pressure port measured values.

\begin{tabular}{cccccc}
$\boldsymbol{V}_{\boldsymbol{Z}} / \boldsymbol{V}_{\boldsymbol{h}}$ & $\boldsymbol{P}_{\mathbf{1}}$ & $\boldsymbol{P}_{\mathbf{2}}$ & $\boldsymbol{P}_{\mathbf{3}}$ & $\boldsymbol{\Delta}_{\mathbf{1 2}}$ & $\Delta \boldsymbol{P}_{\mathbf{1 3}}$ \\
\hline $\mathbf{0 . 2 1 5}$ & -5.6480 & -4.3330 & 5.3623 & -1.3150 & -11.0103 \\
\hline $\mathbf{- 0 . 5 3 8}$ & 23.3222 & 36.9254 & 6.7921 & -13.6032 & 16.5301 \\
\hline $\mathbf{- 0 . 9 6 8}$ & -25.5196 & -9.8494 & -12.4413 & -15.6702 & -13.0783 \\
\hline $\mathbf{- 1 . 0 7 5}$ & -21.6910 & 32.2427 & 14.2468 & -53.9336 & -35.9378 \\
\hline $\mathbf{- 1 . 6 1 3}$ & -8.9992 & 45.6798 & 27.5226 & -54.6790 & -36.5218 \\
\hline $\mathbf{- 2 . 6 8 8}$ & -44.4850 & 90.5861 & 43.8956 & -135.0711 & -88.3806 \\
\hline-4.301 & -39.8939 & 271.7250 & 149.3046 & -311.6189 & -189.1985 \\
\hline
\end{tabular}




\section{References}

[1] B. Rodriguez, "Numerical Simulation of Blade Vortex Interaction and Vortex Ring State Aerodynamics Using a Fully Time Marching Unsteady Wake Model," in 33rd European Rotorcraft Forum, Chatillon, France, 2007.

[2] C. B. Rumsey, "A Water Tunnel Investigation of a Small Scale Rotor Operating in the Vortex Ring State," Naval Postgraduate School, Monterey, USA, 1987.

[3] A. Brand, M. Dreier, R. Kisor and T. Wood, "The Nature of Vortex Ring State," in $A H S$ 63rd Annual Forum, Virginia Beach, USA, 2007.

[4] A. Azuma and A. Obata, "Induced Flow Variation of the Helicopter Rotor Operating in the Vortex Ring State," Journal of Aircraft, vol. 5, no. 4, 1968.

[5] M. D. Betzina, "Tiltrotor Descent Aerodynamics: A Small-Scale Experimental Investigation of Vortex Ring State," in AHS 57th Annual Forum, Washington, USA, 2001.

[6] P. Mullen and G. Bernini, "Vortex Ring State Prediction and Analysis," in 42nd European Rotorcraft Forum, Lille, France, 2016.

[7] K. Grzegorczyk, "Analysis of the Influence of Helicopter Descent Velocity Changes on the Phenomenon of Vortex Ring State," Advances in Science and Technology Research Journal, vol. 7, no. 17, pp. 35-41, 2013.

[8] A. Dziubinski and W. Stalewski, "Vortex Ring State Simulation Using Actuator Disc," in 21st European Conference on Modelling and Simulation, Prague, Czechia, 2007.

[9] D. J. Varnes, "Development of a Helicopter Vortex Ring State Warning System Through a Moving Map Display," Naval Postgraduate School, Monterey, USA, 1999. 
[10] S. Taamallah, "A Qualitative Introduction to the Vortex-Ring-State, Autorotation, and Optimal Autorotation," in 36th European Rotorcraft Forum, Paris, France, 2010.

[11] G. J. Leishman, Principles of Helicopter Aerodynamics, Cambridge, UK: Cambridge University Press, 2000.

[12] M. Ribera and R. Celi, "Time Marching Simulation Modelling in Descending Flight Through the Vortex Ring State," in 63rd AHS Annual Forum, Virginia Beach, USA, 2007.

[13] B. W. McCormick, Aerodynamics, Aeronautics, and Flight Mechanics, University Park, USA: John Wiley \& Sons, 1979.

[14] J. Wolkovitch, "Analytical Prediction of Vortex-Ring Boundaries for Helicopters in Steep Descents," Journal of the American Helicopter Society, vol. 17, no. 3, pp. 13-19, 1972.

[15] J. Stack, F. X. Caradonna and O. Savas, "Flow Visualizations and Extended Thrust Time Histories of Rotor Vortex Wakes in Descent," in AHS 4th Decennial Specialists Conference on Aeromechanics, San Francisco, USA, 2004.

[16] O. R. Shetty and M. S. Selig, "Small-Scale Propellers Operating in the Vortex Ring State," in 49th AIAA Aerospace Sciences Meeting, Orlando, USA, 2011.

[17] R. E. Brown, S. J. Newman, J. G. Leishman and F. J. Perry, "Blade Twist Effects on Rotor Behaviour in the Vortex Ring State," in European Rotorcraft Forum, Bristol, UK, 2002.

[18] L. Chenglong, F. Zhou, W. Jiafang and Z. Xiang, "A Vortex-ring-state-avoiding Descending Control Strategy for Multi-rotor UAVs," in 34th Chinese Control Conference, Hangzhou, China, 2015.

[19] G. A. Ahlin and R. E. Brown, "Investigating the Physics of Rotor Vortex Ring State," in 31st European Rotorcraft Forum, Florence, Italy, 2005. 
[20] O. Westbrook-Netherton and C. A. Toomer, "An Investigation into Predicting Vortex Ring State in Rotary Aircraft," in RAeS Advanced Aero Concepts, Design, and Operations, Bristol, England, 2015.

[21] S. Yoon, H. C. Lee and T. H. Pulliam, "Computational Analysis of Multi-Rotor Flows," NASA Ames Research Center, Moffett Field, USA, 2016.

[22] S. R. Weerasinghe and M. Monasor, "Simulation and Experimental Analysis of Hovering and Flight of a Quadrotor," in 13th International Conference on Heat Transfer, Fluid Mechanics and Thermodynamics, Portoroz, Slovenia, 2017.

[23] E. Seckel and H. C. Curtiss, Aerodynamic Characteristics of Helicopter Rotors, Princeton, USA: Princeton University, 1963.

[24] G. Bramesfeld and M. D. Maughmer, "Relaxed-Wake Vortex-Lattice Method Using Distributed Vorticity Elements," Journal of Aircraft, vol. XLV, no. 2, pp. 560-568, 2008.

[25] D. Bracelos, A. Kolaei and G. Bramesfeld, "Higher Order Potential Flow Analysis of Rotor Performance for Unmanned Aircraft Systems," in 63rd CASI Aeronautics Conference, Toronto, Canada, 2017.

[26] D. Barcelos, "Flow Quality Testing and Improvement of the Ryerson University Low Speed Wind Tunnel," Ryerson University, Toronto, Canada, 2016.

[27] A. Kolaei, D. Barcelos and G. Bramesfeld, "Experimental Analysis of a Small-Scale Rotor at Various Inflow Angles," International Journal of Aerospace Engineering, 2018.

[28] S. B. Pope, Turbulent Flows, Cambridge, UK: Cambridge University Press, 2000. 